\title{
Developing a methodology for assessing the energy potential of residential micro-cogeneration systems
}

by

Geoffrey Louis Johnson

A thesis submitted to

the Faculty of Graduate and Postdoctoral Affairs

in partial fulfilment of

the requirements for the degree of

Doctor of Philosophy

in

\author{
Mechanical Engineering \\ Carleton University \\ Ottawa, Ontario, Canada
}

November 2016

Copyright (c)

2016 - Geoffrey Louis Johnson 


\section{Abstract}

Currently, there is no generally-accepted defensible methodology that can be used to compare the energy performance of micro-cogeneration systems against reference conventional methods for providing residential thermal and electrical demands. In particular, the mathematical models of micro-cogeneration systems being used in this field have uncertainties associated with their predictions. However, these uncertainties have yet to be given serious attention by researchers in this field. This research makes a contribution by developing a more defensible methodology where these model uncertainties are considered.

This methodology is demonstrated with a case study where the energy performance of a fuel-cell based micro-cogeneration system serving only domestic hot water demands is compared to the energy performance of reference conventional methods. A condensing tankless water heater and a central gas-fired combined-cycle plant are considered as these reference conventional methods for providing domestic hot water demands and electrical demands respectively. The simulation results demonstrated that if model uncertainties were ignored, it would have been possible to demonstrate that the considered micro-cogeneration system was more efficient than the reference conventional methods by serving only average consumption levels of domestic hot water. However, if model uncertainties were considered, the micro-cogeneration system could not reliably be shown to be more efficient than the reference conventional methods by serving the domestic hot water needs of a single house. 


\section{Acknowledgments}

I would like to acknowledge the contributions of several members of Natural Resources Canada's CanmetENERGY lab's Buildings and Renewables Group: Gordon Mackenzie, Randy Biggs, Bruce Strathearn, Erik Thorsteinson and Tom Mackintosh in the design and commissioning of the experimental apparatus used to develop the fuel cell model used in this work and that of Mark Douglas for originally extending the invitation to participate in this collaborative effort and for providing helpful comments on this manuscript. I would also like to acknowledge the contributions of Ben Schoenbauer and the Center for Energy and Environment for sharing the data collected in their tankless water heater field-trial study. I am especially grateful for the

continued support of my wife and family. This research would not have been possible without it. And finally, I would like to acknowledge my supervisor for providing me with the opportunity to conduct this research. 


\section{Table of Contents}

Abstract $\quad$ ii

Acknowledgments $\quad$ iii

Table of Contents $\quad$ iv

List of Tables viii

List of Figures $\quad$ X

List of Symbols $\quad$ xiii

1 Introduction 1

1.1 Motivation . . . . . . . . . . . . . . . . 1

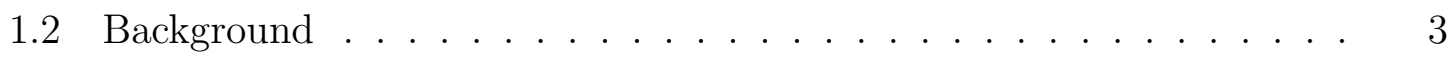

1.3 Research Methods . . . . . . . . . . . . . . . . . . . 6

1.4 Outline of this Thesis . . . . . . . . . . . . . . . 7

2 Literature Review and Thesis Objectives 8

2.1 Simulation Based Research . . . . . . . . . . . . . . . . . 8

2.1.1 Fuel-Cell Models Based on Explicit Representations of Electrical or Chemical Processes . . . . . . . . . . . . 8

2.1.2 Fuel-Cell Models Based on a Grey-Box Approach . . . . . . . 12 
2.2 Experimental Based Research _. . . . . . . . . . . . . . . 18

2.3 Micro-Cogeneration Performance Metrics . . . . . . . . . . . . . . 21

2.3 .1 Economic Analysis . . . . . . . . . . . . . . . . . . 21

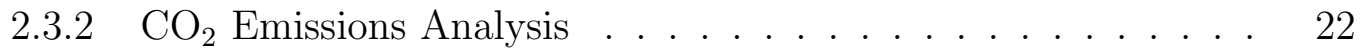

2.3 .3 Energy Analysis . . . . . . . . . . . . . . . . 25

2.4 Thesis Objectives . . . . . . . . . . . . . . . . . . . . . . . . . . . . . . . . . . . 29

3 The Derivation of a Reference Electrical Efficiency and a Methodology for its Comparison with an Electrical Performance Index of a Micro-Cogeneration Device $\quad 32$

3.1 Central Gas Plants . . . . . . . . . . . . . . . . . . . . . 33

3.2 Methodology for Deriving the Electrical Efficiency of a Central Gas Plant . . . . . . . . . . . . . . . . . . . . . . 39

3.3 Methodology for Determining an Equivalent Electrical Performance Index for Cogeneration . . . . . . . . . . . . . . . . . . . . 43

3.4 Electrical Transmission and Distribution Efficiency Modelling . . . . 46

3.5 Gas Transmission and Distribution Efficiency . . . . . . . . 49

3.6 Additional Considerations for the Comparison Between MicroCogeneration Systems and Central Gas Power Generation . . . . . . 51

4 The Development of a Condensing Tankless Water Heater Model to Represent a Reference Method for Producing Domestic Hot Water 53

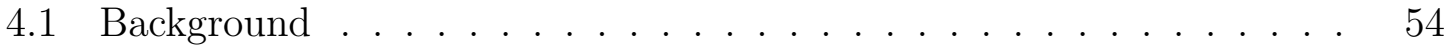

4.2 Tankless Water Heater First-Order Models . . . . . . . . . . . 57

4.2 .1 Step-Response Model . . . . . . . . . . . . . . . . . . . . . . . 59

4.2.2 Step-Response and Initial-Impulse Model . . . . . . . . . . . 63

4.2 .3 Average Model . . . . . . . . . . . . . . . . . 65

4.2.4 Environmental-Decay Model . . . . . . . . . . . . . . 66 
4.3 Experimental Methods . . . . . . . . . . . . . . . . . . 66

4.3 .1 Experimental Uncertainty . . . . . . . . . . . . . . . . . . 69

4.3.2 Calibration of the Tankless Water Heater Heat Capacity . . . 74

4.3.3 Validation of the Tankless Water Heater Heat Capacity . . . . 77

4.3.4 Calibration of the Tankless Water Heater Heat-Loss Coefficient 79

4.3.5 Validation of the Tankless Water Heater Heat-Loss Coefficient 81

4.3.6 Calibration of the Tankless Water Heater Steady-State Efficiency 83

4.3.7 Tankless Water Heater Electrical Power Consumption . . . . . 84

4.3 .8 Whole Model Validation . . . . . . . . . . . . . . 86

4.4 Closing Remarks . . . . . . . . . . . . . . . . . . . 90

5 The Performance Characterization of a Fuel Cell 91

5.1 Model Description . . . . . . . . . . . . . . . . . . . . . . . 92

5.2 Experimental Configuration _. . . . . . . . . . . . . 97

5.3 Instrumentation and Measurement Methods . . . . . . . . . . . . 100

5.4 Uncertainty in Primary Measurements . . . . . . . . . . . . . 103

5.5 Fuel-Cell Model Calibration . . . . . . . . . . . . . . . . . 105

5.5 .1 Fuel Consumption . . . . . . . . . . . . . . . 105

5.5 .2 Heat Recovery . . . . . . . . . . . . . . . . . . 106

5.5 .3 Net AC Output . . . . . . . . . . . . . . . . . . 110

5.5.4 Fuel-Cell Model Uncertainties . . . . . . . . . . . . . . . . 112

5.6 Closing Remarks . . . . . . . . . . . . . . . . . . . . . . . . 113

6 A Demonstration of the Developed Methodology for Assessing the Energy Performance of a Micro-Cogeneration System by Considering the Results from a Simulation Based Case Study 114

6.1 Methodology . . . . . . . . . . . . . . . . 115

6.1.1 Equivalent Electrical Performance Index Definition _. . . . . 118 
6.1 .2 p-Value Definition . . . . . . . . . . . . . . . . . . 119

6.1.3 Plant Component Models . . . . . . . . . . . . . . . . . . . . 121

6.1.4 Reference Electrical Efficiency . . . . . . . . . . . . . . . 124

6.1 .5 Control Mode . . . . . . . . . . . . . . . . . . 126

6.2 Results . . . . . . . . . . . . . . . . . . . . . . . . . . . . . . 129

6.2.1 Sensitivity of Results to Assumptions . . . . . . . . . . . . 133

6.2.2 Technological Advancements that Could Improve the Performance of the Considered Micro-Cogeneration System . . . . . 135

$\begin{array}{lll}7 & \text { Conclusions and Future Work } & 137\end{array}$

$\begin{array}{ll}\text { List of References } & 141\end{array}$ 


\section{List of Tables}

1 Micro-cogeneration research studies by prime-mover . . . . . . . . . . 2

2 The performance of major gas plants in Ontario without cogeneration from $2011-2013$. . . . . . . . . . . . . . . . . . . . . . . . . . . . . 37

3 The performance of major gas plants in Ontario with cogeneration from

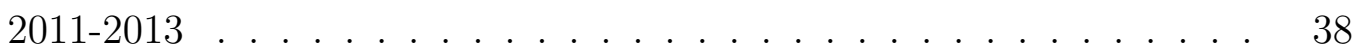

$4 \quad$ Natural gas transmission and distribution compressor station statistics 49

5 Tankless water heater experimental apparatus: Sensor types and mea-

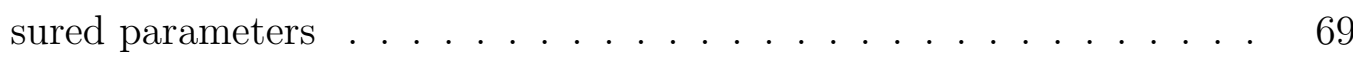

6 Tankless water heater experiments: Range of derived parameters observed during steady-state periods of experiments described in Section 4.3.2, 4.3.3, 4.3.5 and 4.3.6 along with the bias, standard deviation and uncertainty margins at a $95 \%$ confidence level . . . . . . . . . . . 72

7 Summary of 14 experiments used to calibrate the heat capacity of the tankless water heater model . . . . . . . . . . . 76

8 Summary of the sensitivity analysis of the tankless water heater model predictions to each model parameter's uncertainty margin . . . . . . 88

$9 \quad$ Fuel-cell experiments: Operating range and experimentally achieved values for externally controlled boundary conditions . . . . . . . . . . 99

10 Fuel-cell experimental apparatus: Sensor types and measured parameters 102 
11 Fuel-cell experimental apparatus: Bias errors and uncertainty for primary measurement quantities . . . . . . . . . . . . . . . . . . 104

12 Calibration coefficients for the fuel-cell model . . . . . . . . . . . . . 108

13 Fuel-cell model parameter and prediction uncertainties . . . . . . . . 112

14 Summary of simulated individual domestic hot water draw profiles . . 116

15 Calculated reference electrical efficiency for a high-efficiency combinedcycle plant in Ontario, Canada from 2011 to 2013 and uncertainty margins ........................... 125 


\section{List of Figures}

1 A typical residential micro-cogeneration system . . . . . . . . 1

2 Diagrams of proton-exchange membrane and solid-oxide fuel-cells . . 4

3 Temporal variation of the natural gas cost of a residential consumer in Ontario and the monthly average Ontario wholesale electricity cost .

4 Generated electricity in Ontario by primary energy source as a percentage of total monthly energy demand . . . . . . . . . . . 23

5 Central gas plant schematic . . . . . . . . . . . . . 34

6 Topology of the electrical transmission and distribution system that connects a central-combined cycle plant to an urban residential consumer 47

7 A typical temperature-difference response of a tankless water heater and heat input observed during the calibration experiments of Section

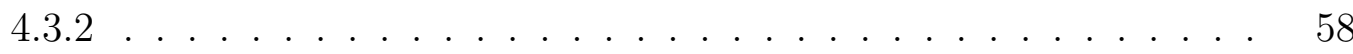

8 Schematic representation of the experimental apparatus used to conduct the experiments to calibrate a condensing tankless water heater model . . . . . . . . . . . . . . . . . . . .

9a Energy input and output of the tankless water heater measured during one of several calibration experiments used to derive its heat capacity each plotted against time from the start of experiment as a separate

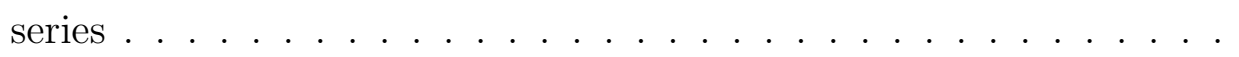


9b Energy input plotted against energy output of the tankless water heater measured during one of several calibration experiments used to derive its heat capacity . . . . . . . . . . . . . . . .

10 Percent error between energy input to the tankless water heater observed during 4 validation experiments and model predictions . . . . 78

11 Initial temperature of the tankless water heater derived from experimental data compared to the exponential decay model for validation when the external exhaust fan was left on between firings . . . . . . . 82

12 The steady-state efficiency of the tankless water heater versus its heat output during a series of 31 calibration experiments . . . . . . . .

13 Comparison of the average model predictions against the measured data provided by Bohac et al. (2010) . . . . . . . . . . . . . . 87

14 Annex 42 fuel-cell micro-cogeneration model . . . . . . . . . . . . . 93

15 Schematic representation of the experimental configuration used to characterize the performance of a fuel cell . . . . . . . . . . . . . . . 98

16 Instrumentation placement on the experimental apparatus used to characterize the performance of a fuel cell . . . . . . . . . . . . . . . 101

17 Test-averaged fuel-cell power module consumption of fuel energy content for each of the 30 steady-state tests . . . . . . . . . . . . . . 107

18 Test-averaged fuel-cell heat recovery for each of the 30 steady-state

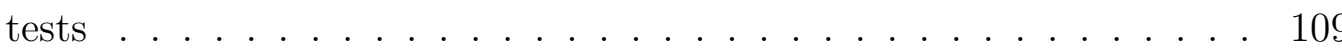

19 Test-averaged fuel-cell net AC output for each of the 46 steady-state

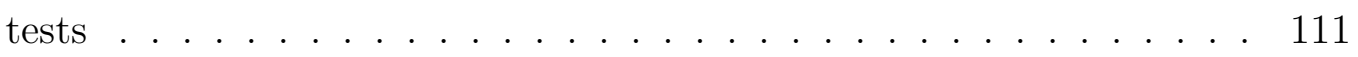

20 Micro-cogeneration plant network to be used in simulations . . . . . . 116

21 Temporal results for 1 sample day for 1 of the 78 domestic hot water profiles that was simulated . . . . . . . . . . . . . . 130 
22 Fuel-cell electrical performance index and the probability that it does not exceed the reference electrical efficiency versus domestic hot water

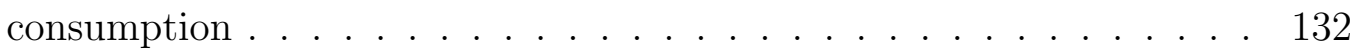




\section{List of Symbols}

\begin{tabular}{ll}
\hline \hline Symbol & Description \\
\hline$E$ & energy $(\mathrm{J})$ \\
$P$ & power $(\mathrm{W})$ \\
$Q$ & heat transferred $(\mathrm{J})$ \\
$q$ & rate of heat transferred (W) \\
$\zeta$ & efficiency \\
$P I_{e l}$ & electrical performance index \\
$U_{95}$ & probability confidence interval \\
$b$ & individual independent source of bias \\
$B$ & total bias \\
&
\end{tabular}




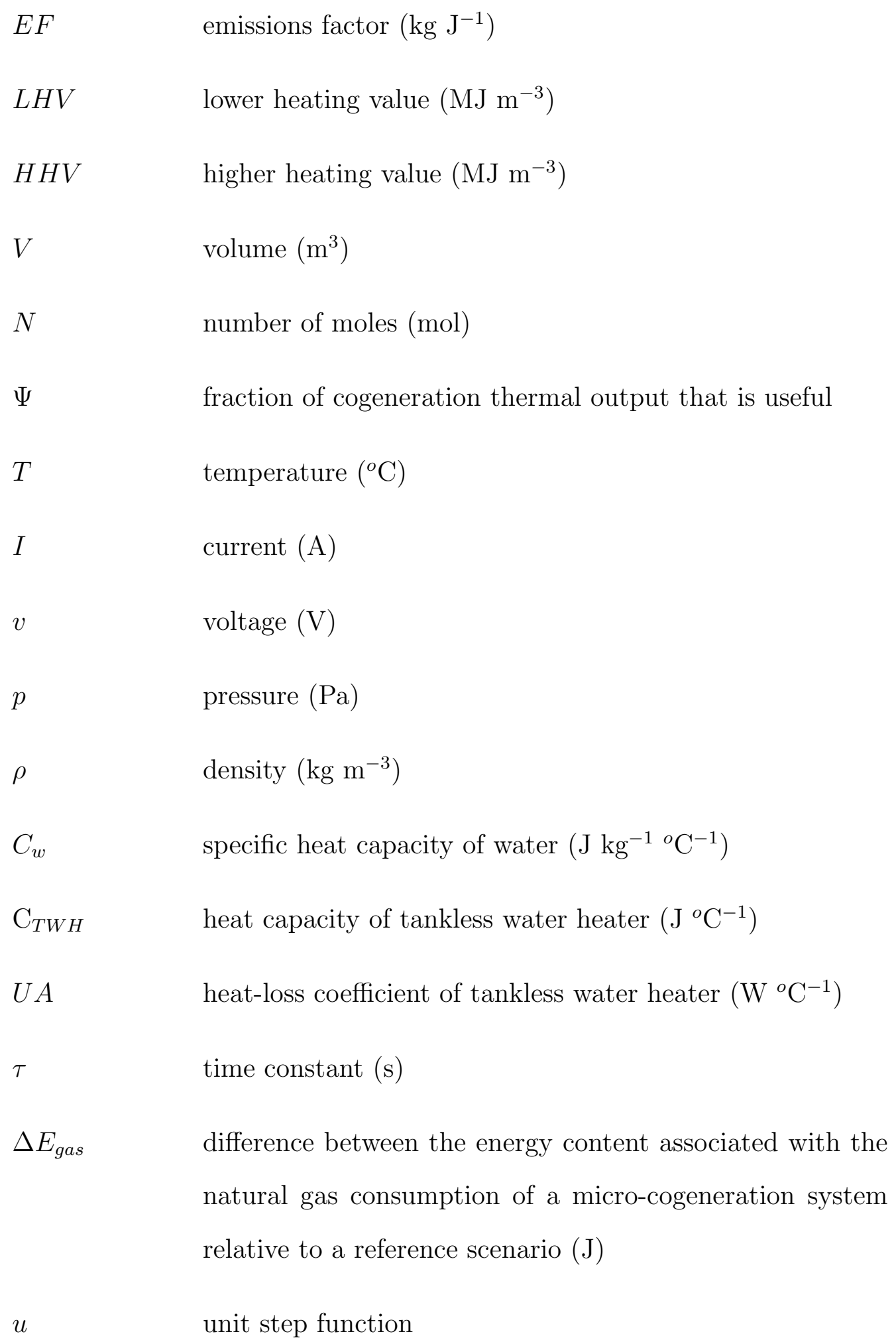




\begin{tabular}{|c|c|}
\hline$\delta$ & Dirac delta distribution \\
\hline$t$ & time $(\mathrm{s})$ \\
\hline$t_{s}$ & Student's t statistic \\
\hline Subscript & Description \\
\hline$A C$ & alternating current \\
\hline$D C$ & direct current \\
\hline$T W H$ & tankless water heater \\
\hline$D H W$ & domestic hot water \\
\hline$P C U$ & power conditioning unit \\
\hline el & electrical \\
\hline fuel & fuel \\
\hline$e x$ & exhaust gas \\
\hline$R S$ & reference scenario \\
\hline cogen & micro-cogeneration \\
\hline th - ref & reference method for providing occupant thermal demands \\
\hline$t h-r e f-e l$ & $\begin{array}{l}\text { electrical consumption of the reference method for provid- } \\
\text { ing occupant thermal demands }\end{array}$ \\
\hline$e l-t$ & electrical transmission system \\
\hline$e l-d$ & electrical distribution system \\
\hline
\end{tabular}




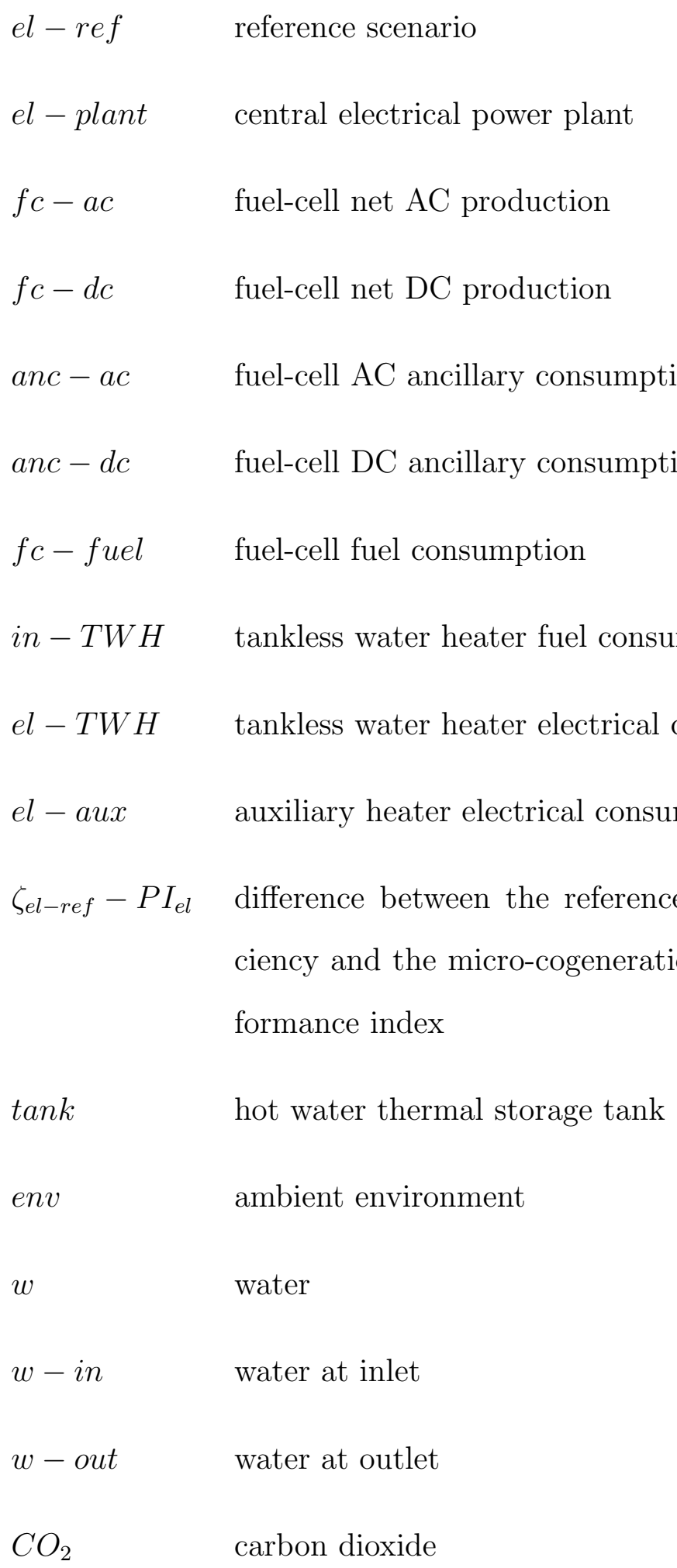




$\begin{array}{ll}\mathrm{NO}_{2} & \text { nitrogen dioxide } \\ \mathrm{CH}_{4} & \text { methane } \\ \text { load } & \text { occupant load } \\ \text { loss } & \text { standing loss from hot water storage tank } \\ \text { process } & \text { an industrial process } \\ \text { s-cool } & \text { fuel-cell thermal output from stack-cooling circuit } \\ \text { out } & \text { output } \\ \text { ss } & \text { steady-state }\end{array}$




\section{Chapter 1}

\section{Introduction}

\subsection{Motivation}

The production of combined heat and electricity on a small scale $\left(<15 k W_{A C}\right)$ from a single fuel source is known as micro-cogeneration. In a recent review of microcogeneration research, Sasso et al. (2016) indicated that by shifting users' energy demands from centralized power plants to decentralized micro-cogeneration systems, energy transmission losses can be reduced and the energy independence of users can be improved. This potentially results in energy savings and reduced $\mathrm{CO}_{2}$ emissions.

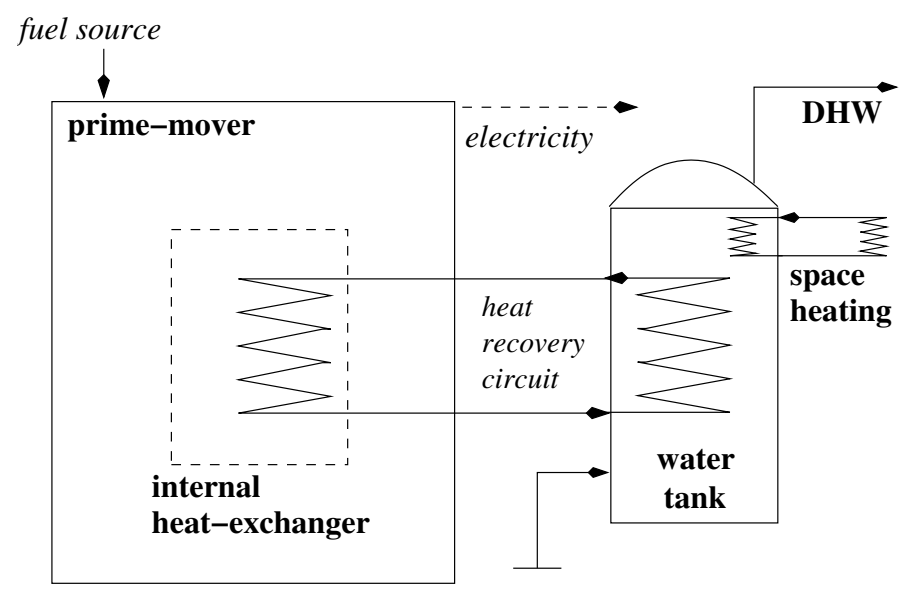

Figure 1: A typical residential micro-cogeneration system 
A typical residential micro-cogeneration system is shown in Figure 1. The "primemover" of this system is any type of device that converts the energy content of a single fuel source to both heat and electricity. Natural gas is a common fuel source. The heat produced by the prime-mover is typically recovered with water from an internal heat-exchanger and stored in a tank. In a residential application, this stored heat can be used to supply domestic hot water (DHW) or space-heating demands. The electricity that is produced can be used on-site or exported to the local electrical grid.

Several devices exist that can be used as the prime-mover of a micro-cogeneration system. The most popular prime-movers are the internal combustion engine (ICE), the Stirling engine (SE), the solid-oxide fuel cell (SOFC) and the proton-exchangemembrane fuel cell (PEMFC). It is sometimes convenient to classify the studies in the literature investigating various aspects of these prime-movers according to whether a study's major contributions were based on simulation or experimental methods as was done by Sasso et al. (2016). The number of studies that investigated each of the popular prime-movers using simulation and experimental based methods that were reviewed by Sasso et al. (2016) is shown in Table 1. Note that the literature summarized in Table 1 is not restricted to residential applications alone as this thesis is.

\begin{tabular}{cccc}
\hline Prime-Mover & \multicolumn{2}{c}{ Number of Studies } \\
\cline { 3 - 3 } ICE & & Simulation & Experimental \\
SE & 22 & 18 \\
SOFC & 18 & 12 \\
PEMFC & 12 & 5 \\
\hline
\end{tabular}

Table 1: Micro-cogeneration research studies by prime-mover as reviewed by Sasso et al. (2016) 
Table 1 shows that fuel cells have not been studied as frequently as engines have been. There is also less experimental than simulation based research. Fuel cells have not been studied as frequently as engines primarily because fuel-cell technology is more expensive; however, efforts in Japan, Germany and South Korea (Staffell and Green, 2013) are contributing to the maturation of this technology and the reduction of its cost. Although there is comparatively less fuel-cell research, fuel cells are ideal prime-movers for residential micro-cogeneration applications because of their greater electrical efficiencies relative to engines (Onovwiona and Ugursal, 2006). For this reason, fuel-cell based micro-cogeneration systems offer greater potential for energy and greenhouse gas emissions savings for many residential applications; however, it is unknown whether the technology can deliver such savings and under what conditions. Moreover, a defensible methodology has not yet been established for making such an assessment. Establishing such a methodology and demonstrating it with a case study that considers a residential application of a fuel-cell based micro-cogeneration system in Ontario (Canada) will be the central objective of this thesis.

\subsection{Background}

The electrochemical operating principle of a PEMFC is shown in the left diagram in Figure 2. PEMFCs are constructed from three layers: the anode, electrolyte and cathode. A summary of the description provided by Onovwiona and Ugursal (2006) for the principle of operation of PEMFCs is provided alongside equations 1 to 3. The anode is normally constructed with platinum to catalyze the following half reaction in equation 1.

$$
H_{2} \Rightarrow 2 H^{+}+2 e^{-}
$$

The $\mathrm{H}_{2}$ in this half-reaction is normally liberated from a hydrocarbon fuel upstream in a process known as reformation. The products of this half-reaction at the anode 


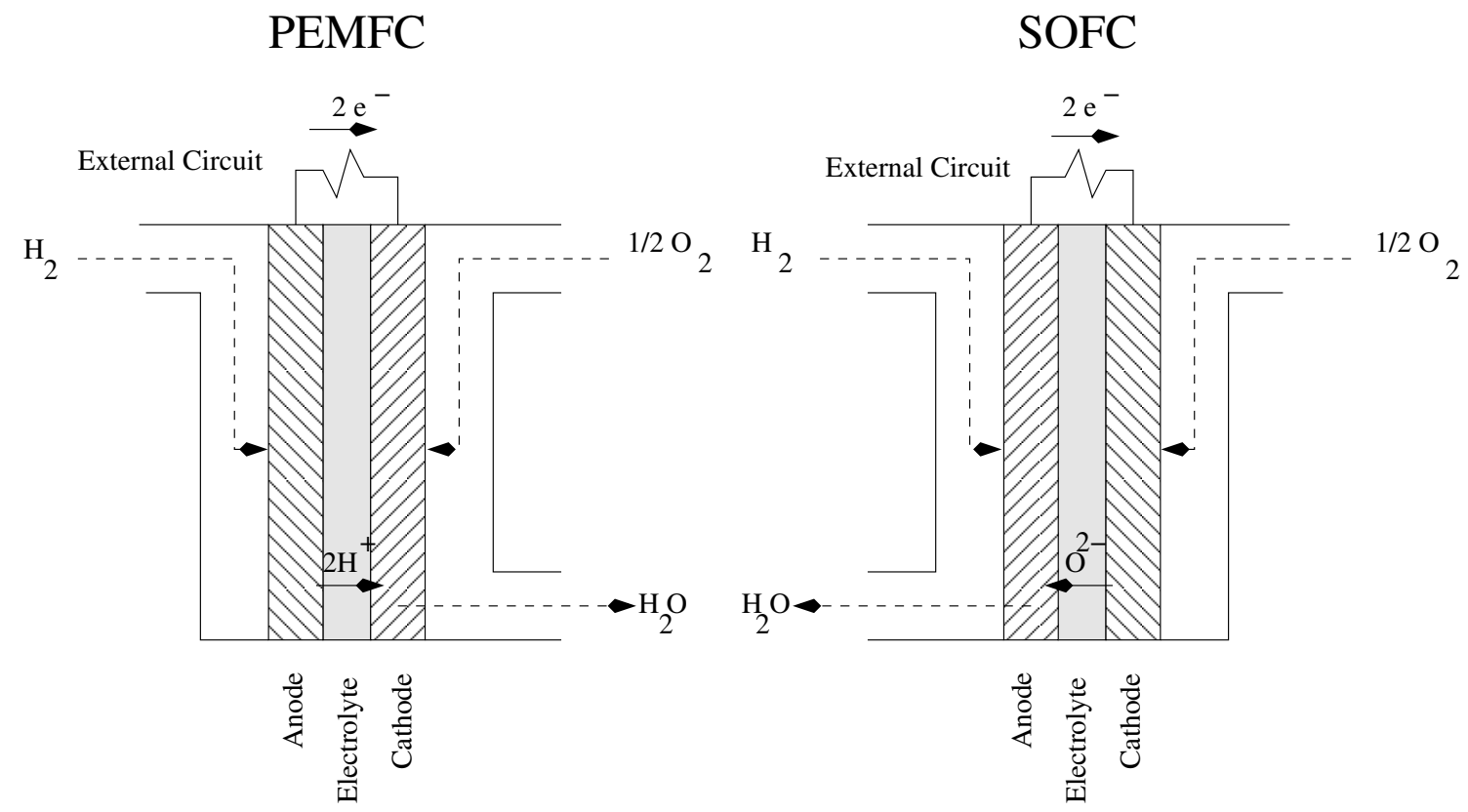

Figure 2: Diagrams of PEMFC (left) (adapted from Moran and Shapiro (2004)) and SOFC (right) (adapted from Murugan and Horák (2016))

are two hydrogen ions $\left(2 H^{+}\right)$and two electrons $\left(2 e^{-}\right)$. The electrolyte is made of a polymer substance that is permeable to ions but not to electrons; therefore, the ions can pass through the electrolyte to the cathode but the electrons are forced to pass through an external circuit to reach the cathode. The cathode is typically constructed from platinum to catalyze the following half reaction in equation 2 .

$$
\frac{1}{2} \mathrm{O}_{2}+2 \mathrm{H}^{+}+2 e^{-} \Rightarrow \mathrm{H}_{2} \mathrm{O}
$$

The overall reaction is then shown in equation 3 .

$$
\frac{1}{2} \mathrm{O}_{2}+\mathrm{H}_{2} \Rightarrow \mathrm{H}_{2} \mathrm{O}
$$


Heat is generated from the overall reaction. The heat generated here is what can be recovered as the useful thermal output in a micro-cogeneration application such as the example illustrated in Figure 1.

All fuel cells operate on similar electrochemical principles. For example, the SOFC shown in the right diagram of Figure 2 operates in a similar manner to the PEMFC. If the fuel used is $\mathrm{H}_{2}$ then the SOFC's overall reaction is identical to the PEMFC's. However, the half reactions at the anode and cathode are different and the charge carrying ion $\left(\mathrm{O}^{2-}\right)$ is different as well. In an SOFC, the electrolyte is constructed from a solid ceramic. An example of such a solid ceramic is yttria-stabilized zirconia $\left(\mathrm{Y}_{2} \mathrm{O}_{3} \mathrm{Zr}_{2}\right)$ (Onovwiona and Ugursal, 2006). It is important to note that the characteristics of fuel cells, and any other prime-mover, change with time as these technologies continue to mature. Interested readers are referred to the recent literature review of Murugan and Horák (2016) for details describing the current technological state of fuel cells and the various other prime-movers of micro-cogeneration systems.

Individual fuel cells are combined in series and/or parallel into a fuel-cell stack in coherent micro-cogeneration scale systems. Utility supplied natural gas is the most common fuel used to supply micro-cogeneration systems. In order to be viable, fuelcell based micro-cogeneration systems must be competitive with current natural-gasfired combined-cycle power plants that have net electrical efficiencies of approximately $55 \%$ relative to their fuel's lower heating value (LHV) (Colpier and Cornland, 2002; DeMoss, 1996). The comparison is reasonable as both of these technologies consume the same type of fuel. Some SOFCs (e.g. the fuel cell studied by Sommer and Mesenhöller (2013)) are approaching the electrical efficiency of combined-cycle plants while PEMFCs have lower values (e.g. $35 \%$ for the fuel cell studied by Johnson et al. (2013)). Therefore, to achieve its full potential and to ensure a favourable comparison with combined-cycle plants it is important that a fuel cell's thermal output is used effectively. 


\subsection{Research Methods}

One method to asses the potential of a PEMFC in a micro-cogeneration application is with a field-trial (e.g. Tanaka (2015) and Sasakura (2015)); however, these are resource and time intensive to conduct and require the cooperation of volunteers. The preceding examples given were both conducted by utilities with the means to overcome these obstacles; however, they are often insurmountable for independent researchers. Consequently, building performance simulation (BPS) is a common research method used to assess the potential of fuel-cell based micro-cogeneration systems. As will be shown in Chapter 2, this is a method well supported in literature.

By using BPS methods it is possible to simulate complex interactions involving micro-cogeneration systems, occupant behaviour, building envelopes, climate data, control systems and conventional residential heating, ventilating, and air conditioning equipment. Annex 42 of the International Energy Agency's Energy Conservation in Buildings and Community Systems Programme (IEA/ECBCS) (Beausoleil-Morrison, 2008) was founded to develop the tools that are necessary to use BPS to assess the potential of micro-cogeneration systems. Annex 54 (Sasso et al., 2016) was founded more recently to study the integration of micro-cogeneration and related energy technologies in buildings.

Although well supported in literature, these BPS methods still require further improvements to make reasonable comparisons between more established technologies and micro-cogeneration systems. As will be shown, one major limitation of current BPS methods used is that they do not account for the uncertainties of their models' predictions. This is especially important to consider because the performance benefits

of micro-cogeneration systems found so far in the literature are often incremental when compared to more established technologies. 
A methodology that accounts for model uncertainties in BPS methods would allow for a more defensible assessment of which of the technologies being compared is more beneficial. Such a methodology could also be used to provide guidance for which technological improvements are necessary so that micro-cogeneration systems can more likely deliver energy and greenhouse gas emissions savings. The case study that will be used to demonstrate this methodology in this thesis will be a comparison of whether it is more efficient to use natural gas for central power generation in a combined-cycle plant or in a PEMFC based micro-cogeneration system.

\subsection{Outline of this Thesis}

This chapter presented an overview of the topic of this thesis and the motivation for its selection. Chapter 2 will review the literature relevant to this topic to more specifically define the objectives of this thesis. The remaining chapters describe attempts to address these objectives before conclusions are drawn. 


\section{Chapter 2}

\section{Literature Review and Thesis Objectives}

The intent of the literature review of this chapter is to identify gaps in the current state of fuel-cell based micro-cogeneration research for residential applications. As was done by Sasso et al. (2016), the literature reviewed in this chapter is broadly classified into two categories, experimental and simulation based research.

\subsection{Simulation Based Research}

Recently, numerous researchers have developed methods for modelling fuel-cell microcogeneration devices. In this section, the literature reviewed is classified according to the approach used for modelling the fuel cell in the simulations that were performed.

\subsubsection{Fuel-Cell Models Based on Explicit Representations of Electrical or Chemical Processes}

In this first approach, models are based on detailed electrical or chemical processes that occur within some component of the coherent fuel-cell micro-cogeneration system. Arsalis et al. (2011a,b, 2012), Martins et al. (2009), Musio et al. (2011), BoiguesMuñoz et al. (2014, 2015a,b), Zuliani and Taccani (2012), and Barelli et al. (2011) are recent examples where models based on the electrochemical processes that occur 
within individual cells were described. Frazzica et al. (2015), Gandiglio et al. (2013, 2014) and Boscaino et al. (2013) are recent examples where models based on voltage and current polarization curves of a fuel-cell stack were described. Di Marcoberardino et al. (2016) and Ahmed et al. (2013) are recent examples where models whose fuel-processing components were modelled in great detail were described.

The level of detail of these models allows for them to be used to assist in the design of fuel-cell micro-cogeneration systems. For example, Kupecki et al. (2015) developed a detailed model of a $1.3 \mathrm{~kW}$ SOFC to study the effect that different stack configurations had on the stack's thermal boundary conditions. Mamaghani et al. (2016) performed a multi-objective optimization procedure to determine the optimum design of a PEMFC for micro-cogeneration based on a detailed model. The optimization objectives were cost and electrical efficiency. Polverino et al. (2016) used a detailed model to detect faults in a $1 \mathrm{~kW}$ SOFC to increase system reliability and lifetime. Belvedere et al. (2013) used a detailed model to study water management strategies within the fuel-cell stack to reduce degradation. Barelli et al. (2012) used a detailed model to study the effect that relative humidity had on the performance of a $3 \mathrm{~kW}$ PEMFC. Yang et al. (2014) simulated an SOFC that was coupled to a storage tank and an auxiliary boiler. The simulations were used to size components of the SOFC and the entire system's balance of plant components. Herdem et al. (2015) studied the performance of a $0.45 \mathrm{~kW}$ PEMFC when fuel was provided by a methanol reformer. They used a previously developed model (Korsgaard et al., 2008) to represent the cells within the stack. In this previously developed model, regression was used to determine equations from experimental data that described the various electrochemical processes that occur within a single cell.

Although very detailed, this has not prevented researchers from using this type of model for BPS. The following researchers performed BPS based studies using this type of detailed model. Wang et al. (2013) simulated the performance of $1.5 \mathrm{~kW}$ PEMFC 
in a distributed generation system in a residential application that also included a supercapacitor, a lead-acid battery and a diesel engine generator. The PEMFC was supplied directly with hydrogen that was assumed to originate from a renewable source. Özgirgin et al. (2015) simulated the performance of a system where a $1.2 \mathrm{~kW}$ PEMFC was used in conjunction with a PV array in a residential application. Zuliani and Taccani (2013) simulated the performance of a $1 \mathrm{~kW}$ PEMFC with an integrated lithium-ion battery storage system in a residential application. Yaji and Diarra (2013) investigated several strategies to modulate the output of a residential SOFC based micro-cogeneration system. Chen et al. (2015) simulated the performance of a 5 $\mathrm{kW}$ PEMFC coupled to a $7 \mathrm{~kW}$ lithium-bromide absorption chiller in a residential application. Arsalis et al. (2013) simulated the performance of a PEMFC in a Danish residential application. Contreras et al. (2010) simulated the annual performance of a PEMFC in rural Venezuela.

The complexity of this type of model can also be reduced by calibrating another simpler model with its predictions. For example, Adam et al. (2013) simulated an SOFC providing space heating and DHW for a $180 \mathrm{~m}^{2}$ house in London. The SOFC model used was developed by Hawkes et al. (2007). This model included the fuel-cell stack along with all balance of plant components. The fuel-cell stack's performance was based on the polarization curves of individual cells (Aguiar et al., 2004; Brett et al., 2006) from a larger $5 \mathrm{~kW}$ system but its performance was assumed to be scalable to systems of different capacities. A simple function of only the SOFC's part-load ratio was fit to the coherent micro-cogeneration system's electrical and thermal efficiencies. In another similar example, Fubara et al. (2014) calculated the cost and primary energy savings from using various micro-cogeneration devices (ICE, SE, SOFC) for a residential application in the U.K. compared to grid electricity and a reference boiler. The SOFC model used was based on a simple function of part-load ratio provided by Hawkes and Leach (2007) that was developed in a manner similar 
to that described by Hawkes et al. (2007). Another approach was used by Kazempoor et al. (2011) who calibrated the Annex 42 model (described in Chapter 5) with the predictions of a detailed model.

The major disadvantage associated with these detailed models and their derivatives is it is difficult to determine whether the level of detail of these models is sufficient or whether some simplifying assumption or some omitted detail invalidates it. The uncertainties of these models' predictions are also unclear. None of the previously mentioned studies contained an analysis where uncertainties in the myriad of model calibration parameters were propagated through to model predictions of a coherent fuel-cell micro-cogeneration system. When this has been done, the results are less than convincing. For example, Arsalis et al. (2015) simulated a $1 \mathrm{~kW}$ PEMFC whose electrical output was coupled to assist driving a heat pump in a residential application. The PEMFC was simulated using a detailed model. This work also contained an analysis that propagated the uncertainties of some calibration parameters to the PEMFC's efficiency. They claim, from this analysis, an uncertainty of $< \pm 1 \%$ for the prediction of the overall efficiency of the PEMFC. However, they later validated their model against an earlier version (Korsgaard et al., 2008) and found their efficiency predictions were lower by approximately 10\%. Notwithstanding the authors' explanation that the difference was caused by the newer model version considering more heat loss and different chemical kinetics, given the complexity of the model it is unclear whether all relevant factors are now included.

In another example, Xu et al. (2013) developed a detailed model of a $1 \mathrm{~kW}$ SOFC for a residential micro-cogeneration unit. They validated their model's predictions against another similar model (Lisbona et al., 2007) for a single set of operating conditions. The predicted electrical efficiencies differed by approximately $6 \%$. The validity of this reference model (Lisbona et al., 2007) is also uncertain as they obtained 
many calibration parameters from an internal report that has not been made widely available.

The only way it can be shown with certainty that these detailed models are accurate representations is with a validation against performance data from a coherent fuel-cell micro-cogeneration system over a wide range of operating conditions. However, if these data are available the question arises: Why not only model the coherent system and ignore modelling the detailed processes? This is the approach that is described in the the following subsection.

\subsubsection{Fuel-Cell Models Based on a Grey-Box Approach}

This second approach to modelling is termed the "grey-box" approach. In this approach, model equations are calibrated to experimental data emanating from programs where a coherent fuel-cell micro-cogeneration system's performance has been measured over a range of operating conditions. These equations do not explicitly represent electrical or chemical processes that occur within system components. Rather, they are often polynomials whose coefficients are determined by regression.

The most well-known example is the Annex 42 fuel-cell model. Efforts by Annex 42 members led to the development of a fuel-cell based micro-cogeneration system model for implementation into BPS tools. In this model, the system is discretized into control volumes whose boundaries exchange energy and mass flows. Although first conceived for modelling SOFCs (Beausoleil-Morrison et al., 2006), the model was later expanded (Kelly and Beausoleil-Morrison, 2007) to consider PEMFCs as well. By exercising the appropriate combination of control volumes the model can be configured to represent either SOFC or PEMFC micro-cogeneration devices. This model is described in more detail in Chapter 5 . 
The Annex 42 model represents the behaviour of the individual sub-systems using empirical data gathered from experiments conducted with coherent fuel-cell microcogeneration devices. A demonstration of this calibration procedure is provided by Beausoleil-Morrison and Lombardi (2009) that shows how data from a series of 45 steady-state and transient tests were used to calibrate the Annex 42 model to represent the behaviour of a $2.8 \mathrm{~kW}$ SOFC micro-cogeneration device. The calibration of the Annex 42 model performed by Beausoleil-Morrison and Lombardi (2009) was validated by Beausoleil-Morrison (2010) using data from 16 additional experiments that were disjunct from those employed in the calibration. This work is an example of a model where uncertainties are well documented.

While the Annex 42 model is the most well-known, it is not the only grey-box approach to modelling that has been used for BPS based studies. A PEMFC was modelled by Entchev et al. (2013) to simulate how it would perform in an application where the PEMFC provided thermal output to two separate users. These users were considered to be a house and an office as these buildings were believed to have thermal demands that were out of phase. Three plant configurations were simulated, only one of which incorporated the PEMFC. In this configuration, the PEMFC was used in combination with a ground-source heat pump. The PEMFC model was not explicitly described but was validated against data from Thorsteinson et al. (2011) that is known to be preliminary. Canelli et al. (2015) and Anindito et al. (2013) performed similar analyses whose PEMFC models have this same limitation.

Cao et al. (2014) investigated the sizing of various micro-cogeneration systems (organic Rankine Cycle, ICE, fuel cells) under different control strategies for a singlefamily house in Finland. Due to the number of technologies simulated, a simplistic constant efficiency and heat-to-power ratio model of the fuel cell was used.

Bianchi et al. (2012, 2013, 2014) simulated the performance of various microcogeneration systems (micro gas turbines, organic Rankine Cycle, fuel cells) under 5 
kW of electrical output capacity. Their fuel-cell model was based on manufacturers' data with unreported uncertainties.

Wakui et al. (2014) simulated the residential application of a $0.75 \mathrm{~kW}$ PEMFC with a plug-in hybrid vehicle. The fuel-cell model was based on manufacturer's data with unreported uncertainties. The performance dependence on temperature of the water supplied to the fuel cell for heat recovery was also not described.

Windeknecht and Tzscheutschler (2015) simulated a $1.5 \mathrm{~kW}$ SOFC in a residential application. The SOFC was operated at a constant output at its maximum electrical efficiency. An electrical resistance heater consumed a portion of the SOFC's output in order to increase the on-site consumption of the electricity that was produced. The SOFC model used was presented by Sommer and Mesenhöller (2013) who did not conduct an uncertainty analysis.

Nižetić et al. (2015) simulated the performance of a system where a $1.2 \mathrm{~kW}$ PEMFC's electrical output was used to drive a heat pump. The PEMFC model was based on manufacturers' data with unreported uncertainties.

Rouholamini and Mohammadian (2015) presented a model of a $2 \mathrm{~kW}$ PEMFC. The model in the simulation was fueled directly with hydrogen that had been stored in a tank that was produced by an electrolyzer. The electrolyzer was powered by a PV array and a wind turbine. Although the model did consider both thermal and electrical performance, it was based solely on the electrical part-load ratio and did not consider the effect of the temperature of the water supplied to the fuel cell for heat-recovery. The model was based on handbook data whose uncertainties were not reported. Zafar and Dincer (2014) performed a similar study whose model had similar limitations. 
The performance of an SOFC based micro-cogeneration system in a $80 \mathrm{~m}^{2}$ singlefamily house was simulated for the different climatic conditions of London, Copenhagen, Paris and Rome by Liso et al. (2011). The SOFC model was based on data provided by Staffell (2009) whose uncertainties were not reported.

Comodi et al. (2014) performed simulations to determine the potential of various micro-cogeneration devices (fuel cells, SEs, ICEs and micro gas turbines) for the Italian household sector. The simulations were conducted at a municipal scale so the various micro-cogeneration devices were not modelled in detail. Rather, constant values for parameters (e.g. efficiency) were used.

Elmer et al. (2015) characterized the efficiency of an SOFC operating at its peak electrical efficiency in a laboratory at steady-state operating conditions. The uncertainties of the measured data were not reported. Also, the thermal output was modelled as a constant $0.75 \mathrm{~kW}$ that did not take into account its reduction when temperatures in the heat recovery circuit rise. More recently, Elmer et al. (2016) simulated the performance of this same SOFC; however, in this more recent study the SOFC's performance was represented using a model provided by Sommer and Mesenhöller (2013). Sommer and Mesenhöller (2013) characterized the performance of a similar SOFC from the same manufacturer as initially studied by Elmer et al. (2015); however, Sommer and Mesenhöller (2013) also modelled the effect when tem-

peratures in the heat recovery circuit rise. The uncertainties of the measured data were still; however, not reported.

Cooper et al. (2014) investigated the performance of air-source heat pumps and SOFCs under different operating scenarios for U.K. climatic conditions. The SOFC model was based on data provided by Payne et al. (2011). Uncertainties were not presented by Payne et al. (2011) nor was the temperature dependence of the SOFC's thermal output described. 
Nakai et al. (2015) simulated the performance of a $0.7 \mathrm{~kW}$ SOFC in an apartment complex. Sumiyoshi et al. (2015) performed a separate but similar investigation. In both of these studies the fuel-cell models were calibrated with manufacturer's data of unreported uncertainties.

None of these previously described simulation efforts where the grey-box approach was used were based on models whose uncertainties were documented in as much detail as those that were presented by Beausoleil-Morrison and Lombardi (2009). However, there have been several simulation based studies where a model that was developed as part of this thesis (Johnson et al., 2013) was used. As will be shown later (Chapter 5), all relevant uncertainties were characterized for this model. The following studies made use of this model. To represent occupant electrical consumption characteristics, these studies also made use of experimentally measured non-heating ventilating and air-conditioning (non-HVAC) electricity consumption data sampled at a one-minute time resolution that were first gathered by Saldanha and Beausoleil-Morrison (2012) from twelve volunteer houses in Ottawa, Canada.

Han et al. (2015) used the model developed by Johnson et al. (2013) to demonstrate how PEMFCs may be used to assist PV arrays in a micro-grid community. While this study did take into account all twelve electricity consumption profiles provided by Saldanha and Beausoleil-Morrison (2012), it focused on electrical interactions with the local grid so the thermal demands were not modelled in as much detail.

Three of the occupant electricity consumption profiles provided by Saldanha and Beausoleil-Morrison (2012) were also used by Kopf (2012) in a simulation based research effort focused on developing a control method for a PEMFC based microcogeneration system coupled to a lithium-ion battery used for electrical storage. In total, nine different control methods for the overall system were studied; however, because of the complexity associated with the addition of the lithium-ion battery, 
Kopf (2012) was only able to evaluate a simplistic control method of the PEMFC where the PEMFC's output was modulated to its minimum in the cooling season to avoid wasting its thermal output.

Using the experimentally gathered non-HVAC load data from four of the twelve houses and the same PEMFC model, McMurtry (2013) optimized different plant configurations and control strategies of a PEMFC based micro-cogeneration in a residential application with respect to the consumer's energy cost. Three control strategies were examined, an electricity price following, a storage tank temperature following and a hybrid strategy. Two plant configurations were examined, a single and double storage tank configuration. The results showed that the advantage of using two storage tanks compared to one is unclear and the optimum size (with respect to energy cost to the consumer) of a single storage tank is $0.7 \mathrm{~m}^{3}$. The results also showed, interestingly, that the energy cost to the consumer was insensitive to the storage tank's volume and that the hybrid control strategy, heavily weighted towards the tank temperature following strategy, was optimal.

Although these studies have significantly improved on other researchers' efforts to simulate PEMFC based micro-cogeneration systems by using measured non-HVAC loads and a PEMFC model based on experimental data with documented uncertainties, Kopf (2012) and McMurtry (2013) relied on a single DHW profile based on stochastic methods (Knight and Ribberink, 2007). In general, these two studies focused on investigating sizing and configuration guidelines for the balance of plant components of a fuel-cell micro-cogeneration system but did not simulate a wide enough variation of occupant behaviour to assess the true potential of these systems. They also did not consider the effect that the documented model uncertainties had on their simulations' results. Kopf (2012) and McMurtry (2013) also considered economic variables as the primary performance metrics to be the objectives of the 
optimizations that determined their systems' configurations and the details of their systems' supervisory control methods.

A supervisory control method is defined here as a method of controlling the output of a micro-cogeneration system to optimize some objective (e.g. minimize the thermal or electrical production that is wasted). Two very common methods of supervisory control are often called "heat led" or "electric led" strategies. McMurtry (2013) is an example of a study where both of these types of strategies were investigated. These two methods attempt to match the output of the system with the thermal or electrical demands of the occupants respectively. Another, less common, example of a method of supervisory control involves using fuzzy logic. Entchev (2003), Shaneb et al. (2012) and Safari et al. (2013) are examples of studies where fuzzy logic supervisory control methods were applied to fuel-cell based micro-cogeneration systems.

\subsection{Experimental Based Research}

The quality of the results from performance analyses of the simulations described in the previous sections is highly dependent on the quality of the micro-cogeneration system models developed from experimental research. Aside from the most noteworthy example (Beausoleil-Morrison and Lombardi, 2009) mentioned earlier, other noteworthy examples are described here.

Arpino et al. (2011) began their investigation of an SOFC for residential microcogeneration applications by publishing an a-priori uncertainty analysis of experimental data to be gathered (eventually published by Arpino et al. (2013a)) characterizing the performance of a $5 \mathrm{~kW}$ SOFC. Arpino et al. (2011) indicated that available experimental performance data of SOFCs are scarce and are published without experimental uncertainty margins indicating poor reliability. Arpino et al. (2011) concluded that 
the fuel input and thermal output of an SOFC are the most problematic measurements to accurately obtain that are relevant to an SOFC's performance.

In the next phase of their research, SOFC performance data were gathered and presented by Arpino et al. (2013a). These data were gathered from a prototype SOFC's integrated measurement system at four different operating conditions. Arpino et al. (2013a) used the gathered experimental data to validate a detailed model of an SOFC. This model's purpose is to be used to simulate different control strategies for the thermal management of the SOFC's stack. This model represents the SOFC's power module in more detail than the Annex 42 model (Kelly and Beausoleil-Morrison, 2007). Explicit representations of a catalytic partial oxidation reactor, stack, cathodic air pre-heater and off-gas burner are present in this model.

In the final phase of their research, Arpino et al. (2013b) used their model developed earlier to assess the potential of the $5 \mathrm{~kW}$ SOFC for residential applications. Arpino et al. (2013b) concluded that a $5 \mathrm{~kW}$ capacity is over-sized for this type of application and that the thermal output for a fuel cell of this size could not be effectively utilized. Arpino et al. (2013b) found that $1 \mathrm{~kW}$ is the most appropriate size of SOFC for a residential micro-cogeneration application.

In a different research effort, Boigues-Muñoz et al. (2013) presented experimental data from a $1 \mathrm{~kW}$ SOFC. Instrument uncertainties were not described nor were data describing the SOFC's thermal output provided. Guo et al. (2015) also omitted detailed data describing the thermal output of the $3 \mathrm{~kW}$ PEMFC they studied.

Staffell (2015) gathered electrical and thermal efficiency data from 8 PEMFC and 6 SOFC systems of various manufacturers. For each group of PEMFCs and SOFCs, normalized electrical and thermal efficiency were given as functions of part-load ratio for the PEMFC. The uncertainties of these data were not described. The dependency of performance on thermal boundary conditions was not described for these functions either. 
Notably, the model used by Canelli et al. (2015) was calibrated with data originating from an earlier version of the apparatus used by Johnson et al. (2013). Canelli et al. (2015) have cited a conference paper (Thorsteinson et al., 2011) as the origin of their data (as was also done by references (Anindito et al., 2013; Entchev et al., 2013)) where the model uncertainties were not yet defined. However, it is not justifiable to use this model for this work when data with documented uncertainties from the same fuel cell exists and are available (Johnson et al., 2013). Note that the work in this reference (Johnson et al., 2013) was performed as part of this Ph.D. thesis.

All widely available fuel-cell models for BPS were reviewed by Ham et al. (2015) who determined that the model presented by Johnson et al. (2013) was still the most accurate and concise. They provided new data for a PEMFC that is oversized (10 kW nominal electrical output) for the application under consideration in this work. They also fit a different model to the calibration data presented by Johnson et al. (2013). However, this new model is of limited validity for this work because it contains simplifications whose influences on the model's uncertainties were not described.

Aside from these models, there are several other studies where fuel-cell performance data are presented that deserve mentioning. Payne et al. (2011) and Sommer and Mesenhöller (2013) presented performance data from a $1.5 \mathrm{~kW}$ SOFC whose electrical efficiency is $60 \%$ at rated conditions. Hody et al. (2015) presented data describing the performance of several SOFCs and PEMFCs in the 1-4 kW output range at nominal operating conditions. Iwami et al. (2015), Postlethwaite et al. (2015), Koda et al. (2015) and Watanabe et al. (2015) presented some performance data from several $0.7 \mathrm{~kW}$ fuel cells. Similar fuel cells have also been demonstrated in field-trials (Sasakura, 2015; Tanaka, 2015). In comparison with the performance of the fuel cell studied by Johnson et al. (2013), the electrical efficiencies of these fuel cells appears to be superior. However, details describing the uncertainties of theses performance data presented by these studies are unavailable. 


\subsection{Micro-Cogeneration Performance Metrics}

The major goal of the BPS studies based on the models described in the preceding sections was to evaluate the performance of a micro-cogeneration system according to some type of metrics. Dorer and Weber (2007) identified three types of microcogeneration system performance analyses (economic, $\mathrm{CO}_{2}$ emissions and energy) along with some corresponding performance metrics. These types of analyses are described in the following sections.

\subsubsection{Economic Analysis}

Hawkes et al. (2009a,b), Napoli et al. (2015) and Pellegrino et al. (2015) all provided examples of how detailed economic performance analyses of micro-cogeneration systems can be performed. This type of analysis is important because if there is to be a widespread adoption of these types of systems, they must eventually provide some economic benefits. However, Dorer and Weber (2007) indicated that economic analyses are the most difficult to perform and are the least meaningful because energy cost structures were (and still are) in an unprecedented state of flux. As an example, consider the temporal variation of the natural gas cost charged by the utility (Enbridge) to a residential consumer in Ontario shown in Figure 3. These data were obtained from the Ontario Energy Board (OEB, 2013).

Figure 3 shows that the natural gas cost has significant temporal variability. As another example, the monthly averaged hourly Ontario energy price (MAHOEP) is shown in Figure 3 as well. This is the wholesale price of electricity generated in Ontario set by the Independent Electricity System Operator (IESO, 2013c). The MAHOEP shows a similar degree of temporal variation as the natural gas cost.

Supply, demand and public policy are several factors that can influence these costs shown in Figure 3. Because of the significant temporal variability in energy 


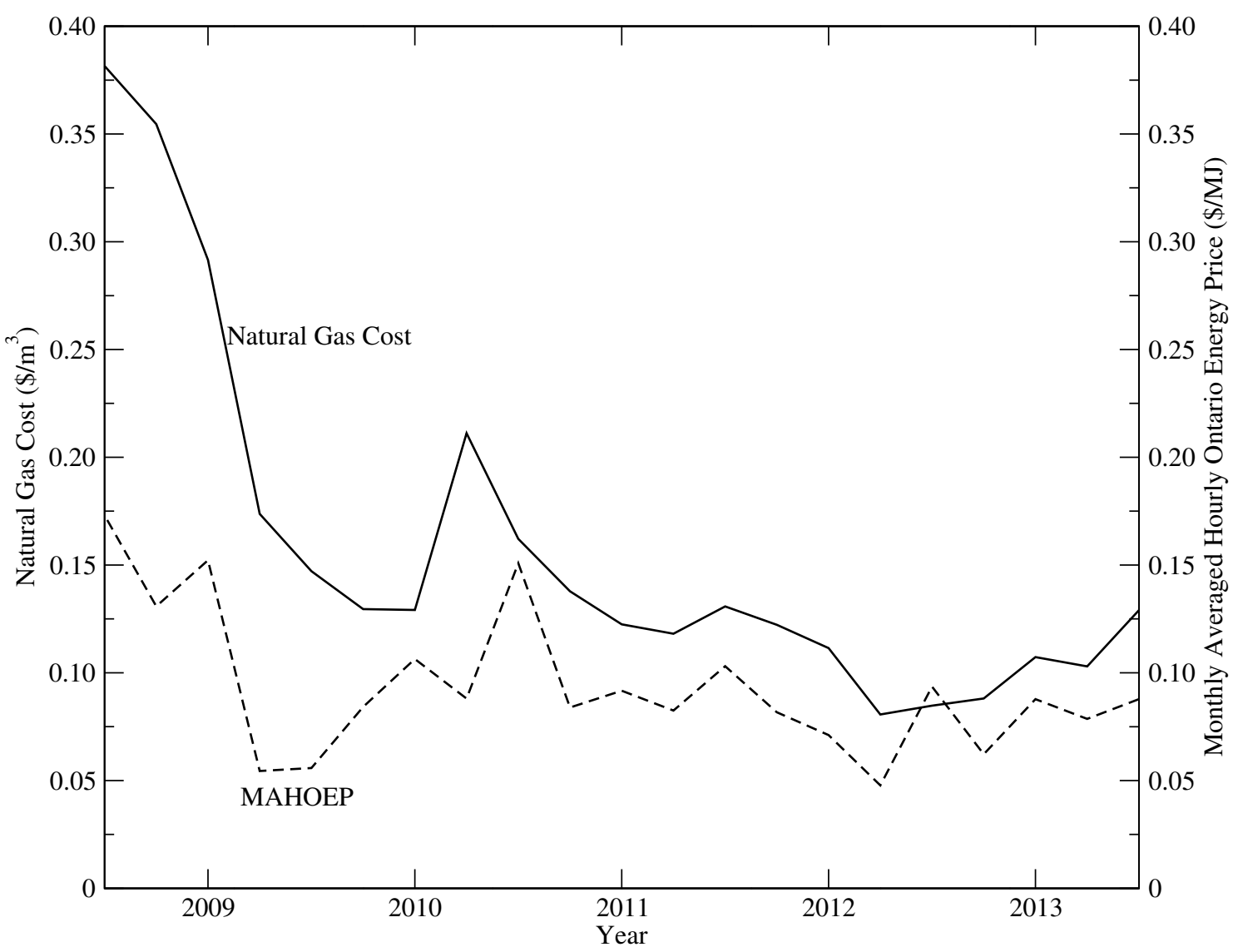

Figure 3: Temporal variation of natural gas cost of a residential consumer in Ontario (OEB, 2013) and the monthly average Ontario wholesale electricity cost (IESO, 2013c)

costs (such as in the examples shown in Figure 3), any economic analyses performed using these costs could become irrelevant quickly. Consequently, this type of analysis will not be be considered in this research.

\subsection{2 $\quad \mathrm{CO}_{2}$ Emissions Analysis}

To perform an emissions analysis it is important to first consider how the various primary energy sources shown in Figure 4 are used to generate electricity in Ontario. The IESO (2015) archives the generated electricity in Ontario by primary energy 
source. These data are shown by the percentage of energy generated by a primary energy source to the total monthly energy demand in Figure 4 for 2015.

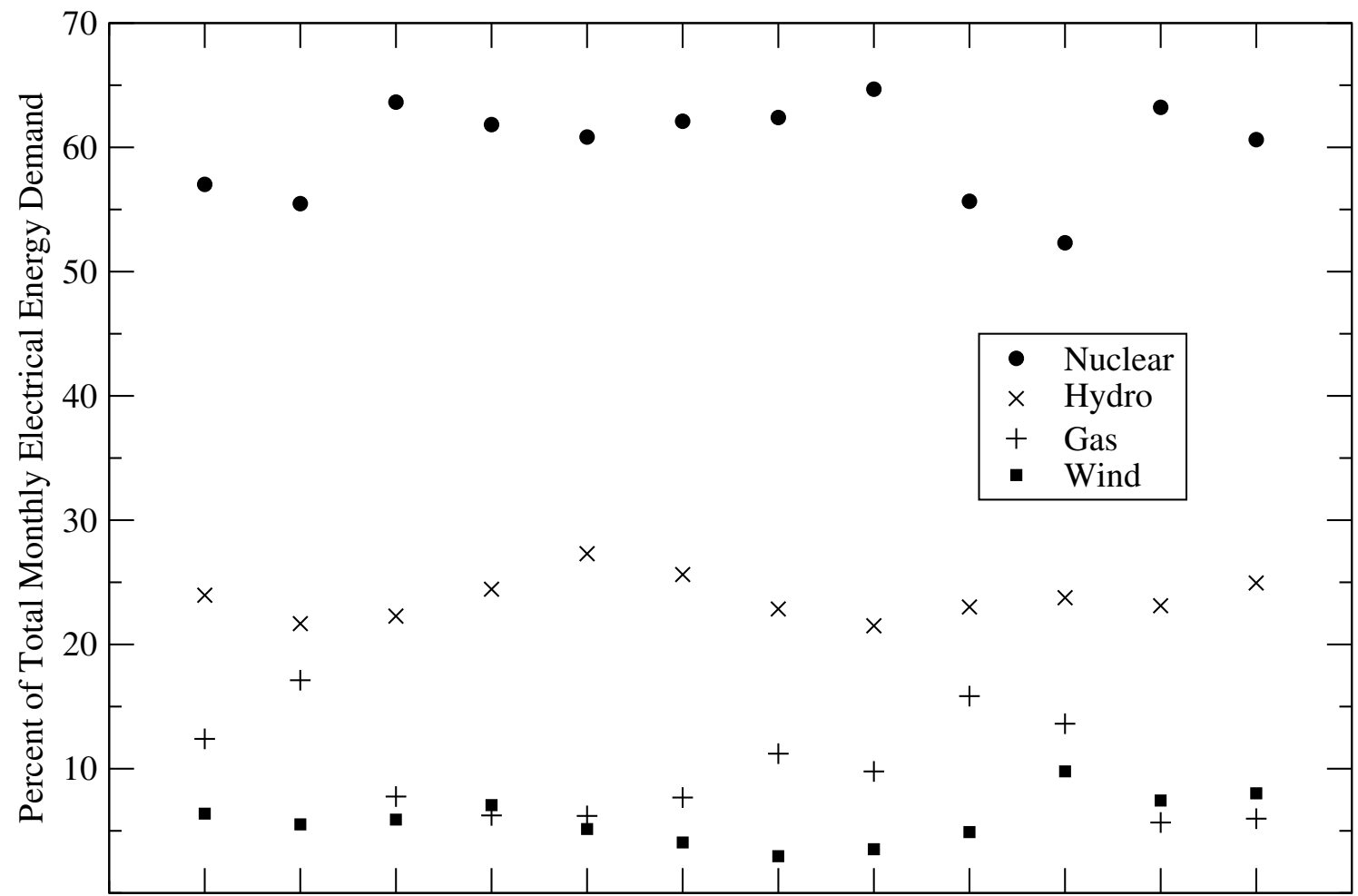

Jan. Feb. Mar. Apr. May Jun. Jul. Aug. Sept. Oct. Nov. Dec. Month (2015)

Figure 4: Generated electricity in Ontario by primary energy source as a percentage of total monthly energy demand (IESO, 2015)

Power plants that generate electricity using gas as a primary energy source are classified as "peaking" plants by the IESO (2016). This is in contrast to nuclear and many hydro plants that are classified as "base load" plants. The IESO (2016) indicates that base load plants have high capital costs and operate continuously above $70-80 \%$ of their maximum capacity, whereas peaking plants operate at $10-30 \%$ of their maximum capacity and their output can be modulated to meet the variable demand 
for electricity. Note that some hydro plants with water storage capabilities are also classified as peaking plants according to the IESO (2016). Wind power is a renewable source whose availability depends on environmental conditions.

According to the Ontario Ministry of Energy (2013), power plants that generate electricity using gas as a primary energy source will continue to be used as peaking plants to meet the variable demand for electricity in Ontario for the foreseeable future. By the year 2030, approximately $10 \%$ of the demand in Ontario will be met with electricity generated using gas as a primary energy source. Although gas is the most greenhouse gas intensive fuel that is still used in large quantities for power generation in Ontario, it will be in use long term so it is worthwhile to consider more efficient ways of using it. Therefore, this research will attempt to answer the question of whether it is better to use natural gas for central power generation or in distributed micro-cogeneration systems.

The performance metric that should be considered in a $\mathrm{CO}_{2}$ emissions analysis recommended by Dorer and Weber (2007) is the mass of $\mathrm{CO}_{2}$ emissions that is saved by a micro-cogeneration system relative to a reference case $\left(\Delta m_{C_{2}}\right)$. To answer the research question under consideration here $\Delta m_{\mathrm{CO}_{2}}$ is given by equation 4 .

$$
\Delta m_{C O_{2}}=\Delta E_{g a s} \cdot E F_{C O_{2}}
$$

where $E F_{\mathrm{CO}_{2}}$ is the emissions factor of a pollutant (in this case $\mathrm{CO}_{2}$ ) and is given as a ratio of the mass of the pollutant produced $(\mathrm{kg})$ for a quantity of fuel energy content consumed $(\mathrm{J})$. In this jurisdiction, the Ontario Ministry of the Environment (MOE, 2014) provides the values for the emissions factors of $\mathrm{CO}_{2}$ and various other pollutants for various industrial activities. For this case, the industrial activity is electricity generation and $\Delta E_{g a s}$ is the amount of fuel energy content saved by using 
micro-cogeneration rather than utility supplied electricity from a central gas plant and a conventional method for satisfying an occupant's thermal demands.

Equation 4 demonstrates how $\mathrm{CO}_{2}$ emissions savings depend on energy savings. Note that this is only true for cases when a comparison is being made between two technologies that use the same fuel such as is being done in this research. Since to answer the question this research attempts to address, emissions savings follow from energy savings (equation 4), this research will focus on developing an approach for an energy analysis. The following section reviews existing approaches to performing an energy analysis.

\subsubsection{Energy Analysis}

In an energy analysis, Dorer and Weber (2007) recommended that energy savings is the most important metric that should be used to evaluate a micro-cogeneration system's performance. To evaluate the energy savings associated with the use of a micro-cogeneration system, the micro-cogeneration system's performance must be compared to a reference scenario. In this section, to demonstrate how these energy savings may be determined, the amount of energy savings that are associated with a micro-cogeneration system supplying only the DHW thermal demands in a residential application is derived. Note that this will be the case for the simulations described later in Chapter 6.

The justification for only considering DHW demands is that they account for much less energy consumption than space-heating demands in Ontario. Natural Resources Canada (NRCan, 2016) estimates the energy consumption related to space heating demands accounts for approximately three times as much energy consumption on an annual basis in comparison with the energy consumption related to DHW demands in Ontario. Therefore, if the goal is to establish a minimum level of demand above which micro-cogeneration systems are more efficient (as is the case in Chapter 6), 
it might be possible to accomplish this by only considering DHW demands. It is obvious that additionally considering space-heating demands would only improve the micro-cogeneration system's probability of exceeding the efficiency of the reference scenario.

Furthermore, it would be an advantage if a DHW only application of a microcogeneration system could be shown to be more efficient than the reference scenario for reasonable levels of DHW demand because DHW demands exist all year in Ontario in comparison to space-heating demands that are seasonal. The plant network of a micro-cogeneration system only supplying DHW demands is also less complex than one that additionally supplies space heating. Additional consideration would be needed to account for the energy consumption of the added space-heating components in the plant network. In the mathematical development that follows only a single reference method for providing thermal demands related to DHW consumption is considered. Including space-heating demands could potentially necessitate the consideration of a second method. In the development that follows it is also further assumed that in the reference scenario, DHW thermal demands are met primarily with a gas-fired device.

The difference between the amount of fuel energy content consumed per unit time to meet the energy demands of a residential occupant between the case where microcogeneration is used relative to the reference scenario $\left(\Delta \dot{E}_{\text {gas }}\right)$ is shown in equation 5. Note that the overhead "dots" in the following equations are used to denote that the derivations being performed are on a time-rate basis. All units are in W.

$$
\Delta \dot{E}_{\text {gas }}=\dot{E}_{\text {cogen }}-\dot{E}_{R S}
$$

where $\dot{E}_{\text {cogen }}$ is the rate of fuel energy content consumed to meet the occupants' energy demands for the case where a micro-cogeneration system is used and $\dot{E}_{R S}$ is 
the rate of fuel energy content consumed to meet the occupants' energy demands for the reference scenario.

It is important to note that, for the case where a micro-cogeneration system is used, fuel may not only be consumed in the fuel-cell $\left(\dot{E}_{f c-f u e l}\right)$, but also in an auxiliary source $\left(\dot{E}_{f c-a u x}\right)$ in case the fuel cell's thermal output $\left(q_{s-c o o l}\right)$ is insufficient to meet the DHW demands at a particular moment. The occupants' electrical demands $\left(P_{\text {load }}\right)$ are met by consuming fuel at a reference central plant while the fuel cell's electrical output $\left(P_{f c-a c}\right)$ displaces fuel consumption at the same reference plant. For this reason, the difference between the occupants' electrical demands and the fuel cell's electrical output $\left(P_{l o a d}-P_{f c-a c}\right)$ appears on the right side of equation 6 . This difference must also be divided by the reference plant's electrical efficiency $\left(\zeta_{e l-r e f}\right)$ to determine the associated fuel energy content so it may be summed with the rate of energy content consumed by the fuel cell and by the auxiliary source in equation 6 . Note that this is only true for when a comparison is being made to establish whether micro-cogeneration systems or central gas-fired combined cycles are more efficient as is the case for this thesis. In reality, in Ontario not all occupant electrical demands are met by consuming fuel in a reference plant that is a gas-fired combined cycle.

$$
\dot{E}_{\text {cogen }}=\frac{1}{\zeta_{\text {el-ref }}} \cdot\left(P_{l o a d}-P_{f c-a c}\right)+\dot{E}_{f c-f u e l}+\dot{E}_{f c-a u x}
$$

For the reference scenario, all of the occupants' electrical demands are met by consuming fuel in the reference plant, whereas the occupants' DHW demands are met by an on-site reference burner as is shown in equation 7 .

$$
\dot{E}_{R S}=\frac{1}{\zeta_{e l-r e f}} \cdot\left(P_{l o a d}\right)+\dot{E}_{t h-r e f}
$$

where $\dot{E}_{t h-r e f}$ is the rate of fuel energy content consumed in the reference burner to meet the occupants' DHW demands. Note that $\dot{E}_{t h-r e f}$ can be expressed in terms of 
the efficiency of the reference burner $\left(\zeta_{t h-r e f}\right)$ and the rate of DHW demand required by the occupants $\left(q_{\text {load }}\right)$ as shown in equation 8 . The reference burner may also consume a small amount of electricity $\left(P_{t h-r e f}\right)$. This amount of electricity is considered to be separate from $P_{\text {load }}$ for the purposes of the development here. Here $P_{\text {load }}$ is considered to represent all electrical consumption in the reference scenario not directly related to DHW consumption. It is also assumed that $P_{\text {load }}$ does not vary between the reference scenario and the case where micro-cogeneration is used. The additional amount of electricity required by the burner in the reference scenario is provided by consuming fuel in the reference plant. For this reason, $P_{t h-r e f}$ is divided by $\zeta_{e l-r e f}$ to determine the associated rate of fuel energy content consumption in equation 8.

$$
\dot{E}_{t h-r e f}=\frac{q_{l o a d}}{\zeta_{t h-r e f}}+\frac{P_{t h-r e f}}{\zeta_{e l-r e f}}
$$

Also note that, when the reference scenario and micro-cogeneration case are considered to provide the exact same amount of DHW, qload can be expressed in terms of the amount of thermal output from the PEMFC $\left(q_{s-c o o l}\right)$ as is shown in equation 9.

$$
q_{\text {load }}=q_{s-\text { cool }} \cdot \Psi+q_{f c-a u x}
$$

Because not all of the thermal output of the PEMFC can be used (a portion is rejected if there is insufficient demand at a particular moment), $q_{s-c o o l}$ is multiplied by a factor $(\Psi)$ in equation 9 that represents the percentage of $q_{s-\text { cool }}$ that may eventually be used by an occupant. The fuel cell may also require assistance from an auxiliary source $\left(q_{f c-a u x}\right)$ to meet the DHW demands of an occupant at a particular moment. The result of combining equations 6 to 9 is shown below in equation 10 .

$$
\Delta \dot{E}_{g a s}=\dot{E}_{f c-f u e l}-\left(\frac{P_{t h-r e f}+P_{f c-a c}}{\zeta_{e l-r e f}}\right)-\left(\frac{q_{s-c o o l} \cdot \Psi+q_{f c-a u x}}{\zeta_{t h-r e f}}\right)+\dot{E}_{f c-a u x}
$$


Therefore, to evaluate $\Delta \dot{E}_{\text {gas }}$ requires that suitable reference efficiencies be selected. Ribberink et al. (2008) argued that, in Ontario, the reference scenario should be based on a system composed of a gas burner in a storage tank for DHW because this type of system is based on traditional technology that is widespread. For the reference electrical efficiency, previously it was suggested in Annex 42 (Dorer and Weber, 2007) that a peak combined-cycle efficiency, relative to the LHV, of $55 \%$ is a reasonable estimate for this value. There has also been a European Commission decision to establish reference electrical and thermal efficiency values (EUROPA, 2011) for its member states.

However, since the performance benefits of micro-cogeneration systems compared to reference scenarios can be incremental (Johnson et al., 2015), and comparison metrics can be very sensitive to small changes in efficiency values (Staffell, 2015), it is questionable whether $\Delta \dot{E}_{\text {gas }}$ is a meaningful parameter on which to base an energy analysis. Uncertainties in all of the parameters on the right side of equation 10 could potentially invalidate this metric. While there are many examples of researchers performing similar energy analyses for fuel-cell based micro-cogeneration systems (Bianchi et al., 2012, 2013, 2014; Napoli et al., 2015; Vialetto et al., 2015; Yaji and Diarra, 2013; Zuliani and Taccani, 2012) based on simulations, none have taken into account the uncertainties on which their models are based, or the uncertainties of the reference efficiencies used, and propagated these uncertainties to their results.

\subsection{Thesis Objectives}

From the literature reviewed it is clear that the following major knowledge gap exists in this field: While there are many examples of simulation-based efforts that attempt to assess the potential of fuel-cell based micro-cogeneration systems, there are no 
examples where authors have attempted to assess the impact of their models' uncertainties on the predictions of their simulations. Given that the performance benefits of a micro-cogeneration system are incremental when compared to conventional methods of providing occupant electrical and thermal demands, this is especially important to consider.

This knowledge gap likely exists because there are only a few examples of fuel-cell models where the uncertainties of performance data on which they are based have been adequately characterized. Although there are a few examples where authors have based their simulations on a fuel-cell model where the uncertainties were adequately characterized, none have taken these uncertainties into account when interpreting the results of their simulations. Considering that this issue exists for any type of analysis (economic, emissions and energy) and that an energy analysis is the simplest to conduct, it is reasonable to begin by developing a more defensible methodology for performing an energy analysis of a micro-cogeneration system. Therefore, the overall objective of this thesis is to develop a methodology where these uncertainties are taken into account for an energy analysis. A summary of the specific tasks that were completed to address this knowledge gap and achieve this research objective is given as follows:

- A reference electrical efficiency of a conventional method for satisfying occupant demands, against which micro-cogeneration systems are competing within the jurisdiction of Ontario, Canada, was determined along with its uncertainty margins. This was accomplished by considering available government data. An electrical performance index was identified as a metric that could be used to perform the energy performance comparison between a micro-cogeneration system and this defined reference electrical efficiency. 
- A condensing TWH was selected as an efficient reference method for providing occupant thermal demands, against which micro-cogeneration systems are competing within the jurisdiction of Ontario, Canada. A new model form of a TWH was developed to represent the performance of this type of device. This necessitated experimental work to assist in the derivation of the model equations and to calibrate them. The uncertainties of this model's predictions are well described.

- A model of a fuel-cell micro-cogeneration system for a residential application was calibrated with performance data from a wide range of operating conditions. This necessitated experimental work to develop/calibrate a model of a fuel-cell micro-cogeneration device. The uncertainties of this model's predictions are well described.

- Simulations were conducted where the performance of the modelled fuel-cell system in a residential micro-cogeneration application was compared to the aforementioned reference methods for providing occupant electrical and thermal demands. The goal of these simulations was to serve as a case study to demonstrate the methodology developed in this thesis for assessing whether a micro-cogeneration system or the conventional technologies was more efficient. This included propagating the uncertainties of model predictions through to the results of these simulations and interpreting the probabilistic nature of these results.

Each of the following chapters describes how these aforementioned objectives were completed before conclusions are drawn. 


\section{Chapter 3}

\section{The Derivation of a Reference Electrical Efficiency and a Methodology for its Comparison with an Electrical Performance Index of a Micro-Cogeneration Device}

There is widespread disagreement in the field of micro-cogeneration concerning a reasonable reference scenario against which the performance of a micro-cogeneration system should be compared to. In the past (Dorer and Weber, 2007), it has been suggested that the peak efficiency of a gas-fired combined-cycle plant should be considered as a reasonable reference scenario; however, this reference scenario does not account for part-loading, production transients, supplementary firing or the production of heat or steam from central-cogeneration plants for nearby industrial processes that occur in practice. More recently, there has been a European Commission Decision (EUROPA, 2011) to establish reference efficiency values for its member states; however, it is unclear whether these values are valid for other jurisdictions. In this 
chapter, another reference scenario is proposed based on government data to account for these factors. For comparison with this reference scenario, an electrical performance index is identified as a metric where the thermal output of any type of cogeneration plant can be combined with its electrical output into a single value. The derivation of this metric is also described in this chapter.

Note that in this chapter, Sections 3.2 to 3.4 are adaptations of the work presented by Johnson et al. (2016). My supervisor, Ian Beausoleil-Morrison, provided feedback for the writing and for all of the ideas presented in this paper. My co-author, Adam Wills, provided the methodology for calculating the electrical transmission system's efficiency. The majority of the work presented in this aforementioned paper was my own.

\subsection{Central Gas Plants}

In Ontario, there are two major types of gas plants that are in operation: those that only generate electricity and those that also generate heat or steam for some nearby process. The latter is termed a central-cogeneration plant and its heat or steam generated is termed its thermal output.

Some essential features common to all gas plants in Ontario are described by the combined-cycle schematic that is shown in Figure 5 with the caveat that the number of gas turbines, steam turbines and heat-recovery steam generators will vary for individual plants and that central gas plants without cogeneration do not extract steam. Also note that those plants of a simple-cycle type employ no steam turbine, nor any other component of the steam power cycle and may also not include a heatrecovery steam generator for simple-cycle plants without cogeneration. Individual plants may also employ reheat, intercooling and regeneration but these aspects are not shown in Figure 5. 


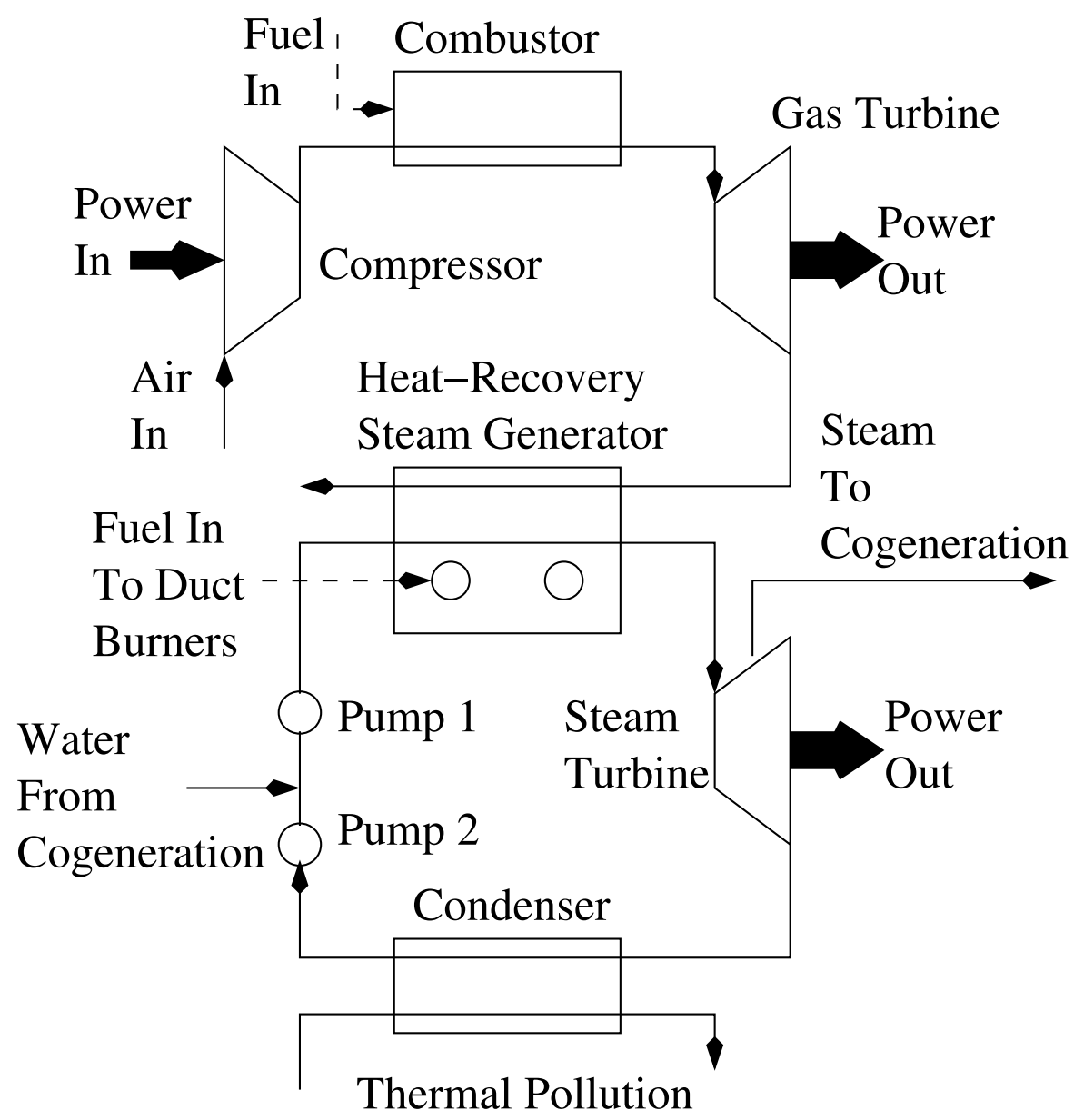

Figure 5: Central gas plant schematic adapted from Moran and Shapiro (2004) and the Ontario Power Authority (OPA, 2016)

The combined-cycle plant shown in Figure 5 is essentially a variation of the basic combined cycle where air is drawn into the compressor to raise its pressure before it is heated in the combustor by the combustion of a fuel. This high pressure and temperature gas mixture is then expanded through a gas turbine to generate power. In a combined cycle, these exhaust gases are then passed through the heat-recovery steam generator that is used to generate steam from liquid water whose pressure has been raised upstream by a pump. For plants without cogeneration, only pump 1 is necessary. This high pressure and temperature steam is then expanded through a 
steam turbine to generate power before being cooled in the condenser to complete the cycle.

In Ontario, all combined-cycle plants, with or without cogeneration, are also supplementary fired by duct burners within the steam generator as is indicated by every plant's publicly available individual application for an air/noise compliance permit to the MOE (2014). Supplementary duct firing has the effect of increasing a plant's output at the expense of decreasing its electrical efficiency, since the fuel consumed by the duct burners only increases the output of the steam turbine. Chase and Kehoe (2015) estimate that for a typical combined-cycle plant, in the output range relevant to those plants being discussed here, supplementary firing can increase a plant's output up to $28 \%$ beyond what could be achieved without supplementary firing. At this level of supplementary firing, the relative efficiency degradation would be approximately $9 \%$ (e.g. from $55 \%$ to $50 \%$ ). The relationship between the incremental output due to supplementary firing and relative efficiency degradation is approximately linear.

In a central-cogeneration plant, a portion of the generated steam is extracted from the steam turbine to be used in a nearby process. Depending on the process, the steam can be extracted from the steam turbine at different pressure levels. This has a detrimental effect on the electrical efficiency of the cycle because the steam extracted for cogeneration bypasses a section of the steam turbine for power generation. The steam is returned from cogeneration as water at an intermediate pressure between pumps 1 and 2. The electrical consumption of each pump is generally considered small and is not shown.

Aside from displacing the fuel consumption of some other boilers that need not be used to meet the thermal demands of some processes, one major reason for using central-cogeneration plants in Ontario is to reduce the amount of heat rejected by condensers to the environment. Heat rejected by condensers to the environment is 
termed thermal pollution (Verbruggen et al., 2013). Excessive thermal pollution is an environmental problem as it has the potential to disrupt nearby ecosystems.

Table 2 lists all the gas plants in Ontario that only generate electricity, whereas Table 3 lists all central-cogeneration plants along with several performance metrics. The capability shown in both tables is the maximum possible output according to the IESO (2013b). The output shown in the next column to the right has been averaged from 2011-2013 and is also based on data from the IESO (2013b). The electrical efficiencies shown in both tables have also been averaged over that same period of years. As the efficiencies shown in Tables 2 and 3 are based on data describing what central gas plants in Ontario have achieved in practice, the detrimental effect to efficiency caused by supplementary fired, part-load and transient operation has been accounted for. Therefore, the efficiencies shown in Tables 2 and 3 are more relevant to the jurisdiction of Ontario than the reference mentioned by Dorer and Weber (2007). The method by which these efficiencies were derived is described in Section 3.2. 
Table 2: The performance of major gas plants in Ontario without cogeneration from 2011-2013 (IESO, 2013b)

\begin{tabular}{|c|c|c|c|c|}
\hline \multirow[t]{4}{*}{ Name } & \multirow[t]{4}{*}{ Type } & \multirow{4}{*}{$\begin{array}{l}\text { Capability } \\
(\mathrm{MW})\end{array}$} & \multirow{4}{*}{$\begin{array}{l}\text { Average } \\
\text { Yearly } \\
\text { Output } \\
\text { (PJ/year) }\end{array}$} & \multirow{4}{*}{$\begin{array}{l}\text { Average } \\
\text { Electrica } \\
\text { Efficiency } \\
(\% \text { LHV) }\end{array}$} \\
\hline & & & & \\
\hline & & & & \\
\hline & & & & \\
\hline Brighton Beach & combined & 597 & 0.31 & 49.9 \\
\hline Goreway & combined & 950 & 2.66 & 49.4 \\
\hline Greenfield & combined & 1153 & 3.34 & 49.5 \\
\hline Halton Hills & combined & 759 & 2.32 & 51.2 \\
\hline Portlands & combined & 641 & 1.33 & 53.1 \\
\hline St. Clair & combined & 639 & 1.26 & 53.2 \\
\hline York $^{\mathrm{a}}$ & simple & 440 & 0.16 & 33.2 \\
\hline Nipigon & combined $^{\mathrm{b}}$ & 43 & 0.30 & 47.5 \\
\hline Kapuskasking & combined $^{\mathrm{b}}$ & 60 & 0.35 & 45.0 \\
\hline North Bay & combined $^{\mathrm{b}}$ & 66 & 0.35 & 44.9 \\
\hline Tunis & combined $^{\mathrm{b}}$ & 60 & 0.34 & 45.0 \\
\hline Lennox & steam $^{\mathrm{c}}$ & 2100 & 0.13 & $\mathrm{~N} / \mathrm{A}$ \\
\hline Cochrane & combined $^{\mathrm{d}}$ & 47 & 0.38 & $\mathrm{~N} / \mathrm{A}$ \\
\hline Kirkland & combined $^{\mathrm{d}}$ & 149 & 0.92 & $\mathrm{~N} / \mathrm{A}$ \\
\hline
\end{tabular}

\footnotetext{
${ }^{\text {a }}$ Operated from 2012-2013

b Also serves a natural gas compressor station

c Also consumes oil as a secondary fuel

d Also consumes biomass as a secondary fuel
} 
Table 3: The performance of major gas plants in Ontario with cogeneration from 2011-2013 (IESO, 2013b)

\begin{tabular}{|c|c|c|c|c|}
\hline Name & Type & $\begin{array}{l}\text { Capability } \\
(\mathrm{MW})\end{array}$ & $\begin{array}{l}\text { Average } \\
\text { Yearly } \\
\text { Output } \\
\text { (PJ/year) }\end{array}$ & $\begin{array}{l}\text { Average } \\
\text { Electrical } \\
\text { Efficiency } \\
(\% \mathrm{LHV})\end{array}$ \\
\hline Ottawa Health & combined & 78 & 0.53 & 45.5 \\
\hline Cardinal & combined & 184 & 1.37 & 40.8 \\
\hline Destec & combined & 140 & 0.96 & 48.0 \\
\hline East Windsor & simple & 100 & 0.20 & 33.4 \\
\hline Lake Superior & combined & 120 & 0.91 & 50.2 \\
\hline Iroquois Falls & combined & 131 & 0.87 & 39.5 \\
\hline TransAlta & combined & 122 & 1.07 & 49.6 \\
\hline \multicolumn{5}{|l|}{ Mississauga } \\
\hline TransAlta Windsor & combined & 78 & 0.52 & 43.4 \\
\hline TransAlta Sarnia & combined $^{\mathrm{a}}$ & 510 & 2.20 & 30.4 \\
\hline Thorold & combined & 287 & 1.06 & 45.3 \\
\hline West Windsor & combined & 128 & 1.09 & 46.5 \\
\hline Whitby & simple & 57 & 0.49 & 38.8 \\
\hline
\end{tabular}

a Operated primarily in simple-cycle mode 


\subsection{Methodology for Deriving the Electrical Effi- ciency of a Central Gas Plant}

The electrical efficiency $\left(\zeta_{e l}\right)$ of a central gas plant is given by equation 11 .

$$
\zeta_{e l}=\frac{E_{e l}}{V_{f u e l} \cdot L H V}
$$

where the net electrical output $\left(E_{e l}\right)$ and the volume of fuel consumed $\left(V_{\text {fuel }}\right)$ of each plant must be known along with the $L H V$ of the fuel.

Data from the IESO (2013b) can be used to estimate the hourly net electrical output for any plant. Unfortunately, similar data that describes the hourly fuel consumption for any plant are not currently available in this jurisdiction. Only data that describes the yearly fuel consumption of each plant are available. Therefore, yearly average values are the finest timescale resolution for $\zeta_{\text {el }}$ that can be calculated with equation 11 in Ontario based on the available data sources. In Canada, there are two federal government ministries that collect and make available yearly fuel consumption data that can be used for this: Environment Canada (2014) and Statistics Canada (2015).

Statistics Canada (2015) surveys all central gas plants to determine the volume of fuel consumed and electrical output of each plant. For reasons of confidentiality, Statistics Canada (2015) only makes publicly available the combined aggregate of every gas plant's fuel consumption and electrical output. Although these values published by Statistics Canada (2015) can be used to estimate the average electrical efficiency of all gas plants in Ontario, this efficiency estimate is problematic to use as the reference electrical efficiency against which micro-cogeneration systems are competing. The major issue is that the average electrical efficiency of all gas plants in 
Ontario does not account for the thermal output of cogeneration plants and is therefore too low to be used as a competitive reference. As can be seen from the average yearly outputs shown in Tables 2 and 3, there is a significant amount of cogeneration present and the electrical efficiencies of cogeneration plants are lower compared to those without cogeneration.

The same issue does not exist with the data made available by Environment Canada (2014) as they publish data for individual plants. Environment Canada (2014) does not publish fuel consumption directly; rather, they publish $\mathrm{CO}_{2}$ emissions (both direct and total equivalent) for all major emitters, including central gas plants, who have a legal obligation to report their emissions. If it is assumed that all of the direct $\mathrm{CO}_{2}$ emissions from a gas plant are caused by the consumption of gas for power generation, the energy content of the fuel consumed can be found by equation 12 .

$$
E_{\text {fuel }}=\frac{m_{\mathrm{CO}_{2}}}{E F_{\mathrm{CO}_{2}}}
$$

where $E F$ is the emissions factor associated with a pollutant and is normally given as a ratio of the mass of pollutant $\left(\mathrm{CO}_{2}\right)$ produced for the energy content of the fuel consumed. The MOE (2014) gives the value for the emissions factor for $\mathrm{CO}_{2}$ for the consumption of natural gas for electricity generation according to equation 13 .

$$
E F_{C O_{2}}=49.03 \mathrm{~kg} \mathrm{GJ}{ }^{-1}
$$

This analysis can also be performed with a facility's reported $\mathrm{CH}_{4}$ and $\mathrm{NO}_{2}$ emissions with corresponding emissions factors $\left(E F_{C_{4}}=12.79 \mathrm{~g} \mathrm{GJ}^{-1}\right.$ and $E F_{\mathrm{NO}_{2}}=1.279 \mathrm{~g}$ $\mathrm{GJ}^{-1}$ ). For the plant eventually selected to represent the reference scenario (described later in Table 15 in Chapter 6), an identical value for $E_{\text {fuel }}$ is obtained if the analysis is performed using their reported $\mathrm{CO}_{2}, \mathrm{CH}_{4}$ or $\mathrm{NO}_{2}$ emissions with the corresponding emissions factor from 2011-2013. Therefore, it is reasonable to conclude that these 
are the exact emissions factors this plant used to estimate their emissions from their known fuel consumption. It is important to understand that by knowing these values exactly, this plant's conversion of their known fuel consumption to emissions can be undone. Therefore, uncertainty associated with these emissions factors can be omitted from the uncertainty analysis performed later.

For the uncertainty analysis performed later, it is important to determine with what uncertainty a plant might know their value of $E_{\text {fuel }}$ to be. They determine $E_{\text {fuel }}$ according to equation 14 .

$$
E_{\text {fuel }}=V_{\text {fuel }} \cdot H H V
$$

A plant determines $E_{f u e l}$ as the product of both the volume of fuel $\left(V_{\text {fuel }}\right)$ it consumes and its higher heating value $(H H V)$ at a standard reference condition of 101.325 $\mathrm{kPa}$ and $15{ }^{\circ} \mathrm{C}$. The Canadian Department of Justice (DOJ, 2016) requires that the volume of gas sold by utilities to be accurate to within $3 \%$. This value will be considered as the uncertainty of $V_{\text {fuel }}$. It includes the accuracy of the flow meter along with the methods used to adjust the measured volume of gas to the standard reference conditions.

Greater uncertainty is associated with the $H H V$. The MOE (2014) allows for natural gas fired plants to obtain their heating value using one of two methods. In the first method, they obtain a value from their supply utility. The two major gas supply utilities in Ontario each reported a 6-month average $H H V$ twice a year, each year from 2011 - 2013 for emissions reporting purposes. In this period, every reported value from each utility was $38 \mathrm{MJ} \mathrm{m}^{-3}$. The MOE provided these values when contacted. However, these values are not site specific and some variation in the $H H V$ between sites is expected.

In the second method, they obtain a value from on-site measurements at the plant. If the $H H V$ is measured on-site at a plant, the MOE (2014) allows for the $H H V$ to 
be determined as inaccurate as $\pm 5 \%$. As the emissions reporting guideline (MOE, 2014) is written, this uncertainty only applies to this second method; however, it is still an indication of what uncertainty the MOE (2014) considers to be acceptable.

From the known information about the previously described two methods that plants use to determine $H H V$ values, it is potentially reasonable to assume an $H H V$ of $38 \mathrm{MJ} \mathrm{m}^{-3} \pm 5 \%$; however, this should also be validated against available information describing the known range of $H H V$ s relevant to the natural gas supplied to plants in Ontario. For this validation, the typical $H H V$ and range of expected values provided by Union Gas (2016) can be used. Note that Union Gas (2016) is the second largest utility that supplies natural gas to plants in Ontario. Union Gas (2016) indicates a range of $H H V$ s of 36.0 to $40.2 \mathrm{MJ} \mathrm{m}^{-3}$ with a typical value being 38.0 $\mathrm{MJ} \mathrm{m}^{-3}$. This typical value is identical to the values provided by the MOE.

For an $H H V$ of $38 \mathrm{MJ} \mathrm{m}^{-3} \pm 5 \%$, the lower uncertainty margin $\left(36.1 \mathrm{MJ} \mathrm{m}^{-3}\right)$ nearly coincides with the lower limit of the range specified by Union Gas (2016) (36.0 $\left.\mathrm{MJ} \mathrm{m}^{-3}\right)$. The agreement between the upper uncertainty margin $\left(39.9 \mathrm{MJ} \mathrm{m}^{-3}\right)$ and the upper limit of what is specified $\left(40.2 \mathrm{MJ} \mathrm{m}^{-3}\right)$ is close as well. This indicates that an uncertainty of $\pm 5 \%$ is reasonable for the $H H V$ and this value will be assumed.

To convert from $H H V$ to $L H V$ for natural gas in Ontario, the MOE (2014) specifies that a factor of 1.11 should be used. This fixed value may be used for any location in Ontario even though there may be variations in gas composition. This is because, in Ontario, the major combustible components of natural gas are methane, ethane and propane whose conversion factors are 1.11, 1.10 and 1.09 respectively (Moran and Shapiro, 2004). Union Gas (2016) provides the range of content values for each of these components present in the natural gas they supply: the methane content ranges from $87.0-97.0 \%$, the ethane content ranges from $1.5-7.0 \%$, the propane content ranges from 0.1 - 1.5\%. Other combustible components are not present in significant amounts. Considering how close the conversion factors are 
for the major combustible components and their relative significance to the overall composition of natural gas, it is reasonable to simply use 1.11 and take this value with no uncertainty. Therefore, the $L H V$ has the same relative uncertainty as the $H H V$.

A more detailed description of the uncertainties of this methodology is presented in Chapter 6 for the reference electrical efficiency that was selected for the case study that was examined by simulations. The following section describes how the thermal output of a cogeneration plant may be combined with its electrical output in a single performance index so it may be compared to this reference electrical efficiency.

\subsection{Methodology for Determining an Equivalent Electrical Performance Index for Cogeneration}

It is not an uncommon practice to determine an equivalent electrical benefit of the thermal output of a cogeneration plant and corresponding equivalent electrical performance index $\left(P I_{e l}\right)$. In this methodology, all that is needed is to assume a reference efficiency of a burner whose fuel consumption (and potentially a small amount of electrical consumption) is being displaced by the thermal output of cogeneration. The precise definition of this equivalent electrical benefit is given later in equation 17. This methodology is described by Simon Fraser University's Canadian Industrial Energy End-Use and Analysis Centre (CIEEDAC (2014)).

Another methodology was introduced by Wu and Wang (2014) recently for a combined-cycle cogeneration plant. Since using a combined cycle for cogeneration to also produce thermal output reduces the efficiency of electrical power generation, $\mathrm{Wu}$ and Wang (2014) used this reduction in electrical power generation efficiency as the cost of generating thermal output. By using this energy cost as a reference, 
$\mathrm{Wu}$ and Wang (2014) calculated a coefficient of performance for the thermal output being generated by cogeneration and compared this to the coefficient of performance of other technologies (absorption chillers and boilers).

This coefficient of performance described by Wu and Wang (2014) was extended to micro-cogeneration systems by Staffell (2015) who considered the reduction in electrical efficiency of a micro-cogeneration system to be with respect to a reference electrical efficiency of a central combined-cycle plant without cogeneration. Staffell (2015) defined this equivalent thermal coefficient of performance $\left(E q C O P_{t h}\right)$ according to equation 15 .

$$
E q C O P_{t h}=\frac{\zeta_{\text {cogen-th }}}{\zeta_{\text {el-ref }}-\zeta_{\text {cogen-el }}}
$$

where $\zeta_{c o g e n-t h}$ and $\zeta_{c o g e n-e l}$ are the thermal and electrical efficiencies of a microcogeneration system and $\zeta_{\text {el-ref }}$ is the reference electrical efficiency of a combinedcycle plant without cogeneration. However, the difficulty with this is that the difference between the reference electrical efficiency and the micro-cogeneration system's electrical efficiency can be small and appears as the denominator in equation 15 . This can cause this parameter to be very sensitive to small changes in efficiency values which is problematic from the perspective of an uncertainty analysis.

For this research, the methodology described by CIEEDAC (2014) will be used to avoid the small difference in the denominator reported by Staffell (2015). Note that CIEEDAC (2014) makes use of the term "equivalent electrical efficiency", whereas in this research the term electrical performance index is used because its value may be greater than 1 if the reference burner efficiency selected is sufficiently poor. It is also worth mentioning that the electrical performance index described in the following section is equally relevant to both central and micro-cogeneration plants. 
The equivalent electrical performance index $\left(P I_{e l}\right)$ of any cogeneration plant is defined here as

$$
P I_{e l}=\frac{E_{e l}+E_{Q}}{V_{f u e l-c o g e n} \cdot L H V}
$$

where $E_{e l}$ is a plant's net electrical production, $Q$ is a plant's thermal output and $E_{Q}$ is the benefit of producing thermal output expressed in terms of an equivalent amount of electrical output. In this methodology, it is assumed that the benefit of the thermal output from the cogeneration plant is that it displaces the thermal output of a reference burner on-site. This displaced thermal output from a reference burner has an associated displaced fuel consumption and potentially some displaced electrical consumption as well. Equation 17 defines the overall equivalent benefit.

$$
E_{Q}=\frac{Q \cdot \Psi}{\zeta_{t h-r e f}} \cdot P I_{e l}+E_{t h-r e f-e l}
$$

where $\zeta_{t h-r e f}$ is the efficiency of a reference burner that need not be used due to the thermal output of cogeneration and $E_{t h-r e f-e l}$ is the electrical consumption of the reference burner. The first term on the right side of equation 17 considers that the displaced fuel consumption from the reference burner can be reinvested in the cogeneration plant to produce an electrical benefit proportional to $P I_{e l}$. The second term on the right side of equation 17 considers that the displaced electrical consumption of the reference burner is an additional benefit.

The ratio $(\Psi)$ of the amount of thermal output actually used in a process $\left(Q_{\text {proccess }}\right)$ to the total amount of thermal output of a cogeneration plant $(Q)$ should be included as well $\left(\Psi=\frac{Q_{\text {process }}}{Q}\right)$. Later in Chapter 6, an approximation of $\Psi$ is given in equation 82. When equations 16 and 17 are combined and $\Psi$ is included, the expression for $P I_{e l}$ becomes equation 18 .

$$
P I_{e l}=\frac{E_{e l}+E_{t h-r e f-e l}+\frac{Q \cdot \Psi}{\zeta_{t h-r e f}} \cdot P I_{e l}}{V_{f u e l-c o g e n} \cdot L H V}=\frac{E_{e l}+E_{t h-r e f-e l}+E_{f u e l-r e f} \cdot P I_{e l}}{E_{f u e l-c o g e n}}
$$


where $E_{\text {fuel-ref }}$ is the energy content associated with the displaced fuel consumption of the reference burner and $E_{\text {fuel-cogen }}$ is the energy content associated with the fuel consumption of the cogeneration system. Equation 18 can then be rearranged to solve for $P I_{e l}$ explicitly as shown in equation 19.

$$
P I_{e l}=\frac{E_{e l}+E_{t h-r e f-e l}}{E_{\text {fuel-cogen }}-E_{f u e l-r e f}}
$$

This $P I_{e l}$ is a suitable metric to compare different cogeneration technologies so long as the reference burner's performance is characterized. It is meaningful to compare the $P I_{e l}$ of a cogeneration system to the electrical efficiency of a system that only generates electrical output (e.g. the plants shown in Table 2). If the $P I_{e l}$ of a cogeneration plant is greater than the efficiency of a plant that only generates electrical output then the fuel is used more efficiently in the cogeneration plant.

When comparing the $P I_{e l}$ of a residential micro-cogeneration system to the electrical efficiency of a plant in Table 2 an additional consideration is that the losses of the electrical transmission and distribution system should be accounted for. This is described in Section 3.4.

\subsection{Electrical Transmission and Distribution Effi- ciency Modelling}

In comparison to a central combined-cycle plant, one advantage of a microcogeneration system that should be considered is that its electrical production is close in proximity to where it will be consumed. Therefore, a micro-cogeneration system will make no use of the electrical transmission system and limited use of the distribution system. The topology of the electrical transmission and distribution system in Ontario is depicted schematically in Figure 6. 


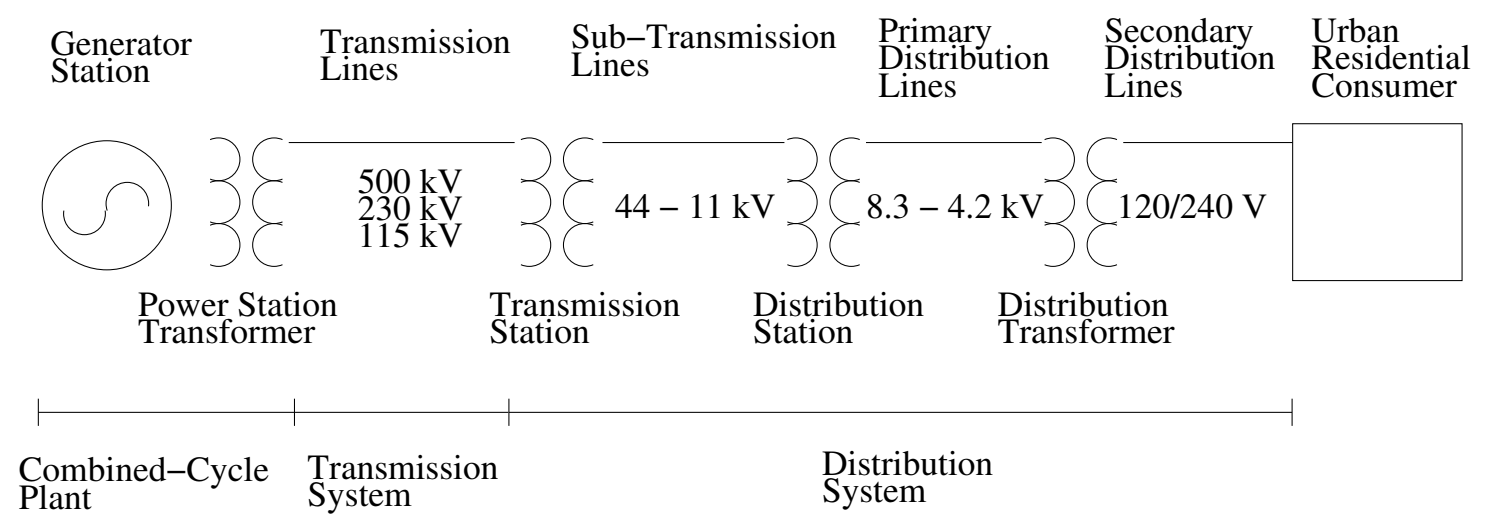

Figure 6: Topology of the electrical transmission and distribution system that connects a central-combined cycle plant to an urban residential consumer

The system used to generate and deliver electricity to an urban residential consumer from a central combined-cycle plant is modelled in three separate segments in this research: the combined-cycle plant, the transmission system and the distribution system. The combined-cycle plant consists of everything from the generator station to the high voltage-side of the power station transformer.

The transmission system consists of all components between the high voltage side of the power station transformer and the high-voltage side of the transmission station. The distribution system consists of all components from the high-voltage side of the transmission station until the urban residential consumer. This consists of the transmission station, the sub-transmission lines, the distribution station, the primary distribution lines, the distribution transformer and the secondary distribution lines.

For the reference combined-cycle plant selected for the case study in Chapter 6, the net generator output values (MW) provided by the IESO (2013b) are gathered as telemetry data from the high-voltage side of the power transformer station (IESO, 2006). This is not necessarily always the case, so care must be taken by other researchers to ensure that the power station's transformer losses have been considered if other reference combined-cycle plants are used. It is worth mentioning that when 
the net generator output value has been measured on both the high and low side of the power station transformer in fossil (gas or coal) plants in Ontario, the difference was measured as $0.12 \%$ (IESO, 2003) on average for all of the facilities sampled but differences as large as $\pm 5 \mathrm{MW}$ were observed at individual facilities.

As data were publicly available from the IESO (2013a) that described the hourly losses in the electrical transmission system in Ontario, the efficiency of the transmission system was calculated from these data. This was done considering an entire year's worth of data, sampled every hour, for 2008 and 2013. The resulting transmission efficiency was $97.4 \%$. Note that these losses include not only transmission lines, but any other component (e.g. series transformers required to step up to or down to the various transmission voltage levels shown) that is part of the transmission system. These data that describe these losses published by the IESO (2013a) are calculated as an intermediate variable from their modelling approach whose goal is to generate dispatch instructions that determine the output of all dispatchable generators in Ontario (Phillips, 2004).

Unfortunately, similar data relevant to the distribution system in Ontario were not available. Distribution efficiency estimates based on a modelling approach (Navigant, 2014) for an urban consumer have shown this value to be approximately $96.7 \%$. It is also difficult to assess how much of this distribution efficiency should be considered when comparing a micro-cogeneration system to a central combined-cycle plant. A micro-cogeneration system may make some use of the distribution system if not all of the electricity it produces can be consumed on-site. It is also important to consider that a substantial portion of the losses within the distribution system in urban Ontario are no-load losses that are not directly related to its load and only to the system's existence (Hydro One, 2007; Piercy and Cress, 2007). The majority of these losses occur in transformers from eddy-current, exciting current, hysteresis and dielectric effects, whereas losses that depend on the load occur due to resistive heating in 
transformer conductor windings as well as in power lines (Flinn et al., 1983). It is also not possible to estimate the uncertainty associated with the distribution system. The same is true for the transmission system. To account for these difficulties, in the simulations to be performed later in Chapter 6, a sensitivity analysis will be conducted.

\subsection{Gas Transmission and Distribution Efficiency}

In Ontario, the gas that is delivered to power plants for electricity generation and the gas delivered to residential consumers has a common origin. The gas is harvested predominantly in the western provinces of Alberta and Saskatchewan before being transported by pipeline to Ontario (Statistics Canada, 2001). Compressor stations located at specified intervals along the pipeline are necessary to compensate for losses. The most common type of compressor station in Canada is a gas turbine (Mora and Ulieru, 2005) that consumes a portion of the gas passing through the pipeline. In North America, compressor stations consume approximately 3-5\% of the transported $\operatorname{gas}(\mathrm{Wu}, 1998)$.

\begin{tabular}{llll}
\hline & $\begin{array}{l}\text { Number } \\
\text { of Com- } \\
\text { pressor } \\
\text { Stations }\end{array}$ & $\begin{array}{l}\text { Combined } \\
\text { Output (MW) }\end{array}$ & $\begin{array}{l}\text { Estimated } \\
\text { Relative } \\
\text { Loss (\%) }\end{array}$ \\
\hline Distribution & 38 & 275 & 16 \\
Transmission & 109 & 1443 & 84 \\
System Total & 147 & 1718 & 100 \\
\hline
\end{tabular}

Table 4: Natural gas transmission and distribution compressor station statistics (Statistics Canada, 2001) 
Statistics Canada (2001) also indicates that, in Ontario, compressor stations consume only $3.2 \%$ of the total gas demanded. In Ontario, both central plants and residential distribution utilities primarily receive their gas directly from the transmission system. Therefore, the incremental penalty to deliver gas to a residential consumer compared to a central plant is associated mainly with the distribution system. Data provided by Statistics Canada (2001) suggest that compressor station losses in gas distribution systems in Ontario only account for a small portion of the overall loss. These data are shown in Table 4.

Potentially, because the gas need only travel an incremental distance from a utility to a residential consumer compared to the distance it has traveled from its origin in the western provinces to a utility's distribution facility, distribution losses account for only approximately $16 \%$ of the total losses. Due to their relative insignificance, gas distribution compressor station losses will be neglected in any further analyses. Consequently, the incremental penalty of delivering gas to a residential consumer for micro-cogeneration through the distribution system compared to if the gas were delivered to a central gas plant will be neglected.

It is worthwhile to note that the performance of the gas distribution system was taken into account by Fubara et al. (2014) in their analyses of micro-cogeneration systems in the U.K.. They estimated the electrical and gas energy consumption of compressor stations in the gas distribution system in the U.K. to be $0.298 \%$ and $0.066 \%$ respectively of the total energy content of the fuel which is transported. Considering the data summarized in Table 4, it is unlikely that in Ontario these values would be substantially different. 


\subsection{Additional Considerations for the Compari- son Between Micro-Cogeneration Systems and Central Gas Power Generation}

The preceding sections of this chapter have described a methodology by which the reference electrical efficiencies of individual central combined-cycle plants could be derived for comparison with micro-cogeneration systems by using $P I_{e l}$ as a metric. However, this approach is only valid for a comparison with combined-cycle plants without cogeneration, since data describing the thermal output of central cogeneration plants are missing for this jurisdiction. To address this, Johnson et al. (2015) attempted to compare the performance of central cogeneration plants in Ontario to those without and found that those without cogeneration were incrementally more efficient. However, this attempt relied on data from another jurisdiction (the United States) to estimate the thermal output of a typical cogeneration plant.

Recognizing this lack of data, CIEEDAC (2014) has attempted to gather their own statistics that characterize the performance of different cogeneration technologies in Canada, including central-cogeneration plants, based on voluntary surveys administered to plants combined with performance metrics that plants make publicly available. Although the methodology CIEEDAC (2014) uses to gather statistics does suffer from self-selection bias and many entries in their cogeneration database are either void or held confidential, CIEEDAC (2014) does provide the most complete database of central-cogeneration plant information that is currently available for any jurisdiction within Canada. Details describing the uncertainties of these data are unavailable so they cannot be used for the application considered here.

Unfortunately, due to the lack of publicly available data, it is not possible to determine with more certainty whether plants with or without cogeneration are more 
efficient. Consequently, for the application considered here, the performance of a fuel-cell based micro-cogeneration system will be compared only to the most efficient combined-cycle plant without cogeneration. The methodology documented in this research could be applied again later to compare micro-cogeneration systems to central cogeneration plants if the missing data becomes available.

In this research, the performance of a micro-cogeneration system only serving DHW demands will be compared to this reference combined-cycle plant. A DHWonly application is a very attractive application for this jurisdiction as DHW thermal demands are present all year whereas space-heating demands are not. If for a DHWonly application it can be shown that the micro-cogeneration system is more efficient it would obviously follow that if space-heating demands were also served the microcogeneration system's performance would only improve. It is less challenging for a micro-cogeneration system to be efficient when there is a greater demand for its thermal output. Therefore, a DHW-only application can be used to establish a baseline thermal demand level above which the micro-cogeneration system's performance is more efficient than the reference combined-cycle plant's. This is the objective of the simulations described in Chapter 6. The following chapters will describe the experimental programs and the models that were developed from them so that the simulations in Chapter 6 could be performed. 


\section{Chapter 4}

\section{The Development of a Condensing Tankless Water Heater Model to Represent a Reference Method for Producing Domestic Hot Water}

The preceding chapter described how an electrical performance index could be determined for a micro-cogeneration system and used for comparison against a reference electrical efficiency of a central combined-cycle plant. To evaluate this electrical performance index, it is necessary to determine the amount of fuel that is displaced from a reference method of satisfying occupant thermal demands by the thermal output of a micro-cogeneration system. For a DHW application, a condensing tankless water heater $(\mathrm{TWH})$ is a potential reference. This chapter describes a project where data were gathered in an experimental program from a condensing TWH to characterize its performance over a range of operating conditions so it could be modelled and used as this reference. This section is primarily composed of excerpts from Johnson and Beausoleil-Morrison (2016). 


\subsection{Background}

As was shown by Bohac et al. (2010) and Hoeschele and Weitzel (2013), a condensing TWH is the most efficient conventional method for supplying DHW. For this reason, a condensing TWH was selected as the device to represent the conventional method for providing occupant DHW demands for comparison with a micro-cogeneration system in this research. For the methodology being developed in this thesis, it is reasonable to use the most efficient method (a condensing TWH) rather than the most widespread method (a storage water heater) as a reference. This is because if it is found that the micro-cogeneration system is more efficient than the reference, the conclusion would clearly be to prefer the micro-cogeneration system. If a less efficient reference was used instead, this conclusion would be confounded by the possibility of easily upgrading the efficiency of the reference heater.

Notwithstanding their conventional use, a simple model of a condensing TWH for a residential DHW application capable of predicting its energy consumption where uncertainties in measurements are propagated through to model predictions is unavailable. This is mainly due to the fact that a TWH's performance is more dependent on its usage profile than storage water heaters are. This is why a steady-state model (e.g. (Bourke and Bansal, 2012)) is inadequate for this application.

The transient period immediately following the activation of a TWH can affect its overall performance when infrequent and intermittent use is common, such as in a DHW application. Schoenbauer et al. (2012) found, of the ten houses they monitored, the average DHW draw was $5.7 \mathrm{~L}$, the average draw duration was $66 \mathrm{~s}$ and, on average, there were 26 draws a day. This is a significant reason why TWHs perform differently under different international standard test conditions (Bourke et al., 2014) and also why the performance of a TWH is, in practice, different from its rated efficiency. It was shown by Bohac et al. (2010), that the North American 
"Energy Factor" overstates the energy efficiency of a TWH in a DHW application. The "Energy Factor" is determined from a standard DHW draw pattern (6 draws of 40.6 L over a 24 hour period) where overall consumption (243 $\left.\mathrm{L} \mathrm{day}^{-1}\right)$ was nearly $70 \%$ greater than was found in practice (Schoenbauer et al., 2012).

Previously (Bohac et al., 2010; Hoeschele and Weitzel, 2013) it has been observed that there is a strong linear relationship between the energy input $\left(E_{\text {in-twh }} \mathrm{kJ}\right)$ and the energy output $\left(E_{\text {out }} \mathrm{kJ}\right.$ ) of a TWH in practice. Both Bohac et al. (2010) and Hoeschele and Weitzel (2013) performed regression analyses to determine the coefficients $\left(c_{i}\right)$ in equation 20 from measured field-trial data.

$$
E_{\text {in-twh }}=c_{1} \cdot E_{\text {out }}+c_{2}
$$

For modelling, Butcher and Schoenbauer (2011) suggested it might be possible to derive the coefficients of this linear relationship for a heater in a laboratory environment from several representative DHW draws. The advantage of this approach was its simplicity. It was noted by Bohac et al. (2010) that although $c_{1}$ clearly represents the reciprocal of the steady-state efficiency $\left(\zeta_{s s}\right), c_{2}$ is related to the heat capacity of a TWH $\left(\mathrm{C}_{T W H}\right.$ in $\left.\mathrm{kJ}{ }^{\circ} C^{-1}\right)$. Healy et al. (2011) found it difficult to robustly characterize $c_{2}$. Scatter in $E_{\text {in-twh }}$ and $E_{\text {out }}$ measurements at higher consumption levels in their experimental program resulted in large uncertainty margins of the $c_{2}$ values they derived from regression. Consequently, Healy et al. (2011) questioned the validity of this approach. This also suggests that a detailed accounting of experimental uncertainties is necessary in any newly developed model forms.

From the literature reviewed, it is clear that there are the following knowledge gaps in this field where there is an opportunity to make a contribution. First, although Bohac et al. (2010) and Hoeschele and Weitzel (2013) gathered an extensive amount of data from their respective field-trials and presented models in the form of equation 20, 
a thorough analysis of the uncertainties of their models' predictions was unavailable. A model for a condensing TWH whose predictions' uncertainties were well described would be an advancement.

Second, Glanville et al. (2013), Healy et al. (2011), Bohac et al. (2010) and Burch et al. (2008) all described a need in this field to determine a simple model form that can be calibrated with an experimental program consisting of a small number of tests. Currently, the only reliable method of calibrating equation 20 is with an extensive field-trial. A more easily calibrated model would allow the performance of a TWH to be simulated for any arbitrary DHW profile and facilitate comparisons between different methods of producing DHW.

Burch et al. (2008) proposed that a model based on a lumped heat capacity (equation 25) would be suitable for calibration by such a simple experimental program. However, whether the large uncertainty margins they presented on their calibration parameters from their experimental program would allow for accurate model predictions is unclear. Glanville et al. (2013) also derived some calibration parameters that could be used with the model developed by Burch et al. (2008); however, the uncertainty of these parameters was not described. Notwithstanding these limitations, a lumped heat capacity approach to modelling could still be viable for a condensing TWH if the uncertainty margins of the calibration parameters could be shown to allow for reasonably accurate predictions. Such a model should also be validated against a large set of actual DHW use data to demonstrate its limitations.

Here a contribution is made by demonstrating that a simpled lumped heat capacity condensing TWH model can be calibrated by an experimental program that is far less onerous than an extensive field-trial. Throughout, the uncertainties of the model calibration parameters are characterized. These uncertainties are also propagated through to model predictions. 
First, based on the analytical solutions to the governing differential equation of the TWH modelled as a lumped heat capacity, a new model will be introduced based on the energy input-output response of the TWH to only a step-input of heat. Second, equation 20 will be shown to represent the energy input-output response of the governing differential equation to the combination of an initial-energy-impulse combined with a step-input of heat. Third, another new model will be introduced as the average of the first two models. Exponential decay will be introduced to account for time between DHW draws. The experimental procedures required to calibrate these models are demonstrated. The validity of the simplifying assumptions inherent in the lumped-heat capacity approach along with the assumed form of the heat-input function are validated against data emanating from an earlier study (Bohac et al., 2010). The next section derives the analytical solutions that are the foundation of this new approach.

\subsection{TWH First-Order Models}

The inspiration for the model forms investigated was from experimental observations (Section 4.3.2). A typical heat-input $\left(\dot{Q}_{i n-t w h}(t) \mathrm{kW}\right)$ and temperature-difference $\left(\Delta T^{\circ} C\right)$ response from a TWH during a DHW draw is shown in Figure 7 . The heat input is given by the following equation.

$$
\dot{Q}_{i n-t w h}(t)=\dot{V}_{f u e l}(t) \cdot H H V
$$

where $\dot{V}_{\text {fuel }}(t)$ is the fuel flow rate that is also a function of time $(t)$ and $H H V$ is the higher heating value of the fuel (discussed in Section 4.3).

Also shown in Figure 7 are two lines that were superimposed to illustrate the inspiration for the model forms investigated in the following sections. The first is a 
horizontal line to represent a step-input whose magnitude is equal to the steady-state input of heat. This is the assumed form of the heat-input that is the inspiration for the model developed in Section 4.2.1. The second is a vertical line with an arrow, at time equal to zero, to represent an initial impulse of energy. The combination of these two lines is the inspiration for the model form investigated in Section 4.2.2.

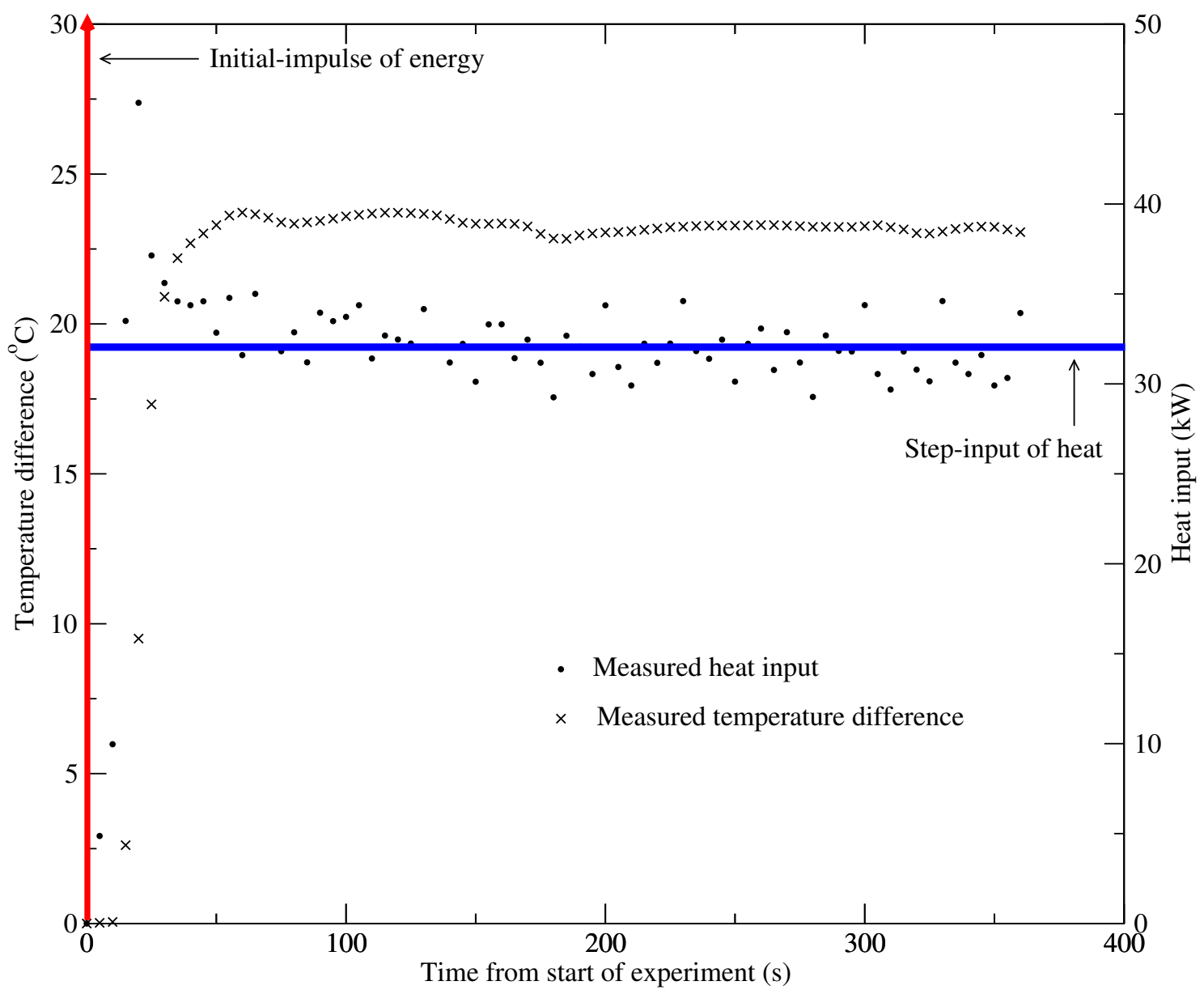

Figure 7: A typical temperature-difference response of a TWH and heat input observed during the calibration experiments of Section 4.3.2

By inspection, it can be seen that the measured heat-input profile resembles a step input, although there is significant overshoot initially, while the temperature difference profile resembles a first-order-step response that is delayed by several seconds. This overshoot is likely caused by the controller of the TWH that has been 
configured to inject additional energy at the beginning of activation so that the outlet water reaches a warm temperature quickly so that users of this TWH do not have to wait long for hot water to be provided. It is for this reason that the initial impulse has been considered in the modelling of this device.

\subsubsection{Step-Response Model}

The major assumption of the first-order-step-response model is that the heat input $\left(\dot{Q}_{i n-t w h}(t)\right)$ can be represented by the step function defined in equation 22 .

$$
\dot{Q}_{i n-t w h}(t)=u(t) \cdot \dot{Q}_{i n-t w h}
$$

where $u(t)$ is the unit-step function given by the following definition.

$$
u(t)= \begin{cases}0 & t<0 \\ 1 & t \geq 0\end{cases}
$$

where $\dot{Q}_{i n-t w h}$ is the steady-state rate of heat input given by the following equation.

$$
\dot{Q}_{i n-t w h_{s s}}=H H V \cdot \dot{V}_{f u e l_{s s}}
$$

where $H H V$ is the higher heating value of the fuel $\left(\mathrm{kJ} \mathrm{m}^{-3}\right)$ and $\dot{V}_{f u e l}$ is the steadystate volumetric flow-rate of the fuel $\left(\mathrm{m}^{3} \mathrm{~s}^{-1}\right)$ if both values are at the same standard temperature and pressure conditions. This assumption neglects the initial heat-input overshoot that was observed experimentally in Section 4.3.2. It is a significant departure from the model introduced by Burch et al. (2008) but is necessary to allow for an analytical solution to the governing differential equation shown in equation 25 . 
According to Burch et al. (2008), the differential equation governing the TWH system can be reasonably well approximated by the following equation.

$$
\dot{m}_{w} \cdot C_{w} \cdot\left(T-T_{w-i n}\right)+\mathrm{C}_{T W H} \cdot \frac{d T}{d t}+U A \cdot\left(T-T_{e n v}\right)=\dot{Q}_{i n-t w h}(t) \cdot \zeta_{c}
$$

where $\dot{m}_{w}$ is the mass flow-rate of water $\left(\mathrm{kg} \mathrm{s}^{-1}\right), C_{w}$ is the specific heat capacity of water $\left(\mathrm{kJ} \mathrm{kg}^{-1}{ }^{o} C^{-1}\right), T$ is the temperature of the TWH which is assumed equal to the outlet water temperature $\left({ }^{\circ} C\right), T_{w-i n}$ is the inlet water temperature, $\zeta_{c}$ is the combustion efficiency, $T_{\text {env }}$ is the air temperature in the ambient environment, $U A$ is the heat-loss coefficient of the TWH $\left(\mathrm{kW}^{\circ} C^{-1}\right)$ and $\mathrm{C}_{T W H}$ is the heat capacity of the TWH $\left(\mathrm{kJ}{ }^{\circ} \mathrm{C}^{-1}\right)$.

Heat loss to the ambient environment is orders of magnitude less than the heat input during the initial firing stage. Therefore, it can be neglected during the step input (equations 22 and 23) of the initial firing stage, representing the governing equation in terms of the difference between outlet and inlet temperatures $(\Delta T)$ (equation 26). Note that a substitution for the derivative $\left(\frac{d T}{d t}=\frac{d \Delta T}{d t}\right)$ has been made to simplify the solution procedure. This substitution is an approximation that assumes $T_{w-i n}$ does not vary over the firing period.

$$
\dot{m}_{w} \cdot C_{w} \cdot \Delta T+\mathrm{C}_{T W H} \cdot \frac{d \Delta T}{d t}+{\underline{U A \cdot\left(T-T_{e n v}\right)}}^{0}=\dot{Q}_{i n-t w h_{s s}} \cdot u(t) \cdot \zeta_{s s}
$$

Equation 26 also assumes that $\dot{m}_{w}$ is constant with time and $\zeta_{c}=\zeta_{s s}$. The solution to the differential equation shown in equation 26 is the well-known first-order-step response. With an initial condition $\left(\Delta T_{0}\right)$, the solution is given by the following equation.

$$
\Delta T(t)=\Delta T_{s s}+\left(\Delta T_{0}-\Delta T_{s s}\right) e^{-\frac{t}{\tau}}
$$


where $\Delta T_{s s}$ is the steady-state temperature difference between outlet and inlet. The parameter $\tau$ is termed the time constant and has the same units as $t(\mathrm{~s})$. It is given by the following equation.

$$
\tau=\frac{\mathrm{C}_{T W H}}{\dot{m}_{w} \cdot C_{w}}
$$

The following integral can be used to find $E_{\text {out }}(t)$.

$$
E_{\text {out }}(t)=\int_{0}^{t} \dot{m}_{w} \cdot C_{w} \cdot \Delta T(t) \cdot d t
$$

Substituting the step response for $\Delta T(t)$ from equation 27 into this integral yields the following equation.

$$
E_{\text {out }}(t)=\int_{0}^{t} \dot{m}_{w} \cdot C_{w}\left(\Delta T_{s s}+\left(\Delta T_{0}-\Delta T_{s s}\right) e^{-\frac{t}{\tau}}\right) \cdot d t
$$

Evaluating the integral in equation 30 yields the following equation.

$$
E_{\text {out }}(t)=\left[\dot{m}_{w} \cdot C_{w} \cdot\left(\Delta T_{s s} \cdot t-\left(\Delta T_{0}-\Delta T_{s s}\right) \tau \cdot e^{-\frac{t}{\tau}}\right)\right]_{0}^{t}
$$

Substituting $\tau$ from equation 28 into equation 31 and evaluating the expression inside of the square brackets from equation 31 yields the following equation.

$$
E_{\text {out }}(t)=\dot{m}_{w} \cdot C_{w} \cdot \Delta T_{s s} \cdot t+\left(\Delta T_{0}-\Delta T_{s s}\right) \cdot \mathrm{C}_{T W H}\left(1-e^{-\frac{\dot{m}_{w} \cdot C_{w}}{\mathrm{C}_{T W H}} \cdot t}\right)
$$

The energy input to the TWH can be found easily by integrating equation 22 according to the following equation.

$$
E_{i n-t w h}(t)=\int_{0}^{t} u(t) \cdot \dot{Q}_{i n-t w h_{s s}} d t=\dot{Q}_{i n-t w h_{s s}} \cdot t
$$


The steady-state efficiency $\zeta_{s s}$ is given according to equation 34 .

$$
\zeta_{s s}=\frac{\dot{m}_{w} \cdot C_{w} \cdot \Delta T_{s s}}{\dot{Q}_{i n-t w h}}
$$

The definition of $\zeta_{s s}$ (from equation 34) along with an expression for $t$ in terms of $E_{\text {in-twh }}(t)$ (from equation 33) can be substituted into equation 32 to express the energy input in terms of the energy output according to equation 35.

$$
E_{\text {in-twh }}(t)=\frac{E_{\text {out }}(t)}{\zeta_{s s}}+\frac{\left(\Delta T_{s s}-\Delta T_{0}\right) \cdot \mathrm{C}_{T W H}}{\zeta_{s s}}\left(1-e^{-\frac{E_{i n-t w h}(t) \zeta_{s s}}{\mathrm{C}_{T W H} \Delta T_{s s}}}\right)
$$

An interesting observation can be made regarding equation 35. By taking the limit as $t$ approaches infinity, the first-order-step-response model in equation 35 approaches the form of equation 20 as is shown below.

$$
\lim _{t \rightarrow \infty} E_{\text {in-twh }}(t)=\frac{E_{\text {out }}(t)}{\zeta_{s s}}+\frac{\left(\Delta T_{s s}-\Delta T_{0}\right) \cdot \mathrm{C}_{T W H}}{\zeta_{s s}}\left(1-e^{-\frac{E_{\text {in-twh }}(t) \zeta s s}{\sigma_{T W H} \Delta T_{s s}}}{ }^{0}\right)
$$

Equation 36 is of the form $E_{\text {in-twh }}(t)=c_{1} \cdot E_{\text {out }}(t)+c_{2}$. By comparison with equation $20, c_{1}$ is the reciprocal of the steady-state efficiency $\left(1 / \zeta_{s s}\right)$ and $c_{2}$ is equal to the amount of energy input required to raise the temperature of the TWH from its initial condition to its steady-state value $\left(\left(\Delta T_{s s}-\Delta T_{0}\right) \cdot \mathrm{C}_{T W H} / \zeta_{s s}\right)$. This result is consistent with the earlier works of Bohac et al. (2010) and Hoeschele and Weitzel (2013) who observed a simple linear energy input-output relationship. This result also satisfies the desire expressed by Healy et al. (2011) for a model that can account for the temporal distribution of a draw pattern. If the TWH is initially at an elevated temperature due to recent use, the energy input required to raise it to its steady-state value will be less than if the TWH was initially at the inlet temperature value. 


\subsubsection{Step-Response and Initial-Impulse Model}

The only difference between the model developed here and the one in Section 4.2.1 is the assumption of the functional form of the heat input. In the preceding section, it was assumed that the functional form was a step function whose magnitude was equal to the steady-state heat input. In this section, the functional form will be assumed to be the combination of the earlier step function plus an initial impulse of energy equal to the energy required to instantly bring the TWH from its initial condition $\left(\Delta T_{0}\right)$ to its steady-state value $\left(\Delta T_{s s}\right)$. This functional form is shown in the following equation.

$$
\dot{Q}_{i n-t w h}(t)=\dot{Q}_{i n-t w h_{s s}} \cdot u(t)+\left(E_{s s}-E_{0}\right) \cdot \delta(t)
$$

where $E_{s s}-E_{0}$ is the energy input required to raise the temperature of the TWH to its steady-state value from its initial condition and is given according to the following.

$$
E_{s s}-E_{0}=\frac{\mathrm{C}_{T W H} \cdot\left(\Delta T_{s s}-\Delta T_{0}\right)}{\zeta_{s s}}
$$

The unit impulse $\delta(t)$, given by the Dirac distribution, used in equation 37 has the following property.

$$
\int_{0-}^{0+} \delta(t) d t=1
$$

Note that $\delta(t)$ can be regarded in this case as the derivative of $u(t)$ with respect to time so the units on the right hand side of equation 37 are consistent. Interested readers may find this reference (Kamen and Heck, 2000) to be a good resource for describing how the Dirac distribution may be used for modelling physical systems. 
Using the same assumptions as in Section 4.2.1, the governing differential equation is given by the following equation.

$$
\dot{m}_{w} \cdot C_{w} \cdot \Delta T+\mathrm{C}_{T W H} \cdot \frac{d \Delta T}{d t}+{\underline{U A \cdot\left(T-T_{e n v}\right)}}^{0}=\left(\dot{Q}_{i n-t w h} \cdot u(t)+\left(E_{s s}-E_{0}\right) \cdot \delta(t)\right) \cdot \zeta_{s s}
$$

The right-hand side of equation 40 is the linear combination of two terms; the solution is therefore the linear combination of the solution of each term. The solution to the first term is already given by equation 27 . The solution to the second term is the well-known impulse response given by the following equation.

$$
\Delta T(t)_{i m p}=\left(\Delta T_{s s}-\Delta T_{0}\right) \cdot e^{-\frac{t}{\tau}}
$$

where $\Delta T(t)_{i m p}$ is the solution to only the impulse term on the right-hand side of equation 40. The linear combination of equations 27 and 41, which is the solution to the differential equation shown in equation 40 , is then given by the following equation.

$$
\Delta T(t)=\Delta T_{s s}+\left(\Delta T_{0}-\Delta T_{s s}\right) \cdot e^{-\frac{t}{\tau}}+\left(\Delta T_{s s}-\Delta T_{0}\right) \cdot e^{-\frac{t}{\tau}}=\Delta T_{s s}
$$

Performing a similar integration as in equation 29 yields the expression for $E_{\text {out }}$ in the following equation.

$$
E_{\text {out }}(t)=\dot{m}_{w} \cdot C_{w} \cdot \Delta T_{s s} \cdot t
$$

Integrating the expression for $\dot{Q}_{i n-t w h}$ in equation 37 yields the energy input according to the following equation.

$$
E_{i n-t w h}(t)=\int_{0}^{t} \dot{Q}_{i n-t w h} \cdot u(t)+\left(E_{s s}-E_{0}\right) \cdot \delta(t) d t=\dot{Q}_{i n-t w h} \cdot t+\left(E_{s s}-E_{0}\right)
$$

Isolating for $t$ and combining equations 34, 38, 43 and 44 yields the final model form shown below. 


$$
E_{\text {in-twh }}(t)=\frac{E_{\text {out }}(t)}{\zeta_{s s}}+\frac{\mathrm{C}_{T W H}}{\zeta_{s s}} \cdot\left(\Delta T_{s s}-\Delta T_{0}\right)
$$

Although this result is somewhat obvious, it shows that a simple linear energy inputoutput relationship of the form in equation 20 can be thought of as the TWH's response to a step-input of heat combined with an initial-impulse of energy. This insight assists in understanding the selection for the third and final model form described in the following section.

\subsubsection{Average Model}

As has been shown at the beginning of Section 4.2, the heat input can have some overshoot followed by a steady period. Essentially, the two models previously described represent extreme cases. The step-response model in Section 4.2.1 is a situation with no heat-input overshoot and only a steady period. The step-function and initial-impulse-response model in Section 4.2.2 represents a situation with a large, instantaneous overshoot followed by a steady period. By recognizing that in reality, the actual heat input potentially lies somewhere between the two extremes, the arithmetic average of the two models presents itself as an interesting option. It is given by the following equation, formed by averaging equations 35 and 45 .

$$
E_{i n-t w h}(t)=\frac{E_{\text {out }}(t)}{\zeta_{s s}}+\frac{\left(\Delta T_{s s}-\Delta T_{0}\right) \cdot \mathrm{C}_{T W H}}{\zeta_{s s}}\left(1-\frac{1}{2} \cdot e^{-\frac{E_{i n-t w h}(t) \zeta_{s s}}{\mathrm{C}_{T W H} \Delta T_{s s}}}\right)
$$

All three of these defined model forms only account for the periods of time when the TWH is firing. The periods between firings are referred to as environmental-decay periods (Glanville et al., 2013). As all three models are based on a lumped heat capacity assumption, environmental-decay periods can be modeled using the same method for all three models. 


\subsubsection{Environmental-Decay Model}

According to Glanville et al. (2013), the differential equation governing the behaviour of the TWH during environmental-decay periods can be approximated by the following equation.

$$
\mathrm{C}_{T W H} \cdot \frac{d T}{d t}+U A \cdot\left(T-T_{\text {env }}\right)=0
$$

The solution of this equation is the well-known exponential-decay equation shown below.

$$
T=\left(T^{\prime}-T_{e n v}\right) \cdot e^{-\frac{U A}{\mathrm{C}_{T W H}} t}+T_{e n v}
$$

where $T^{\prime}$ is the temperature of the TWH at the end of the previous firing period. It will be shown, in Sections 4.3.5 and 4.3.8, that this equation can be used reasonably well to predict the initial condition $\left(\Delta T_{0}\right)$ required by the models defined by equations 35, 45 and 46 . Note that $\Delta T_{0}$ can be determined from equation 48 by simply subtracting $T_{w-i n}$ from both sides as is shown below.

$$
\Delta T_{0}=\left(T^{\prime}-T_{e n v}\right) \cdot e^{-\frac{U A}{\mathrm{C}_{T W H}} t}+T_{e n v}-T_{w-i n}
$$

The remainder of this chapter will be devoted to demonstrating the validity of this and other aspects of these models through experiments. The following section describes the experimental apparatus that was used to gather these data necessary for this purpose.

\subsection{Experimental Methods}

The experiments conducted in this chapter were performed at Carleton University in the facility originally developed by Boucher (2013) with some modifications. More 
details describing the manufacturers' names, models and precision of the instrumentation used here are described by Boucher (2013). The TWH that was the subject of the experiments in this chapter had a burner capable of providing 5 to $60 \mathrm{~kW}$ and had a spark ignition. For the experiments described in this chapter, Figure 8 illustrates the hydronic configuration of the apparatus that was used along with the location of the various primary measurements used to derive the necessary parameters relevant to the models described in the preceding sections. For each experiment, a fixed-speed pump was used to circulate water from two $1300 \mathrm{~L}$ water tanks through the TWH. A throttling valve was manually adjusted to control the flow-rate of water in each experiment.

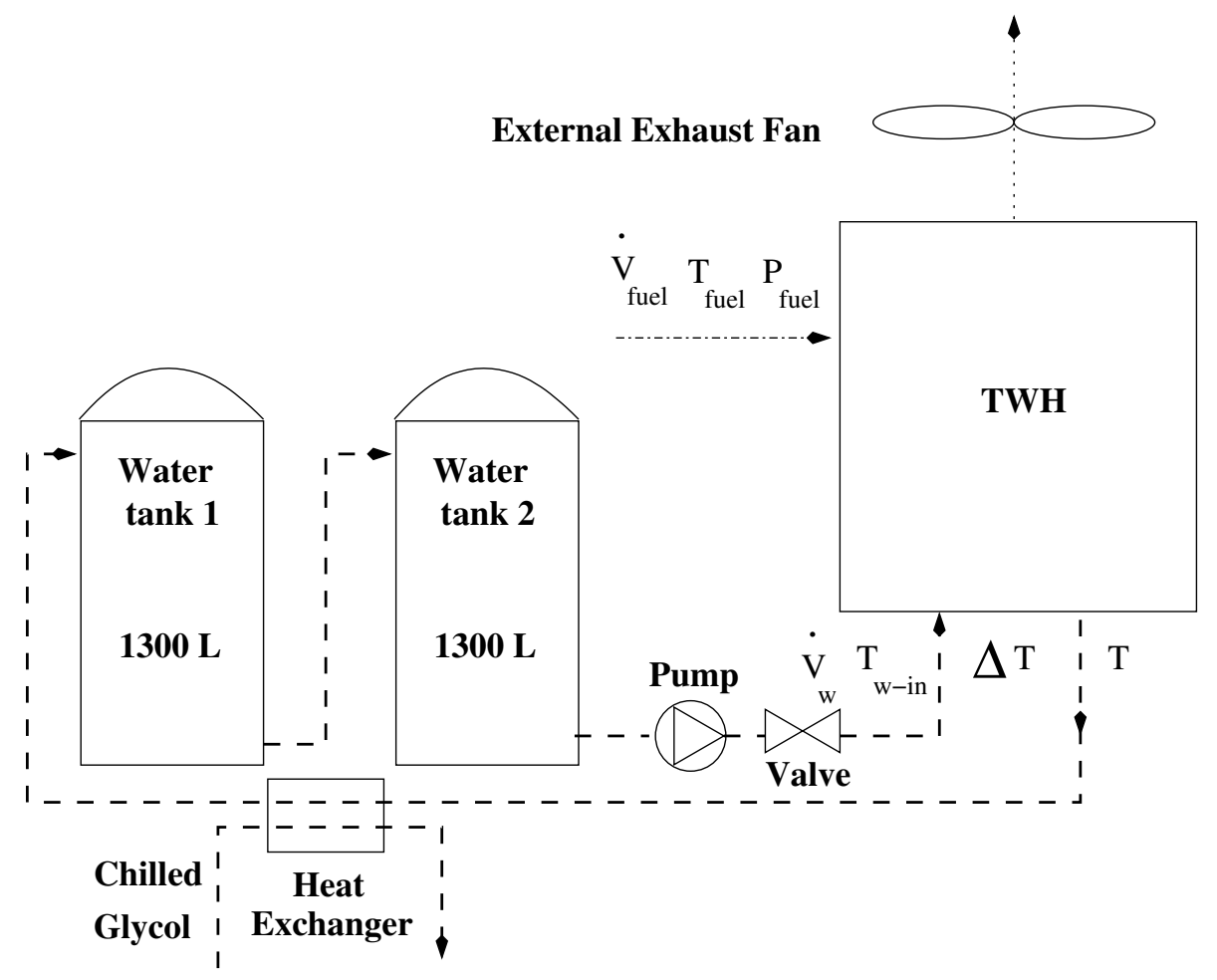

Figure 8: Schematic representation of the experimental apparatus used to conduct the experiments to calibrate a condensing TWH model

The large thermal mass of the water tanks would ensure the TWH inlet temperature would rise slowly (approximately $<0.05^{\circ} \mathrm{C}$ per minute was achieved in practice). 
An external chilled glycol stream $\left(8^{\circ} \mathrm{C}\right)$ could be activated on-demand and used to cool the water stored in the tanks before, after or during experiments via the heat exchanger at the TWH outlet.

The TWH was vented into the building's exhaust system which necessitated the use of an additional external exhaust fan not present in a typical residential application. However, the use of this external fan did not impact measurements during firings, as this fan was manually controlled in the lab to impose typical airflow conditions as measured by a pressure sensor internal to the TWH. This sensor likely primarily exists as a safety feature to ensure that there is no blockage in the exhaust line that would prevent the exhaust gases from being purged. It might also be involved in determining if the air-to-fuel ratio is suitable for combustion to occur efficiently. This sensor would prevent firings if the imposed airflow was too low but would also prevent firings if the imposed airflow was too high. Therefore, for each experiment, a setpoint was manually determined so that the imposed airflow was not too high or too low. Although this sensor would ensure normal operation during firing, there were some implications related to its use between firings that are discussed in Sections 4.3.4 and 4.3.5.

Table 5 describes the instrumentation of the apparatus. All temperatures were measured with copper-constantan thermocouples that were calibrated beforehand in the laboratory. Temperature difference was measured across the inlet and outlet of the TWH using a five-junction copper-constantan thermocouple (thermopile) that was also calibrated beforehand in the laboratory. These sensors had exposed junctions that were submerged in the flow.

The pressure of the supply gas was measured with a transducer so the flow-rate of gas could be corrected to a consistent temperature and pressure $\left(15^{\circ} \mathrm{C}\right.$ and 101.325 $\mathrm{kPA}$ ) for use with the $H H V$ provided by the utility $\left(38.15 \mathrm{MJ} \mathrm{m}^{-3}\right)$. This value has a bias of $\pm 0.3 \mathrm{MJ} \mathrm{m}^{-3}$ to account for its monthly variation over the period that the 


\begin{tabular}{|c|c|c|c|}
\hline $\begin{array}{l}\text { primary } \\
\text { measurement }\end{array}$ & $\begin{array}{l}\text { sensed } \\
\text { quantity }\end{array}$ & $\begin{array}{l}\text { sensor } \\
\text { type }\end{array}$ & bias \\
\hline$T, T_{w-i n}, T_{\text {fuel }}$ & temperature & \multicolumn{2}{|c|}{ thermocouple $\pm 0.5^{\circ} \mathrm{C}$} \\
\hline$\Delta T$ & $\begin{array}{l}\text { temperature } \\
\text { difference }\end{array}$ & thermopile & $\pm 0.1{ }^{\circ} \mathrm{C}$ \\
\hline$p_{\text {fuel }}$ & $\begin{array}{l}\text { absolute } \\
\text { pressure }\end{array}$ & $\begin{array}{l}\text { strain } \\
\text { gauge }\end{array}$ & $\pm 0.4 \mathrm{kPa}$ \\
\hline$\dot{V}_{w}$ & $\begin{array}{l}\text { volumetric } \\
\text { flow rate }\end{array}$ & $\begin{array}{l}\text { oval-gear } \\
\text { flow meter }\end{array}$ & $\begin{array}{l} \pm 1 \% \text { reading and } \\
\pm 0.0019 \mathrm{~L} \mathrm{~s}^{-1}\end{array}$ \\
\hline$\dot{V}_{f u e l}$ & $\begin{array}{l}\text { volumetric } \\
\text { flow rate }\end{array}$ & $\begin{array}{l}\text { diaphragm } \\
\text { meter }\end{array}$ & $\begin{array}{l} \pm 1 \% \text { reading and } \\
\pm 0.0057 \mathrm{~L} \mathrm{~s}^{-1}\end{array}$ \\
\hline
\end{tabular}

Table 5: TWH experimental apparatus: Sensor types and measured parameters

experiments were conducted. It also accounts for the fact that the utility calculated this value from the gas composition determined by chromatograph. When $H H V$ values are determined in this way they are known to be accurate to within $\pm 0.25 \%$ (LaNasa, 2003).

The bias on the volumetric water and gas flow-rate measurements are presented as a percent reading combined with an absolute error in $\mathrm{L} \mathrm{s}^{-1}$. The absolute error accounts for the pulse resolution of each meter. The impact of the instrumentation bias errors listed in Table 5 on the parameters derived from them is explained in the following section.

\subsubsection{Experimental Uncertainty}

According to Moffat (1988), individual sources of bias error $\left(B_{i}\right)$ for a primary measurement $(\theta)$ can be combined into an overall bias for that primary measurement $\left(B_{\theta}\right)$ 
with the following equation.

$$
B_{\theta}=\sqrt{\sum_{i=1}^{n}\left(B_{i}^{2}\right)}
$$

The total bias on an individual primary measurement propagates to any parameter $(\phi)$ derived from them according to the following equation.

$$
B_{\phi}=\sqrt{\sum_{i=1}^{n}\left(\frac{\partial \phi}{\partial \theta_{i}} B_{\theta_{i}}\right)^{2}}
$$

If the sample mean $(\bar{\phi})$ of the parameter is used to estimate the population average, the uncertainty margins are given according to the following equation.

$$
\bar{U}_{\phi, 95 \%}=\sqrt{B_{\phi}^{2}+\left(\frac{t_{s} \cdot \sigma}{\sqrt{n}}\right)^{2}}
$$

where $n$ is the number of repeated observations of the same derived parameter $\phi$ in the sample and the population average can be estimated according to the following equation.

$$
\phi^{\prime}=\bar{\phi} \pm \bar{U}_{\phi, 95 \%}
$$

A description of how the uncertainty calculations were performed in practice is given in the following sections.

\section{Steady-State Parameters}

For any steady-state experiment, each measurement sampled every $5 \mathrm{~s}$ was viewed as a repeated observation. Here any parameter is denoted by $\phi$ and repeated observations of this parameter are denoted by $\phi_{i}$. For example, a steady-state experiment of $120 \mathrm{~s}$ in duration was considered to consist of 24 repeated observations of the same parameter $(n=24)$. The observations would be referred to as $\phi_{1}, \phi_{2}, \phi_{3}, \ldots \phi_{24}$. 
There were several parameters derived from steady-state periods of operation that were relevant. First, according to Glanville et al. (2013), UA can be derived from a steady-state experiment where the TWH is disabled and water at an elevated temperature is circulated through it. Under these conditions, an instantaneous measurement of this parameter $\left(U A_{i}\right)$ is given by the following equation.

$$
U A_{i}=\frac{\rho_{w} \cdot C_{w} \cdot \dot{V}_{w, i} \cdot \Delta T_{i}}{T_{e n v, i}-T_{i}}
$$

where $\rho_{w}$ is the density of water. Note that it was assumed $T_{\text {env }}=T_{\text {fuel }}$. The calibration value of $U A$ determined for modelling, described in more detail in Section 4.3.4, was the sample mean of this parameter $(\bar{\phi})$ measured over a steady period.

This steady period was achieved by first circulating warm water through the inactive TWH for a period of over an hour until it was observed that the temperature difference across the heater had stabilized. Following this period to further ensure that the temperature difference had stabilized, 4 experiments were conducted each approximately 5 minutes of duration. The average temperature difference (from inlet to outlet) observed for each of these experiments was $0.22{ }^{\circ} \mathrm{C}, 0.23{ }^{\circ} \mathrm{C}, 0.22{ }^{\circ} \mathrm{C}$ and $0.22{ }^{\circ} \mathrm{C}$ respectively. This consistent observation of the same temperature difference over 4 separate experiments spanning a period of over 20 minutes was taken as justification that a steady period had been achieved.

A summary of other important steady-state derived parameters and their uncertainties is described in Table 6. The instrumentation, in particular the flow meters, had greater accuracy at greater flow rates as was shown in Table 5. Also, experiments were more unsteady at lower heat-input rates. This is where the greater standard deviations $(\sigma)$ shown in Table 6 were measured.

For experiments, instantaneous measurements of $\dot{Q}_{i n-t w h, i}, \dot{Q}_{\text {out }, i}$ and $\zeta_{i}$ were derived according to the following equations. 


\begin{tabular}{|c|c|c|c|c|}
\hline $\begin{array}{l}\text { derived } \\
\text { parameter }\end{array}$ & measurement range & $\begin{array}{l}\text { range of } \\
B \\
(\% \\
\text { value) }\end{array}$ & $\begin{array}{l}\text { range of } \\
\sigma \\
(\% \\
\text { value) }\end{array}$ & $\begin{array}{l}\text { range of } \bar{U}_{95 \%} \\
(\% \text { value })\end{array}$ \\
\hline$\dot{Q}_{i n-t w h_{s s}}$ & $7.2-44.6 \mathrm{~kW}$ & $1.4-3.3$ & $2.2-13.8$ & $1.6-5.4$ \\
\hline$\dot{Q}_{\text {out }_{s s}}$ & $5.9-42.3 \mathrm{~kW}$ & $1.2-2.8$ & $0.0-5.6$ & $1.3-2.9$ \\
\hline$\zeta_{s s}$ & $84.6-95.9 \%(H H V)$ & $1.9-4.4$ & $1.8-13.8$ & $2.0-6.2$ \\
\hline
\end{tabular}

Table 6: TWH experiments: Range of derived parameters observed during steadystate periods of experiments described in Section 4.3.2, 4.3.3, 4.3.5 and 4.3.6 along with the bias, standard deviation and uncertainty margins at a $95 \%$ confidence level

$$
\begin{gathered}
\dot{Q}_{i n-t w h, i}=\dot{V}_{f u e l, i} \cdot H H V \\
\dot{Q}_{o u t, i}=\dot{V}_{w, i} \cdot \rho_{w} \cdot C_{w} \cdot \Delta T_{i} \\
\zeta_{i}=\frac{\dot{Q}_{\text {out }, i}}{\dot{Q}_{\text {in-twh }, i}}
\end{gathered}
$$

The steady-state values for these parameters $\left(\dot{Q}_{i n-t w h}, \dot{Q}_{o u t_{s s}}\right.$ and $\zeta_{s s}$ reported in Table 6) were defined as their respective sample's mean $(\bar{\phi})$ measured from steady periods of operation.

\section{Integrated Parameters}

Aside from the steady-state derived parameters in the preceding discussion, for the experiments conducted in this chapter, there were several important parameters that were integrated over the duration of the steady-state and startup transient periods of TWH operation. One such parameter was the energy input to the TWH $\left(E_{i n-t w h}\right)$ 
which was derived from the following equation.

$$
E_{i n-t w h}=\sum_{i=1}^{m} \dot{Q}_{i n-t w h, i} \cdot \Delta t
$$

where $\dot{Q}_{i n-t w h, i}$ is the heat input measured during the $\mathrm{i}^{\text {th }}$ sample interval of duration $\Delta t$. Summing the quantity on the right-hand side of equation 58 from the first to last sample interval yields the total energy input over that period. It is important to note that for $E_{i n-t w h}$, and other integrated parameters, the experimental uncertainty had to be handled differently than the steady-state parameters in the preceding discussion.

For example, consider the experiment shown in Figure 7. This experiment is composed of a transient startup period followed by a steady-state period. If, for example, $E_{i n-t w h}$ was calculated after $120 \mathrm{~s}(m=24)$; this $E_{i n-t w h}$ could only be considered as a single observation of $\phi$. This experiment would have to be repeated several times under the same boundary conditions; then, for each repeated experiment, each $E_{\text {in-twh }}$ calculated after $120 \mathrm{~s}$ could be considered as a repeated observation of $\phi$.

For the experiments in this chapter, equation 59 was used to estimate the bias on the energy input as the experiments were predominantly steady-state. A similar approach was taken to estimate the bias on the energy output as well. This approach is an approximation for the first several measurements during the initial transient stage of a firing. However, the most important use of these uncertainty margins was to estimate the uncertainty of the TWH's heat capacity (Section 4.3.2) and it will later be shown (Section 4.3.8) that the uncertainty of the TWH's heat capacity only causes a relative uncertainty $0.4 \%$ for model predictions, so this approach was found to be adequate.

$$
B_{E_{i n-t w h}}=\bar{U}_{95 \%, \dot{Q}_{i n-t w h} s} \cdot m \cdot \Delta t
$$


The bias on the energy input is expressed as a product of the uncertainty margin of the average value of $\dot{Q}_{i n-t w h}$ and the duration of the experiment $(m \cdot \Delta t)$. Equation 59 guarantees that $B_{E_{i n-t w h}}$ is the same percentage of $E_{i n-t w h}$ as $\bar{U}_{95 \%, \dot{Q}_{i n-t w h s}}$ is to $\dot{Q}_{i n-t w h}$.

\subsubsection{Calibration of the TWH Heat Capacity}

The heat capacity $\left(\mathrm{C}_{T W H}\right)$ is assumed to be a characteristic constant of each individual TWH system. To derive this value, a series of calibration experiments, with initial conditions equal to zero, were conducted. Each experiment was conducted in the following manner. Before the experiment, in order to ensure the initial condition was zero $\left(\Delta T_{0}=0\right)$, water was circulated through the TWH until $\Delta T \approx 0$ was observed. This would ensure the time between experiments was not a factor. All boundary conditions $\left(T_{w-i n}, T_{\text {out }}\right.$ and $\left.\dot{V}_{w}\right)$ were held steady for the duration of the experiment. Between experiments boundary conditions were changed by adjusting the set point of the TWH $\left(T_{\text {out }}\right)$, adjusting the throttling valve $\left(\dot{V}_{w}\right)$ or heating the tank for an extended period of time $\left(T_{w-i n}\right)$. Data from one such experiment are shown in Figures 9a and 9b. In total, 14 such experiments were conducted.

The measured energy input $\left(E_{\text {in-twh }}(t)\right)$ and output $\left(E_{\text {out }}(t)\right)$ are each plotted in Figure 9a against time. The error bars shown are the bias errors derived according to equation 59. For the same experiment, $E_{\text {out }}$ is plotted against $E_{i n-t w h}$ in Figure 9b. After the TWH reaches a steady-state period of operation, the linearity of the relationship between $E_{\text {out }}(t)$ and $E_{\text {in-twh }}(t)$ is apparent. For the calibration experiments, 100 s of operation was observed to be sufficient for the steady-state period to be reached. The goal of each calibration experiment was to derive $\mathrm{C}_{T W H}$ according to the following equation.

$$
\mathrm{C}_{T W H}=\frac{c_{2} \cdot \zeta_{s s}}{\Delta T_{s s}}
$$




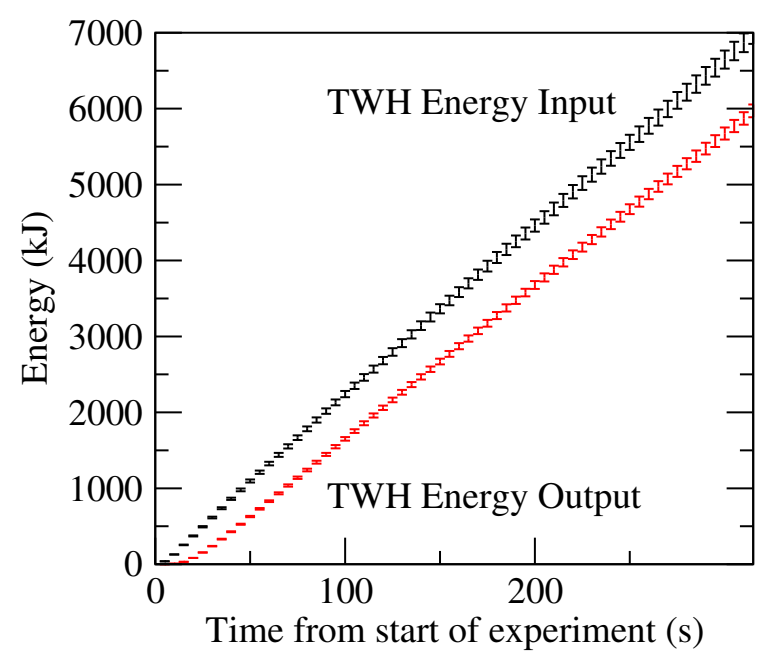

Figure 9a: Energy input and output of the TWH measured during one of several calibration experiments used to derive $\mathrm{C}_{T W H}$ each plotted against time from the start of experiment as a separate series

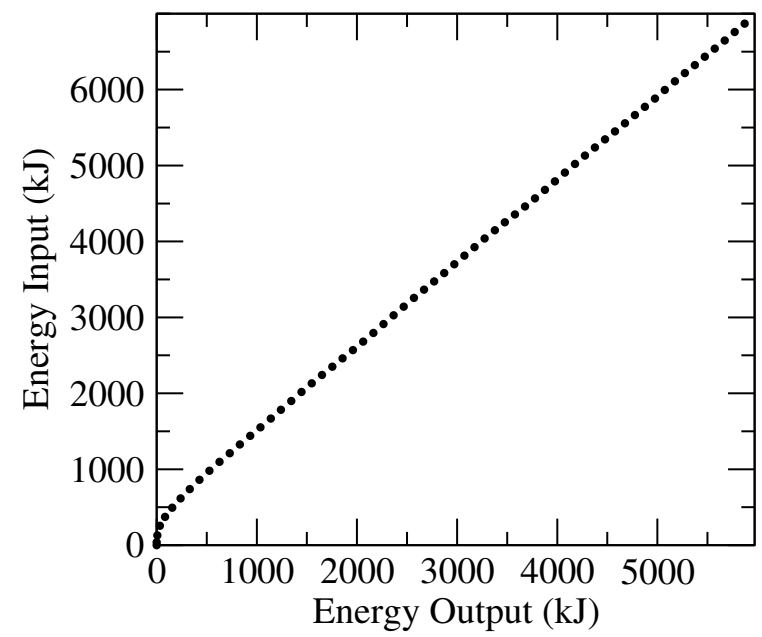

Figure 9b: Energy input plotted against energy output of the TWH measured during one of several calibration experiments used to derive $\mathrm{C}_{T W H}$ 
where $c_{2}$ is the coefficient from equation 20. It was derived by a linear least-squares regression fit to the data shown in Figure $9 \mathrm{~b}$ during the steady-state period. To estimate the bias on $c_{2}$ for the uncertainty analysis, the bias on $E_{\text {out }}$ and the bias on $E_{i n-t w h}$ (both as a \% of value) along with the maximum residual of the least-squares regression fit were combined according to standard methods (Moffat, 1988).

In total, 14 tests similar to the one shown in Figures 9a and 9b were conducted to calibrate $\mathrm{C}_{T W H}$. A summary of the boundary conditions and results of these experiments is shown in Table 7 . Note that the $\dot{V}_{w}$ values investigated are at the upper range of what would be expected in a DHW application (Schoenbauer et al., 2012).

\begin{tabular}{|c|c|c|c|}
\hline parameter & \multicolumn{3}{|c|}{ range investigated } \\
\hline$T_{w-i n}$ & \multicolumn{3}{|c|}{$21.3-30.3{ }^{\circ} \mathrm{C}$} \\
\hline$T_{w-\text { out }}$ & \multicolumn{3}{|c|}{$43.0-48.1^{\circ} \mathrm{C}$} \\
\hline$\Delta T_{s s}$ & \multicolumn{3}{|c|}{$13.3-26.3{ }^{\circ} \mathrm{C}$} \\
\hline$\dot{V}_{w}$ & \multicolumn{3}{|c|}{$0.28-0.3 \mathrm{~L} \mathrm{~s}^{-1}$} \\
\hline$\dot{Q}_{i n-t w h_{s s}}$ & \multicolumn{3}{|c|}{$17.1-35.0 \mathrm{~kW}$} \\
\hline$\dot{Q}_{\text {out }_{s s}}$ & \multicolumn{3}{|c|}{$15.1-32.9 \mathrm{~kW}$} \\
\hline$\zeta_{s s}$ & \multicolumn{3}{|c|}{$87.9-94.1 \%(H H V)$} \\
\hline$\overline{\mathrm{C}}_{T W H}$ & range & range of $B$ & $\bar{U}_{95 \%}$ \\
\hline $23.1 \mathrm{~kJ}{ }^{\circ} \mathrm{C}^{-1}$ & $21.7-25.3$ & $0.88-2.17$ & 2.25 \\
\hline
\end{tabular}

Table 7: Summary of 14 experiments used to calibrate the heat capacity of the TWH model

The average value for the heat capacity observed from the 14 experiments $\left(\overline{\mathrm{C}}_{T W H}\right)$ is shown at the bottom of Table 7 . The range of specific heat values along with the corresponding range of biases observed are shown to the right of $\overline{\mathrm{C}}_{T W H}$. The maximum bias observed was used to calculate $\bar{U}_{95 \%}$ along with the standard deviation 
$(\sigma)$ of the entire sample. It is noteworthy that the estimate of $\bar{U}_{95 \%}$ explains the range

of values observed for $\overline{\mathrm{C}}_{T W H}$. This validates the approach that was used to estimate experimental uncertainty in this chapter. In addition to being more amenable for use with generally accepted methods of deriving experimental uncertainty parameters, using this methodology to derive the heat capacity described here produced a narrower range of observed values than was achieved by Glanville et al. (2013) and Burch et al. (2008).

\subsubsection{Validation of the TWH Heat Capacity}

To validate the value for $\overline{\mathrm{C}}_{T W H}$ derived during calibration, 4 additional validation tests were conducted in the same manner as the calibration experiments in the preceding discussion with one important exception. Although the range of temperatures spanned by the validation experiments were similar to the calibration experiments, the water flow rates of the validation experiments were significantly less at $0.08 \mathrm{~L} \mathrm{~s}^{-1}$ for each of these experiments. The reasoning behind this was that these lower flow rates could potentially be challenging for the models to make accurate predictions. In general, lower heat-input rates, relative to the specific heat of the TWH, will result in a slower response and a longer transient period of operation. These flow rates are also more typical of what would be expected in a DHW application (Schoenbauer et al., 2012). Also note that these experiments are considered as a validation only of the value of the TWH heat capacity determined from calibration in the preceding section because the steady-state efficiency used to make the model predictions for each of these 4 additional validation tests was measured during each test. This is in contrast to the whole model validation that was performed in Section 4.3.8 where the steady-state efficiency (and heat-loss coefficient) determined from calibration were used. 


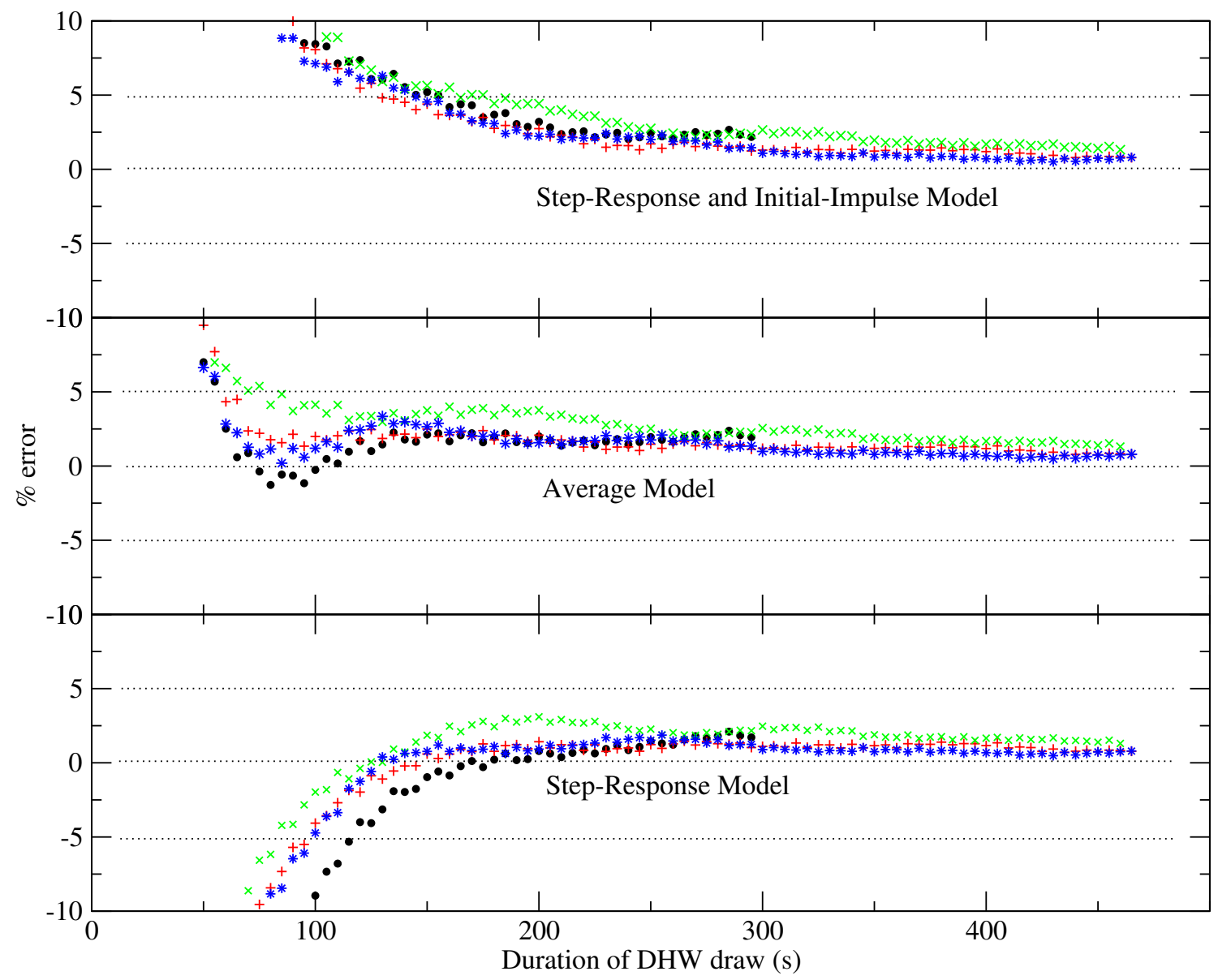

Figure 10: Percent error between energy input to the TWH observed during 4 validation experiments and predictions made by model equations 35, 45 and 46 
Figure 10 compares model predictions from the 4 validation experiments to observed experimental values. Each of the 3 graphs shown in Figure 10 compares a different model's predictions to experiments. Each series in each graph represents the percent difference between a model's predictions and observed experimental values for a single validation experiment. A positive percent difference indicates an overprediction of energy consumption. Model predictions were made using the value of $\overline{\mathrm{C}}_{T W H}$ at the bottom of Table 7. For clarity, in Figure 10 the range of model predictions shown is restricted to be between $\pm 10 \%$ of the measured value, therefore, predictions at the beginning of the DHW draw outside of this range are not shown.

It can be seen that the average model (in the center of Figure 10) converges more quickly to the experimentally measured values in comparison with the other two models. Within $60 \mathrm{~s}$, this model can make predictions to within $5 \%$ of the measured energy input. The other models can take over $100 \mathrm{~s}$ to make predictions as accurate. It can also be seen that the step-response and initial-impulse model (at the top of Figure 10), converges to its final value from large positive values, while the step-response model (at the bottom of Figure 10) converges to its final value from lower values. This indicates that the logic behind the selection of the average model is somewhat justified by these experiments. Recall this logic was explained in Section 4.2 where it was observed that the actual heat input function lies somewhere between only a step input at one extreme and a combination of an initial-impulse and step input at the other extreme. All 3 models converge to within $1 \%$ of the actual measured value after nearly $400 \mathrm{~s}$.

\subsubsection{Calibration of the TWH Heat-Loss Coefficient}

The calibration value for $U A$ along with its associated uncertainty margins were determined according to the methods described in Section 4.3.1. This type of experiment was difficult to conduct accurately due to the small $\Delta T$ that was measured across the 
TWH while it was disabled. While the external fan was operating, $U A$ was determined to be $0.0076 \mathrm{~kW}^{\circ} C^{-1} \pm 33 \%$ based upon the measured data. In practice, an external fan is most often unnecessary so the value of $U A$ was also determined when this fan was off. With this fan off, $U A$ was determined to be $0.0023 \mathrm{~kW}^{\circ} C^{-1} \pm 46 \%$ based upon the measured data. This uncertainty margin is almost entirely due to the uncertainty of the thermopile $\left( \pm 0.1^{\circ} \mathrm{C}\right)$ that was used to measure the temperature difference observed from inlet to outlet $\left(0.22^{\circ} \mathrm{C}\right)$ for the experiments used to derive the calibration value of $U A$. It will be demonstrated in Section 4.3 .8 that these large uncertainty margins still allow for reasonably accurate model predictions. This is potentially because the energy associated with the heat lost in this manner is less significant to the overall energy balance of the TWH in comparison with the energy input from the gas and the energy output to provide DHW.

For example, consider the simulation results for the TWH that are shown later in Chapter 6 at the top of Figure 21. The average temperature difference between the heater and the ambient is approximately $24{ }^{\circ} \mathrm{C}$ for the decay periods that occur between the first and last firing of the TWH for the day shown. These decay periods have a combined duration of approximately 700 minutes. A $U A$ value of $0.0023 \mathrm{~kW}$ ${ }^{o} C^{-1} \pm 46 \%$ results in approximately $2.3 \pm 1.1 \mathrm{MJ}$ of energy associated with this heat loss to the ambient during these decay periods. When contrasted to the amount of energy associated with the DHW draws during this same period (32.4 MJ) the uncertainty margin from this estimation is an order of magnitude less. Therefore, it would be reasonable to expect this uncertainty margin to only have a small impact on the predictions from this model.

Note that an energy balance can be used to verify this result. For this energy balance, the energy input to the heater multiplied by its steady-state efficiency $\left(\zeta_{s s}\right.$. $\left.E_{i n-t w h}\right)$ is $35.4 \mathrm{MJ}$ and represents the only energy gain of the system. The difference between this value and the energy associated with the DHW draws (32.4 MJ) is, 
therefore, the sum of the energy associated with the heat loss (2.3 MJ) and the energy that remains stored within the heater $(0.7 \mathrm{MJ})$ after the last firing of the TWH. It should also be noted that $U A$ is a characteristic of a TWH's installation. Local ambient conditions and heat-transfer characteristics could result in differences between the heat-loss coefficient derived here and in another location.

\subsubsection{Validation of the TWH Heat-Loss Coefficient}

The experimental program used to validate the calibration value determined for $U A$ in the preceding section is described as follows. For this program, initial conditions $\left(\Delta T_{0}\right)$ were estimated by comparing the $c_{2}$ coefficients from a series of 5 minute DHW draw experiments where first there was a preceding experiment where $\Delta T_{0}$ was equal to zero. This preceding experiment was then followed by several other 5 minute DHW experiments where $\Delta T_{0}$ was not equal to zero. Between any two experiments there was an idle period where the temperature of the TWH was allowed to decay while the external fan was left on. For this experimental program the following equation was used to derive $\Delta T_{0}$.

$$
\Delta T_{0}=\frac{\left(c_{2}-c_{2}^{\prime}\right) \cdot \zeta_{s s}}{\mathrm{C}_{T W H}}
$$

where $c_{2}$ was derived from the preceding experiment where $\Delta T_{0}$ was zero (according to the methods discussed in Section 4.3.2) and $c_{2}^{\prime}$ was the y-intercept coefficient derived from each experiment that followed. The advantage of performing the experimental program in this way, by using equation 61 , was that initial conditions could be derived rather than measured directly. Measuring the initial condition directly is difficult to perform accurately as it is unclear how to define precisely when the initial condition occurs during this highly transient period. The results from 9 separate validation experiments conducted in this manner are shown in Figure 11. 


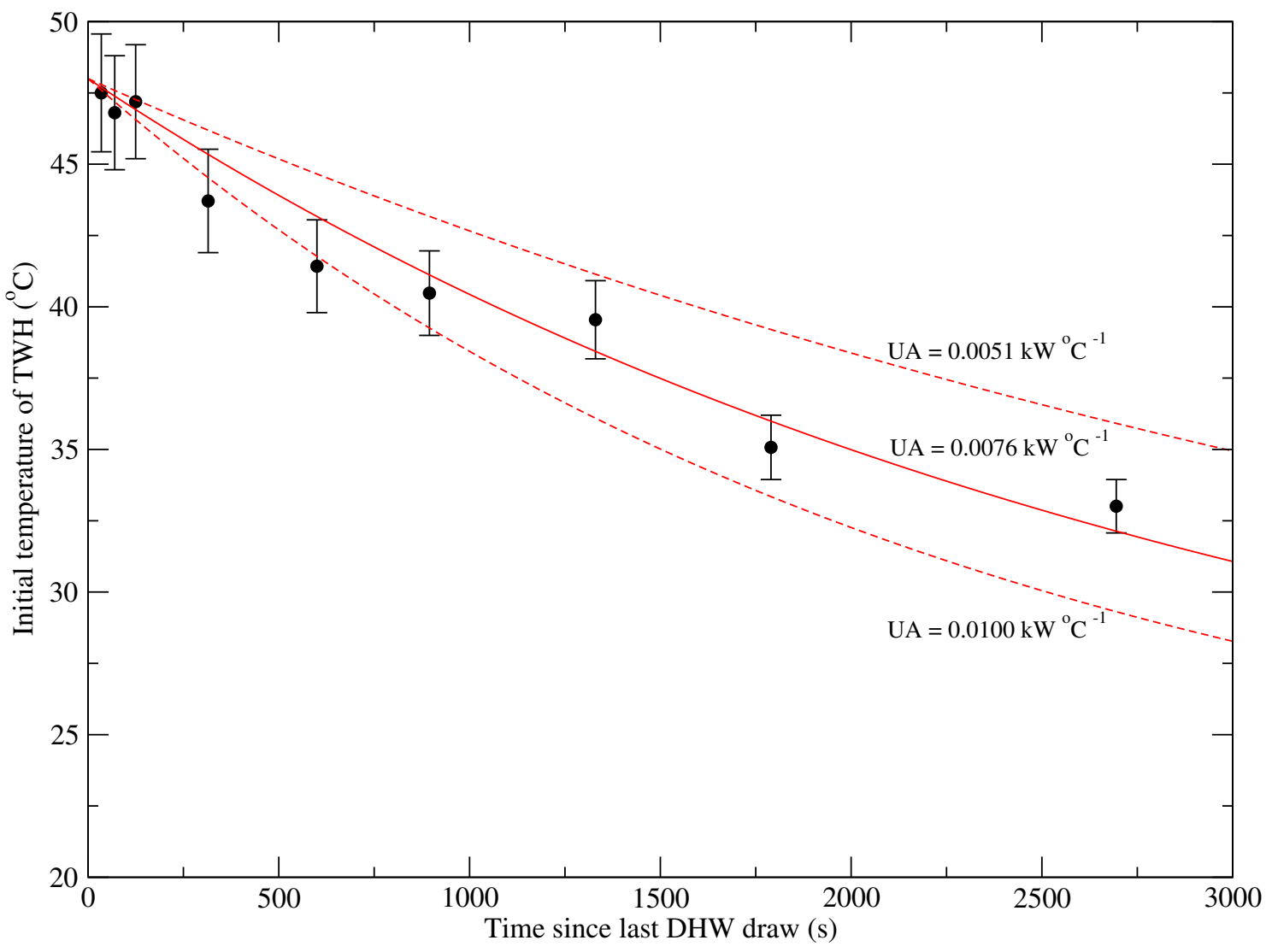

Figure 11: Initial temperature of the TWH derived from experimental data compared to the exponential decay model for validation when the external exhaust fan was left on between firings 
In Figure 11, the initial temperature of the TWH $\left(T_{0}\right)$ is shown rather than $\Delta T_{0}$. The derived value of $T_{0}$ of a single experiment is represented by the individual markers. The error bars represent the bias on $T_{0}$ calculated using analogous methods to those described in Section 4.3.2. Shown as a solid line is the environmental-decay model given by equation 48 with $T_{e n v}=21{ }^{\circ} C, U A=0.0076 \mathrm{~kW}^{\circ} C^{-1}, \mathrm{C}_{T W H}=23.1$ $\mathrm{kJ}{ }^{\circ} \mathrm{C}^{-1}$ and $T^{\prime}=48{ }^{\circ} \mathrm{C}$. Also shown, as broken lines, is the environmental-decay equation with $U A=0.0100 \mathrm{~kW}^{\circ} C^{-1}$ and $U A=0.0057 \mathrm{~kW}^{\circ} C^{-1}$ to represent the large uncertainty margins derived in Section 4.3.4. As can be seen, the value of $U A$ from calibration while the external fan was left on estimated $T_{0}$ reasonably well.

As the external exhaust fan was manually controlled it was not possible to guarantee that it would be off for an entire period between firings so a similar experimental program for when the fan was off was not attempted. However, these results still demonstrate that exponential decay is potentially suitable for modelling the period between firings. The $U A$ determined for when the fan was off $\left(0.0023 \mathrm{~kW}^{\circ} \mathrm{C}^{-1}\right)$ is more typical of a residential application where an external exhaust fan is not needed. For this reason, this lower $U A$ value is validated against actual DHW use data in Section 4.3.8.

\subsubsection{Calibration of the TWH Steady-State Efficiency}

In this section, the $\zeta_{s s}$ parameter required to calibrate model equations 35,45 and 46 has been derived through an additional separate series of 31 experiments according to the methods presented in Section 4.3.1. The period of operation where the steadystate efficiency can be measured can be identified by considering when the relationship between $E_{\text {out }}$ and $E_{\text {in-twh }}$ becomes linear. For example, in Figure $9 \mathrm{~b}$ it can be observed by inspection that this linear period begins somewhere between 500 and $1000 \mathrm{~kJ}$ of $E_{\text {out }}$ corresponding to approximately 50 to $85 \mathrm{~s}$ of operation for the experiment shown. The amount of energy input that is required to reach steady state will depend on the 
initial condition of the heater. The time that is required to reach steady state will also depend on the rate of energy input. However, it would be unlikely that more than several minutes would be required to reach steady state for most conditions. All of the steady-state experiments conducted in this section were performed after the heater had been in operation for at least 15 minutes.

The experiments spanned a wide range of boundary conditions, $\left(10<T_{w-i n}<\right.$ $\left.23{ }^{\circ} C, 0.08<\dot{V}_{w}<0.27 \mathrm{~L} \mathrm{~s}^{-1}, 36<T_{\text {out }}<48{ }^{\circ} C\right)$. The presence of liquid water condensate as a combustion product was physically observed for each of these experiments.

Although in practice there are certainly DHW draws that will have lower flow rates than the lower limit achieved during experiments, the lower limit is still representative of an average flow rate $\left(0.076 \mathrm{~L} \mathrm{~s}^{-1}\right.$ Schoenbauer et al. (2012)). The impact of this limitation of the calibration procedure is addressed by the validation in Section 4.3.8. The results from these experiments are shown in Figure 12.

As $\zeta_{s s}$ was relatively insensitive to the boundary conditions over the ranges investigated, only the average $\zeta_{s s}$ from the 31 experiments of $93.9 \%$ is recommended for use. The maximum residual was $3.6 \%$ of value.

\subsubsection{TWH Electrical Power Consumption}

According to Bohac et al. (2010) a significant source of electrical consumption, that could be measured and is relevant to other installations, is the standby electric consumption of the TWH. This was determined to be $5.5 \pm 0.3 \mathrm{~W}$ based upon the measured data. Another source of electric power consumption is known as freeze protection (Bohac et al., 2010). This aspect has not been investigated here.

During firings, typically the electrical consumption of the fan would initially increase quickly to approximately $80 \mathrm{~W}$ for a period of several seconds before stabilizing at a lower level for the rest of the firing that depended on $\dot{Q}_{\text {out }_{s s}}$. This aspect was 


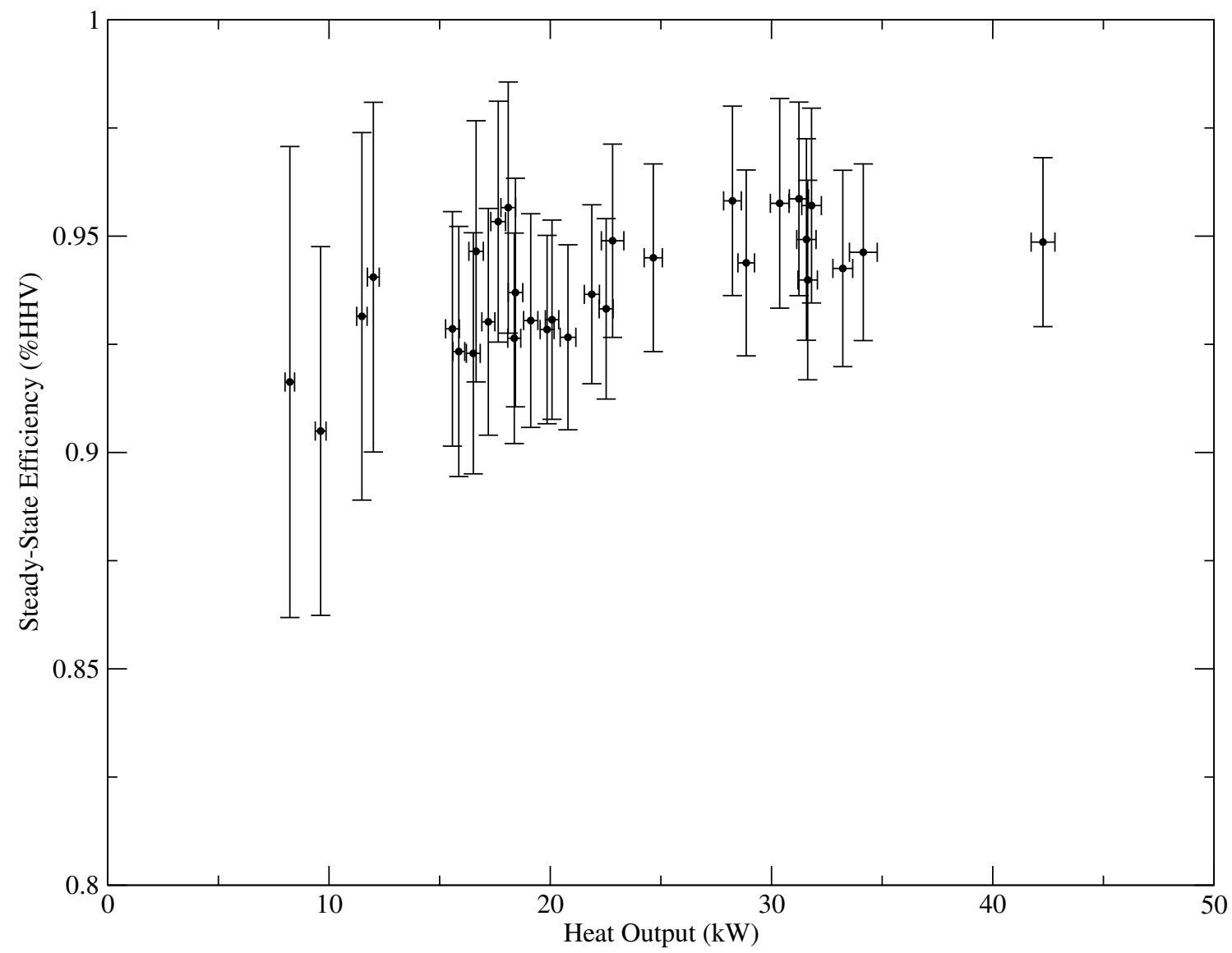

Figure 12: The steady-state efficiency of the TWH versus its heat output during a series of 31 calibration experiments 
not modelled in detail; the electrical consumption during firings was only measured to ensure it was small in comparison with the heat-input from combustion. This was true for all experiments described in this chapter where the heat input ranged from $7.2-44.6 \mathrm{~kW}$.

\subsubsection{Whole Model Validation}

To demonstrate the validity of the whole average model along with the exponential decay equation, measured residential DHW profiles from TWHs emanating from an earlier study (Bohac et al., 2010) were made available to the authors of this study and the following analysis was performed. Bohac et al. (2010) described their instrumentation, experimental program and gathered profiles in detail.

In the analysis performed here, model predictions for $E_{i n-t w h}$ were made for 43 separate DHW profiles and compared to the values measured by Bohac et al. (2010). Each profile was 1 week of data where sampling was performed every second. The profiles were from 4 separate sets of occupants, who used 3 different condensing TWHs. For each profile, the daily average DHW usage spanned a range of 3.958.5 $\mathrm{MJ} \mathrm{day}^{-1}$ for the profiles investigated. For this range of DHW consumption, a range of 5.9-69.3 MJ day ${ }^{-1}$ of TWH energy consumption was measured (Bohac et al., 2010). The comparison of modelled and measured energy consumption is illustrated in Figure 13. The measured values from Bohac et al. (2010) are plotted against the abscissa while the average model predictions are plotted against the ordinate. The differences observed between modelled $E_{i n-t w h}$ values for separate profiles with similar measured $E_{i n-t w h}$ values that can be seen in Figure 13 are due to the differences between the temporal distributions of DHW draw profiles, the differences between the environments in which the TWHs were installed and in some cases the differences between the constructions of the TWHs. 


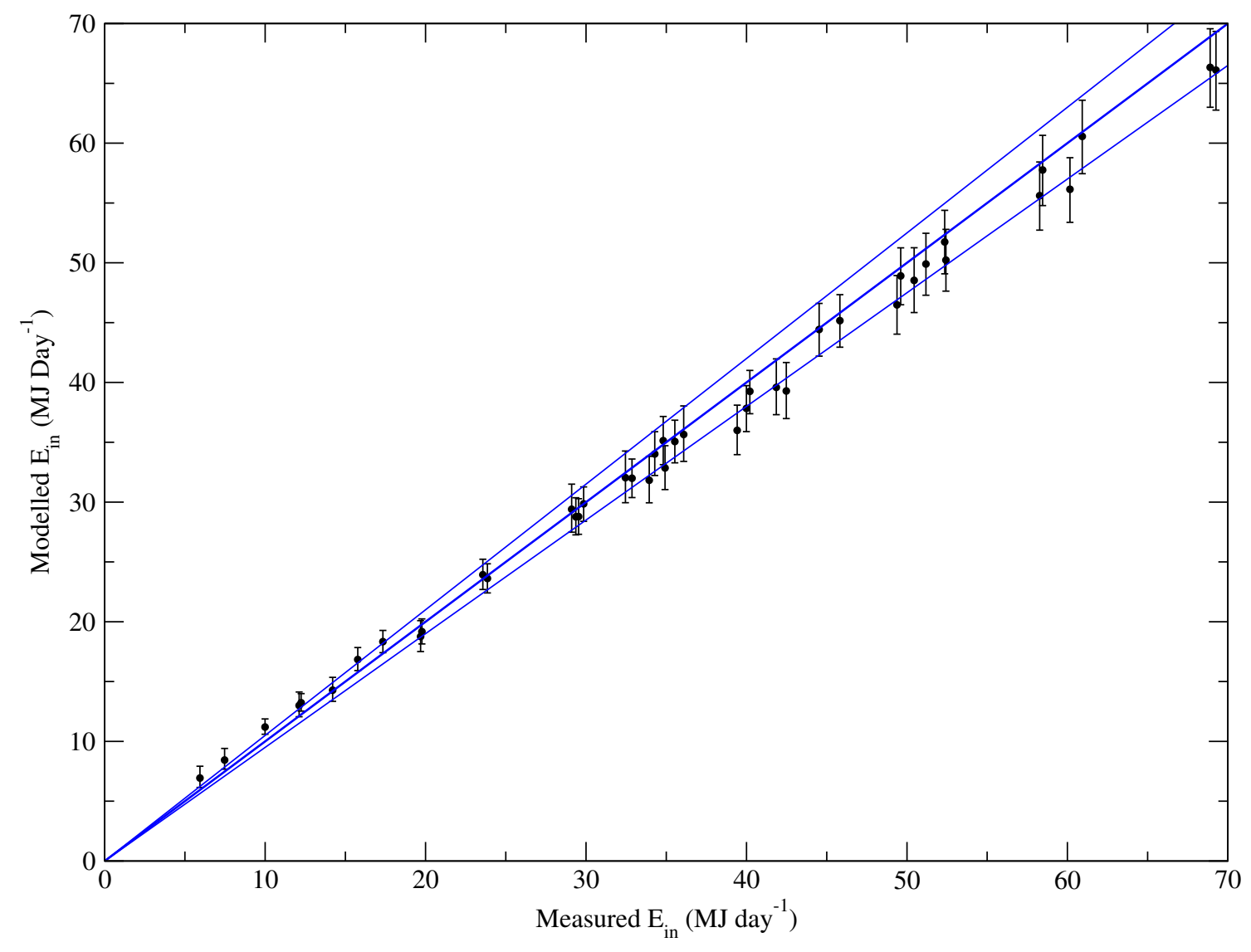

Figure 13: Comparison of the average model predictions against the measured data provided by Bohac et al. (2010) 
In this analysis, the temperature of the TWH $(T(t))$ was modelled according to the following equation.

$$
T(t)=\Delta T_{s s}+\frac{\left(\Delta T_{0}-\Delta T_{s s}\right) e^{-\frac{E_{i n-t w h}(t) \zeta_{s s}}{C_{T W H} \Delta T_{s s}}}}{2}+T_{w-i n}
$$

This equation is consistent with the average model and is necessary to determine the temperature of the TWH at the end of a firing period from which the environmentaldecay period begins (equation 49).

The model parameters that were used are shown in Table 8 along with a summary of how the error bars shown in Figure 13 were derived from a sensitivity analysis. The parameters that were used for modelling were those determined by calibration in Sections 4.3.2, 4.3.4 and 4.3.6 in a laboratory environment and are different than those that would be determined from the TWHs studied by Bohac et al. (2010). However, as can be seen from the results of the sensitivity analysis at the bottom of Table 8, the model predictions are relatively insensitive to changes in the parameters' values over a reasonably wide range. This indicates that a comparison between the performance of different TWHs in different environments is reasonable even if the model parameters are significantly different.

\begin{tabular}{ccccc}
\hline & $U A$ & $\zeta_{s s}$ & $\mathrm{C}_{T W H}$ & $\bar{U}_{95 \% \text { tot }}$ \\
\hline$x_{i}$ & $0.0023 \mathrm{~kW}^{\circ} C^{-1}$ & 0.939 & $23.1 \mathrm{~kJ}{ }^{o} C^{-1}$ & \\
$\bar{U}_{95 \%}$ & $\pm 0.0011 \mathrm{~kW}{ }^{o} C^{-1}$ & \pm 0.042 & $\pm 2.25 \mathrm{~kJ}{ }^{o} C^{-1}$ & \\
$\frac{\partial E_{i n-t w h}}{\partial x_{i}} \cdot \frac{\Delta x_{i}}{E_{i n-t w h}}$ & $\pm 2.9 \%$ & $\pm 4.7 \%$ & $\pm 0.4 \%$ & $\pm 5.5 \%$ \\
\hline
\end{tabular}

Table 8: Summary of the sensitivity analysis of the TWH model predictions to each model parameter's uncertainty margin

To estimate the uncertainty margin for each of the 43 DHW profiles, model predictions were made for the "base case", where the model parameters' values $\left(x_{i}\right)$ were 
those determined by calibration in this paper. Model predictions were then repeated for each DHW profile for "sensitivity cases" where each model parameter was varied by its uncertainty margin. Note that the $\bar{U}_{95 \%}$ value shown for $\zeta_{s s}$ is a combination (according to Moffat (1988)) of the maximum residual reported in Section 4.3.6 along with the $\bar{U}_{95 \%}$ values determined experimentally shown on Figure 12 for $\dot{Q}_{\text {out }_{s s}}$ greater than $15 \mathrm{~kW}$.

In Table $8, \frac{\partial E_{i n-t w h}}{\partial x_{i}} \cdot \frac{\Delta x_{i}}{E_{i n-t w h}}$ was calculated as the mean percent difference between the base case and a sensitivity case, for each parameter $x_{i}$, over the $43 \mathrm{DHW}$ profiles analyzed. The mean result of this analysis is summarized at the bottom of Table 8 . Note that it was unreasonable to derive uncertainty margins from the data measured by Bohac et al. (2010) due to the highly transient nature inherent in field-trial data.

Notwithstanding this limitation, the result of this comparison indicates that the average model's predictions are commensurate with what has been measured in practice from other condensing TWHs. The solid line in the center of Figure 13 represents the line of perfect agreement. Above and below this line are two other lines that represent a $\pm 5 \%$ deviation from perfect agreement. For the entire range of the average model's predictions, the coefficient of determination ( $\mathrm{r}^{2}$ value) was 0.990 . The average error (difference between the average model predictions and the measured values) was $4.1 \%$ (in relative terms) while the root-mean-square error was $4.5 \%$. The maximum error for a single point was $16.8 \%$ at a DHW consumption of approximately 3.9 $\mathrm{MJ} \mathrm{day}^{-1}$. Above DHW consumption values of $15 \mathrm{MJ}$ day $^{-1}$, the coefficient of determination ( $\mathrm{r}^{2}$ value) was 0.981 . The average error (difference between the average model predictions and the measured values) was $3.0 \%$ (in relative terms) while the root-mean-square error was $4.2 \%$. The maximum error for a single point was $8.7 \%$ at a DHW consumption of approximately $30.2 \mathrm{MJ}_{\text {day }}{ }^{-1}$. 


\subsection{Closing Remarks}

The model developed in this section is an advancement over those that existed previously. It allows for the estimation of the amount of fuel energy content consumed by a condensing TWH in a DHW application given an occupant's DHW profile. It also allows for the uncertainty margins of these predictions to be estimated as well. This model considers the reduction in efficiency of the TWH caused by the highly transient nature of DHW draw profiles. The TWH efficiencies determined from the simulations described in Chapter 6 using the model developed in this section ranged from $85 \%$ to $92 \%$ for DHW consumption levels from 21 to $90 \mathrm{MJ}$ day $^{-1}$. Had only the steady-state value been considered, the efficiency would have been $93.9 \%$ for the entire range of consumption levels. For these reasons, the model developed in this section allows for a more reasonable estimate and will be used to represent the reference burner required by the methodology being developed in this thesis. 


\section{Chapter 5}

\section{The Performance Characterization of a PEMFC}

The methodology being developed in this thesis is intended to assess whether a microcogeneration system or conventional methods for providing occupant thermal and electrical demands is more efficient. The preceding two chapters described how the conventional methods in the reference scenario were defined. This chapter describes how the performance of a micro-cogeneration system was defined. As a case study, a $1 \mathrm{~kW}$ PEMFC was selected as the prime-mover for the cogeneration system to demonstrate the methodology being developed in this thesis. To represent the performance of this particular micro-cogeneration device, a PEMFC model was adapted from an existing version and calibrated with data gathered from an experimental program where the performance of a $1 \mathrm{~kW}$ PEMFC was characterized over a range of operating conditions. This chapter describes how these adaptations were made along with this experimental program and is primarily composed of excerpts from Johnson et al. (2013). My contribution to this original work was to perform many of the experiments, the data processing and the uncertainty analysis. I adapted the Annex 42 fuel-cell model to the form that I calibrated with the data gathered from these experiments. My supervisor provided me with guidance throughout. I also performed the 
majority of the writing with feedback from my supervisor. My colleagues at Natural Resources Canada performed the majority of the work involved in commissioning the experimental apparatus.

\subsection{Model Description}

As described in Chapter 2, the Annex 42 model can be configured to represent either a SOFC or a PEMFC micro-cogeneration device. A detailed description of aspects of the model critical to the treatment of SOFCs and their calibration was provided by Beausoleil-Morrison and Lombardi (2009). This section supplements that material by focusing on the aspects of the model that are unique to the treatment of PEMFCs.

A number of the control volumes included in the Annex 42 model are not pertinent to PEMFC devices. States 7-19 shown on the left side of Figure 14 refer to working fluid states relevant to the gas-water heat-exchanger that is used to produce the useful thermal output in SOFC systems, as well as an optional auxiliary burner and a dilution air heat recovery ventilator (HRV). These components do not exist in PEMFC systems. Rather, a water-water heat-exchanger that recovers thermal energy from the PEMFC stack produces the useful thermal output (see states 21-26 in the bottomcentre of Figure 14).

The Annex 42 model represents the stack cooling loop in detail. The stack coolant fluid is circulated by a pump (states 24 to 21) to the internal heat-exchanger of the fuel-cell power module (FCPM) where it recovers the heat that is generated by electrochemical processes (states 21 to 22). The stack coolant fluid then passes through a water-water heat-exchanger (called the external heat-exchanger, states 22 to 23), where energy is transferred to an external coolant stream (states 25 to 26). This external coolant stream is connected to the plant network that exploits this thermal output to supply the building's space and/or water heating needs. The Annex 


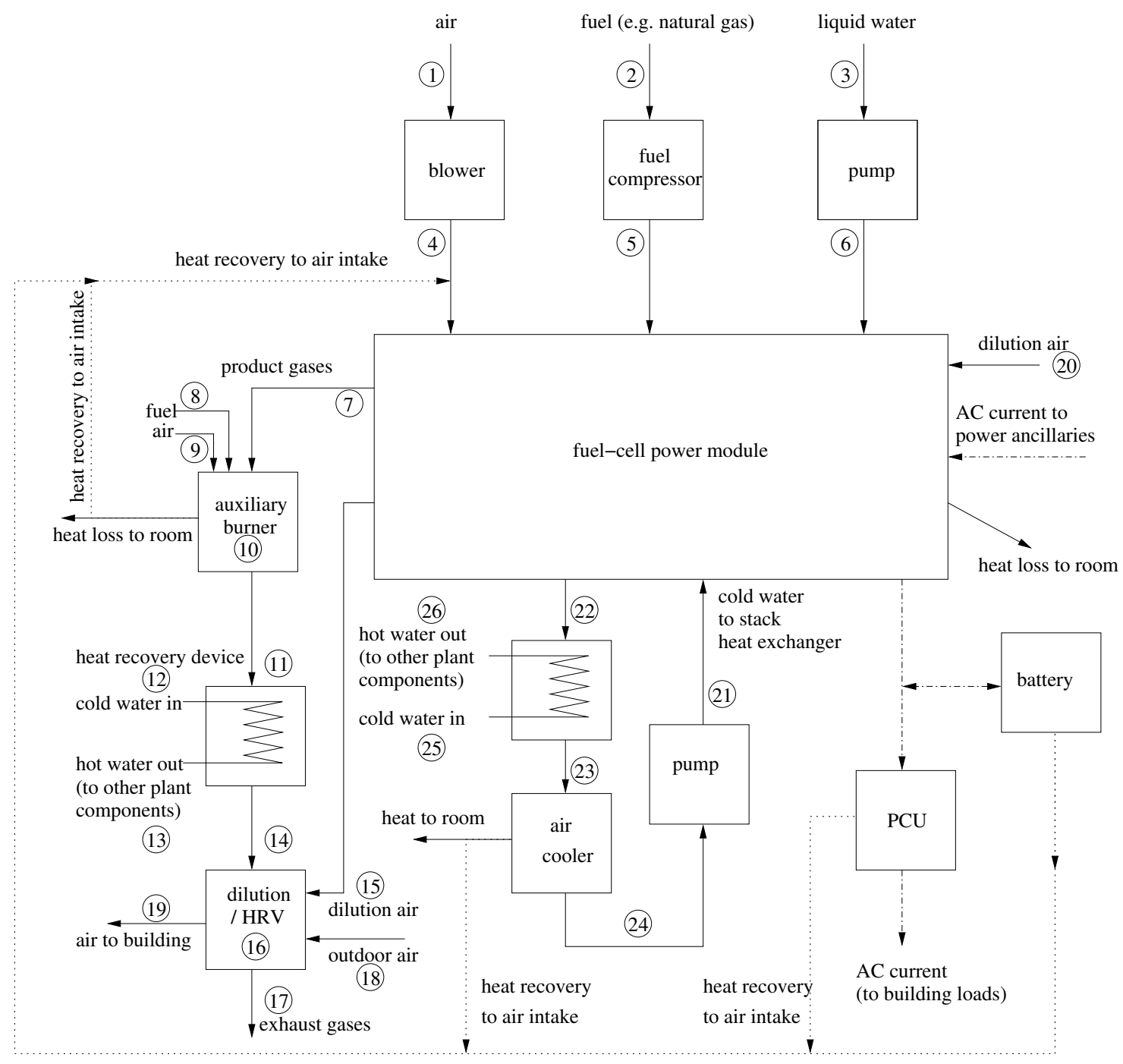

Figure 14: Annex 42 fuel-cell micro-cogeneration model 
42 model also includes an air cooler (states 23 to 24 ) in the stack cooling loop that is present in some PEMFC micro-cogeneration devices for rejecting additional heat to regulate the stack temperature. Methods are prescribed in the Annex 42 model for resolving the pump, the FCPM's internal heat-exchanger, the external water-water heat-exchanger, and the air cooler (Kelly and Beausoleil-Morrison, 2007).

This explicit representation of the stack cooling loop was added to the Annex 42 model to support the representation of PEMFC devices. However, as the model was never calibrated to represent the performance of an actual PEMFC microcogeneration device, the practicality of this approach was never assessed. Some disadvantages of these aspects of the Annex 42 model have become apparent during the current study. Firstly, it would be excessively difficult to implement in practice the instrumentation required to measure the thermal and electrical performance of the pump and air cooler. Furthermore, the calibration of the external water-water heatexchanger requires measuring the flow rate and temperature of the stack coolant fluid at states 22 and 23, necessitating invasive measurements. Finally, the method recommended for modelling the external water-water heat-exchanger is not well supported in the literature and is cast in a functional form that is not pragmatic to calibrate.

For the reasons cited above, an alternate method is proposed here for treating the stack cooling loop. Rather than attempting to resolve the sub-components of the stack cooling loop (pump, air cooler, internal heat-exchanger), with this method the stack cooling is treated in a manner that is pragmatic from a model calibration perspective. It recognizes that it is only practical to directly measure the flow rate and temperatures in the external-cooling-stream side of the external water-water heatexchanger, that is states 25 and 26. This alternative method preserves the structure of the Annex 42 model, but essentially nullifies the air cooler, pump, and internal heat-exchanger in the stack cooling loop, and makes no attempt to solve state points 21 through 24. Rather, an energy balance is formed on the external heat-exchanger 
that equates the thermal energy released by the FCPM to the thermal energy increase in the external-cooling-stream side of the external water-water heat-exchanger. If it is assumed that the heat loss from the external heat-exchanger is negligible and that the heat capacity of the fluid stream remains constant through the heat-exchanger, then the energy balance can be written as,

$$
q_{s-\mathrm{cool}}=\dot{N}_{w} \cdot C_{w} \cdot\left(T_{w-o u t}-T_{w-i n}\right)
$$

where $q_{s-\text { cool }}$ is the heat released by the FCPM (W). $\dot{N}_{w}$ is flow rate of the external coolant through the heat-exchanger $\left(\mathrm{kmol} \mathrm{s}^{-1}\right)$ and $C_{w}$ is its specific heat capacity $\left(\mathrm{J} \mathrm{kmol}^{-1}{ }^{o} \mathrm{C}^{-1}\right) . T_{w-i n}$ is the temperature of the coolant stream entering the heat exchanger (state 25 in Figure 14). $T_{w-\text { out }}$ is the temperature of water exiting the heat-exchanger (state 26).

In the Annex 42 model $q_{s-\text { cool }}$ is determined as a third-order parametric function of the FCPM's net DC power production $\left(P_{f c-d c}\right.$ in W). The measurements gathered in the present study revealed that $T_{w-i n}$ was also a significant determinant of $q_{s-\text { cool }}$. Consequently, an alternate functional form is proposed,

$$
q_{s-c o o l}=r_{0}+r_{1} \cdot P_{f c-d c}^{\alpha_{0}}+r_{2} \cdot\left(T_{w-i n}-T_{0}\right)^{\alpha_{1}}
$$

where $r_{i}, \alpha_{i}$, and $T_{0}$ are parameters to be determined by calibrating the dependent observations of $q_{s-c o o l}$ to the independently controlled boundary conditions $P_{f c-d c}$ and $T_{w-i n}$. There is no physical basis for the form of the preceding equation as well as equations 65 and 66 used to model the fuel cell. Rather, they were found to represent the observed data well within the range of boundary conditions investigated with experiments. Consequently, these equations should not be used to make predictions outside of their calibration range. 
The preceding model adaptations were described by Johnson et al. (2013). Also, Johnson et al. (2013) characterized the heat-loss from the fuel cell to the surrounding environment. Johnson et al. (2013) considered this aspect to include all losses to the the room together as a single loss. This includes, for example, the heat lost from the FCPM to the room and from the air cooler to the room shown in Figure 14 (states 23 -24). However, this aspect is only important when the environment in which the fuel cell operates in is explicitly modelled. Therefore, it was not required for the simulations in Chapter 6 where the environment was modelled with a constant $18^{\circ} \mathrm{C}$ air temperature.

In addition to these adaptations, there are several further adaptations that were made to this model for the particular simulations described in Chapter 6. Although the data presented by Johnson et al. (2013) and in this chapter are the most reliable, the associated model was intended for general purpose use, so it was calibrated over a broad range of operating conditions with detailed sub-component models. However, for the specific purpose under consideration here, the exact operating range was known along with the specific model outputs required. These adaptations are described as follows.

First, a new model equation that directly describes the relationship between the PEMFC's net DC output $\left(P_{f c-d c}\right.$ in W) and AC output $\left(P_{f c-a c}\right.$ in W) was derived. This was to allow for a more direct calculation of $P I_{e l}$ in equation 71 in Chapter 6. This equation is shown below.

$$
P_{f c-a c}=e_{0}+e_{1} \cdot P_{f c-d c}
$$

where $e_{i}$ are the model calibration coefficients given in Table 12 .

Second, a new model equation that directly describes the relationship between the PEMFC's net DC output $\left(P_{f c-d c}\right.$ in W) and consumption of fuel energy content 
$\left(\dot{E}_{f c-f u e l}\right.$ in W) was derived. Again, this was to allow for a more direct calculation of $P I_{e l}$ in equation 71 in Chapter 6 . This equation is shown below.

$$
\dot{E}_{f c-f u e l}=f_{0}+f_{1} \cdot P_{f c-d c}+f_{2} \cdot P_{f c-d c}^{2}
$$

where $f_{i}$ are the model calibration coefficients given in Table 12 .

The final adaptation is that only data that were within the range of temperatures at the PEMFC inlet in the heat-recovery circuit $\left(T_{w-i n}\right.$ in $\left.{ }^{\circ} \mathrm{C}\right)$ permissible in the simulations were used used to calibrate this model. This was to ensure more accurate model fits to reduce model prediction uncertainties (described in Table 13) associated with using equations 64 and 66. Note that this final adaptation was not necessary for the calibration of equation 65 since $P_{f c-a c}$ is predominantly determined by the

efficiency of the power conditioning unit (shown in Figure 15) where $T_{w-i n}$ is not a boundary condition. Therefore, it was reasonable to calibrate equation 65 with all data available from Johnson et al. (2013).

The derivation of the $r_{i}, e_{i}, f_{i}, \alpha_{i}$, and $T_{0}$ for characterizing other aspects of the PEMFC micro-cogeneration device will be described in Section 5.5. The next section describes the experimental methods employed to gather the data necessary to perform these calibrations.

\subsection{Experimental Configuration}

A schematic representation of the experimental configuration is illustrated in Figure 15. The fuel cell was configured to draw air from the surrounding laboratory environment and was supplied with methane from cylinders. Coolant water was supplied to the PEMFC's heat-exchanger from a tank. The temperature of the tank could be controlled by rejecting energy from the tank through a water-air heat-exchanger in an 
air-handling unit. The tank's temperature could also be controlled by drawing off hot water and replacing it with cold water from the city mains. An experimental plan was designed according to the one recommended by Beausoleil-Morrison (2007) to characterize the performance of the PEMFC micro-cogeneration device under precisely controlled operating conditions using this setup.

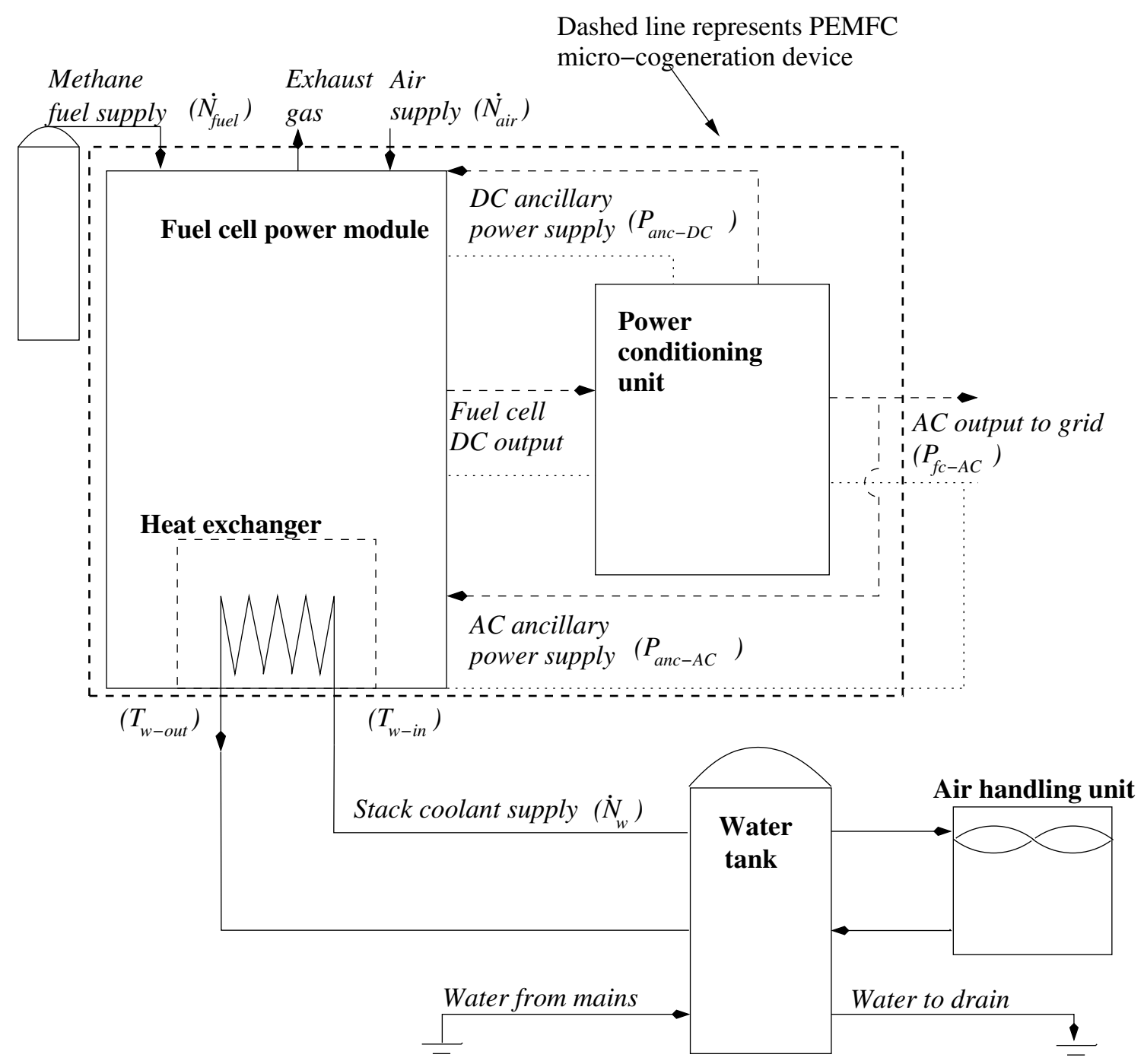

Figure 15: Schematic representation of the experimental configuration used to characterize the performance of a PEMFC

Two variables were controlled in the experiments. The first was the temperature of the coolant water supplied to the PEMFC, $T_{w-i n}$ (refer to Figure 15). The second 
was a control setting on the device that determined the net $\mathrm{AC}$ power supplied to the grid, $P_{f c-a c}$. The target range over which these variables were controlled and the nominal values achieved by Johnson et al. (2013) in the experiments are given in Table 9. Note that only a subset of these experiments was used to calibrate the model described in this section and used for simulations in Chapter 6 as indicated in Table 9.

\begin{tabular}{|c|c|c|c|}
\hline boundary condition & operating range & \multicolumn{2}{|c|}{ experimentally investigated values } \\
\hline \multirow{3}{*}{$T_{w-i n}$} & & & $\begin{array}{l}\text { used for calibration of } \\
\text { equations } 64-66\end{array}$ \\
\hline & $15-60^{\circ} \mathrm{C}$ & $\underbrace{16,20,25,30,35{ }^{\circ} \mathrm{C}}$ & $\overparen{40,45,55,59^{\circ} \mathrm{C}}$ \\
\hline & \multicolumn{3}{|c|}{ used for calibration of equation 65} \\
\hline$P_{f c-a c}$ & $250-1000 \mathrm{~W}$ & \multicolumn{2}{|c|}{$272,540,750,980 \mathrm{~W}$} \\
\hline
\end{tabular}

Table 9: PEMFC experiments: Operating range and experimentally achieved values for externally controlled boundary conditions

The PEMFC micro-cogeneration device's control system would respond to these boundary conditions by modulating a number of variables pertinent to the model's calibration, for example the fuel $\left(\dot{N}_{f u e l}\right)$ and air $\left(\dot{N}_{\text {air }}\right)$ supply rates. As well, it would modulate the temperature of the exiting coolant water $\left(T_{w-o u t}\right)$ by controlling an internal pump that determined the coolant water flow rate $\left(\dot{N}_{w}\right)$ through the device. Consequently, the DC and AC ancillary power consumption $\left(P_{a n c-d c}\right.$ and $\left.P_{a n c-a c}\right)$ were determined by the PEMFC micro-cogeneration device's control system's response to the externally controlled boundary conditions.

Steady-state tests were conducted for each of the combinations of $T_{w-i n}$ and $P_{f c-a c}$ given in Table 9. Each test lasted about 60 minutes. After a stabilization period, during which the boundary conditions were monitored to ensure that steady-state conditions had been achieved, data were logged for a period of about 30 minutes. The duration of these periods was chosen to allow for enough data to be logged such 
that the precision index (see Section 5.4) would be negligible for most cases. These data were utilized to derive the steady-state performance parameters that were used to calibrate the model.

\subsection{Instrumentation and Measurement Methods}

Thorsteinson et al. (2011) described the development of the experimental apparatus that was used to operate the PEMFC micro-cogeneration device and to control the external boundary conditions discussed above. A number of important modifications were made to the experimental apparatus described in this earlier work in order to reduce experimental uncertainty. Firstly, to reduce the uncertainty in predicting the heating value of the fuel supply, the device was operated with tanks of methane rather than utility-supplied natural gas. The composition was certified to be $99 \%$ methane. A bias error on the fuel's LHV was assigned based upon the unknown concentration of the remaining $1 \%$. In the extreme, if the remaining gas was not combustible or entirely ethane, this would affect the LHV by $1 \%$. Consequently, a bias error of $1 \%$ was assigned to the fuel's LHV.

Secondly, some of the instrumentation was modified to accord with Figure 16. The types of measurements taken and the sensors employed are listed in Table 10. The gross DC power output was derived from current $\left(I_{D C}\right)$ and voltage $\left(v_{D C}\right)$ measurements, taken with a current shunt and voltage divider respectively. The same methods were used to determine the DC ancillary power supply $\left(P_{\text {anc-dc }}\right)$ from current $\left(I_{a n c-d c}\right)$ and voltage $\left(v_{a n c-d c}\right)$ measurements. The net AC power output to the grid $\left(P_{f c-a c}\right)$ was measured directly by a meter that combined a current transformer and a voltmeter. The AC current output to the grid $\left(I_{A C}\right)$ was separately measured with a second current transformer. The AC ancillary current $\left(I_{\text {anc-ac }}\right)$ and the AC current output by the PCU $\left(I_{P C U}\right)$ were also measured with current transformers. 


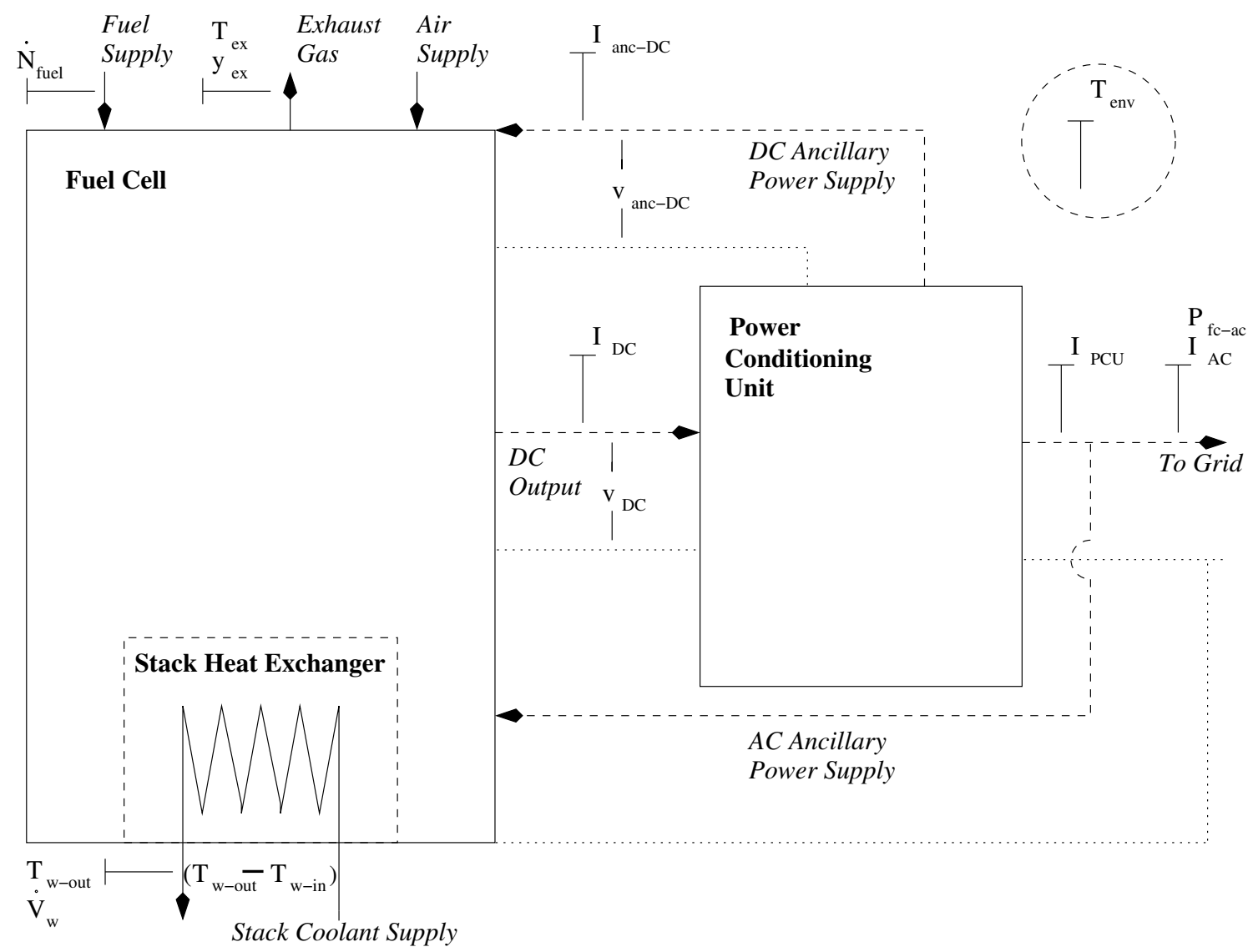

Figure 16: Instrumentation placement on the experimental apparatus used to characterize the performance of a PEMFC 


\begin{tabular}{cll}
\hline primary measurement & sensed quantity & sensor type \\
\hline$T_{w-\text { out }}, T_{e n v}, T_{e x}$ & temperature & $\begin{array}{l}\text { resistance temperature de- } \\
\text { tector (RTD) }\end{array}$ \\
$\Delta T_{w}$ & temperature differ- & matched RTDs \\
& ence & \\
$\dot{V}_{w}$ & volumetric flow & ultrasonic flow meter \\
$\dot{N}_{f u e l}$ & rate & \\
$y_{e x}$ & molar flow rate & Coriolis flow meter \\
& dry molar percent- & non-dispersive infrared ab- \\
$P_{f c-a c}$ & age of $C O_{2}$ & sorption \\
& AC power & current transformer and \\
$I_{P C U}, I_{a n c-a c}$ & AC current & coltmeter \\
$v_{D C}, v_{a n c-d c}$ & DC voltage & voltage divider \\
$I_{D C}, I_{a n c-d c}$ & DC current & current shunt \\
\hline
\end{tabular}

Table 10: PEMFC experimental apparatus: Sensor types and measured parameters 
The temperature rise of the coolant through the heat-exchanger $\left(\Delta T_{w}=T_{w-\text { out }}-\right.$ $T_{w-i n}$ in ${ }^{\circ} \mathrm{C}$ ) was measured directly with a pair of matched RTDs with calibrated wire lengths sensed by a revenue grade heat meter. $T_{w-\text { out }}$ was measured with one RTD of the matched pair that was located at the heat-exchanger's outlet. $T_{w-i n}$ was derived from measurements of $\Delta T$ and $T_{w-o u t}$. The flow rate of the coolant through the heat-exchanger $\left(\dot{N}_{w}\right.$ in $\left.\mathrm{kmol} \mathrm{s}^{-1}\right)$ was derived from measurements of the volumetric flow rate $\left(\dot{V}_{w}\right.$ in $\left.\mathrm{L} \mathrm{min}^{-1}\right)$ taken with an ultrasonic flow meter and determination of the coolant's density from its temperature at the heat-exchanger inlet $\left(T_{w-i n}\right.$ in $\left.{ }^{\circ} \mathrm{C}\right)$.

The rate of fuel supplied to the PEMFC micro-cogeneration device $\left(\dot{N}_{f u e l}\right.$ in kmol $\mathrm{s}^{-1}$ ) was measured directly with a Coriolis mass flow meter. The ambient temperature of the laboratory housing the experiment was also sensed $\left(T_{e n v}\right.$ in $\left.{ }^{o} \mathrm{C}\right)$ as were the exhaust gas temperature $\left(T_{e x}\right.$ in $\left.{ }^{\circ} \mathrm{C}\right)$ and dry molar percentage of $C_{2}$ in the exhaust gas $\left(y_{e x}\right)$.

Most of the instruments were sensed and their data logged by a data acquisition system (DAQ) at an interval of 6 seconds. There were several exceptions to this. $T_{w-\text { out }}$ and $\Delta T_{w}$ were logged by a heat meter that subsequently output these data to the DAQ. However, the heat meter produced its output at a lower frequency, sending a signal to the DAQ every 72 seconds. $P_{f c-a c}$ was directly logged by a separate computer. To ensure synchronization between these measurements and those taken with the DAQ, the clocks of the computer and the DAQ were synchronized daily.

\subsection{Uncertainty in Primary Measurements}

The $\bar{U}_{P, 95 \%}$ values associated with each primary measurement quantity over the range of values measured during the steady-state tests are provided in Table 11. In most cases the higher levels of uncertainty are associated with measurements of smaller quantities, particularly in the case of electrical currents, flow rates, and temperature 


\begin{tabular}{ccc}
\hline measured quantity & $B_{P}$ & $\bar{U}_{P, 95}$ \\
\hline$v_{D C}$ & $0.5 \%$ of value & $0.5 \%$ of value \\
$I_{D C}$ & $0.5 \%$ of value & $0.5 \%$ of value \\
$v_{\text {anc-dc }}$ & $0.5 \%$ of value & $0.5 \%$ of value \\
$I_{\text {anc-dc }}$ & $0.5 \%$ of value & 0.5 to $0.7 \%$ of value \\
$I_{P C U}$ & $1.1 \%$ of value & $1.1 \%$ of value \\
$I_{A C}$ & $1.1 \%$ of value & $1.1 \%$ of value \\
$P_{f c-a c}$ & 3.5 to $5.9 \%$ of value & 3.5 to $5.9 \%$ of value \\
$\dot{N}_{f u e l}$ & $0.7 \%$ of value & $0.7 \%$ of value \\
$\dot{V}_{w}$ & 2.2 to $4.9 \%$ of value & 2.2 to $6.5 \%$ of value \\
$T_{w-\text { out }}$ & $0.6{ }^{\circ} \mathrm{C}$ & 0.6 to $0.8{ }^{\circ} \mathrm{C}$ \\
$\Delta T_{w}$ & 0.8 to $1.5 \%$ of value & 0.8 to $4.9 \%$ of value \\
& $\left(0.13\right.$ to $\left.0.38{ }^{\circ} \mathrm{C}\right)$ & \\
$y_{\text {ex }}$ & 2.9 to $7.4 \%$ of value & 2.9 to $7.4 \%$ of value
\end{tabular}

Table 11: PEMFC experimental apparatus: Bias errors and uncertainty for primary measurement quantities 
differences. By contrasting the $B_{P}$ and $\bar{U}_{P, 95 \%}$ values in this table, it can be seen that in most cases the bias errors are the dominant contributor to uncertainty. The exception to this is with $\Delta T_{w}$, where it was found that the precision index dominated in some cases because of the lower sampling frequency of the heat meter (refer to Section 5.3). Additionally, the larger $\bar{U}_{95}$ values for $\Delta T_{w}$ were only observed for the experiments that were conducted where the inlet temperature was very close to the upper limit of what was permissible. For these boundary conditions unsteadiness was always present. This unsteadiness was caused by the action taken by the PEMFC controller to modulate the water flow rate to achieve a desired $T_{w-o u t}$. Other than these boundary conditions for these experiments, the fact that the uncertainties were primarily dominated by the bias errors of the instruments is an indication of how well steady conditions were achieved. The next section describes how these primary measurements were used to derive the thermal and electrical performance parameters necessary to calibrate the model.

\subsection{PEMFC Model Calibration}

\subsubsection{Fuel Consumption}

Rather than determine a relationship between net DC output and DC electrical efficiency as was done by Johnson et al. (2013), the model form shown in equation 66 is a relationship between the net DC electrical output $\left(P_{f c-d c}\right)$ and the rate of con-

sumption of the fuel energy contents $\left(\dot{E}_{f c-f u e l}\right)$. The model groups the fuel-cell stack with other components such as the fuel processor into the FCPM control volume; it makes no attempt to simulate the electrochemical processes occurring within the fuel cell. The net DC output was derived according to equation 67 ,

$$
P_{f c-d c}=v_{D C} \cdot I_{D C}-v_{a n c-d c} \cdot I_{a n c-d c}
$$


while the rate of consumption of fuel energy content was derived according to equation 68.

$$
\dot{E}_{f c-f u e l}=\dot{N}_{f u e l} \cdot L H V_{f u e l}
$$

where $L H V_{\text {fuel }}$ is the lower heating value of methane at $25^{\circ} \mathrm{C}$ and $101.325 \mathrm{kPa}$.

In total there were 26 tests presented by Johnson et al. (2013) that were within the range of inlet water temperatures that were available that could be used for the calibration of this aspect of the model. A summary of these tests is illustrated in Figure 17. Each solid marker represents the average value derived from measurements from a single steady-state test. The error bars represent the uncertainty margins derived at a 95\% confidence level. The hollow markers represent model prediction values. Note that there is considerable overlap between the model prediction and the values derived from measurements and it is difficult to distinguish between the two from Figure 17.

A least-squares regression was performed on equation 66 to establish the values of the $f_{i}$ coefficients that produced the best fit to the data plotted in Figure 17. The values of the coefficients determined from this analysis are presented in Table 12 .

\subsubsection{Heat Recovery}

Similar methods were used to fit parameters to equation 64 , but in this case a nonlinear regression method was employed. The $r_{i}, \alpha_{i}$, and $T_{0}$ parameters that produced

the best fit to the values of $q_{s-\text { cool }}$ derived from the primary measurements using equation 63 are given in Table 12. Also note the necessary primary measurements were data available from 6 additional experiments for the calibration of equation 64 . 


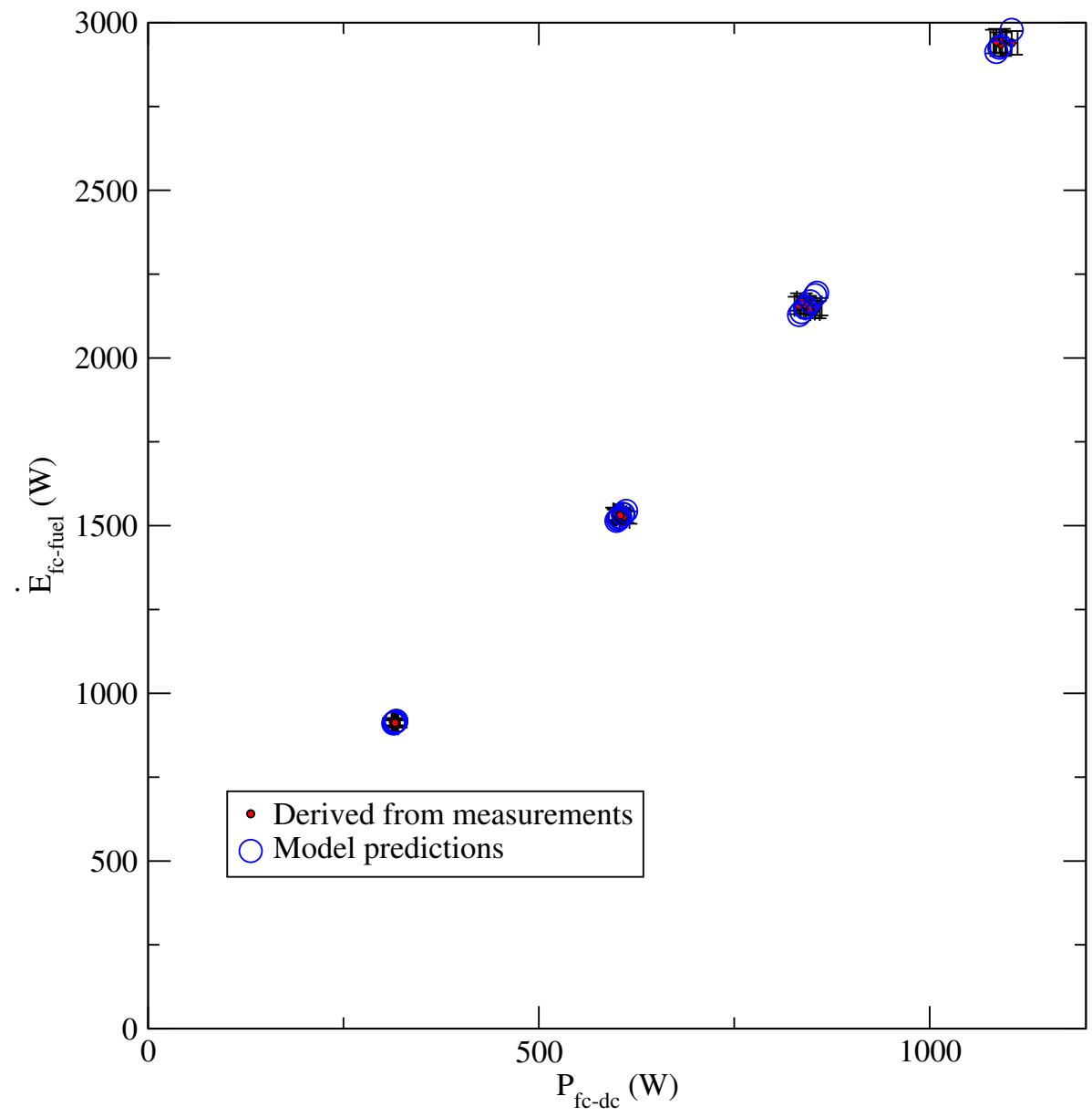

Figure 17: Test-averaged fuel-cell power module consumption of fuel energy content for each of the 30 steady-state tests 
$\mathrm{AC}$ output coefficients for $e_{0}=-4.276677 ; e_{1}=8.910647 \cdot 10^{-1}$; equation 65

Consumption of fuel en- $f_{0}=432.73315 ; f_{1}=1.21272$;

ergy content coefficients for $f_{2}=9.8793471 \cdot 10^{-4}$;

equation 66

$\begin{array}{ll}\text { Heat recovery parameters } & r_{0}=2.340002 \cdot 10^{2} ; r_{1}=1.7938934 \cdot 10^{-2} ; \\ \text { for equation } 64 & r_{2}=-1.7851876 \cdot 10^{-1} ; \alpha_{0}=1.6 ; \\ & \alpha_{1}=2 ; T_{0}=26.5\end{array}$

Range of applicability:

$40{ }^{\circ} \mathrm{C} \leq T_{w-i n} \leq 59.1{ }^{\circ} \mathrm{C}$

$315 W \leq P_{f c-d c} \leq 1110 W$

$T_{\text {env }} \approx 22{ }^{\circ} \mathrm{C}$

Table 12: Calibration coefficients for the PEMFC model 


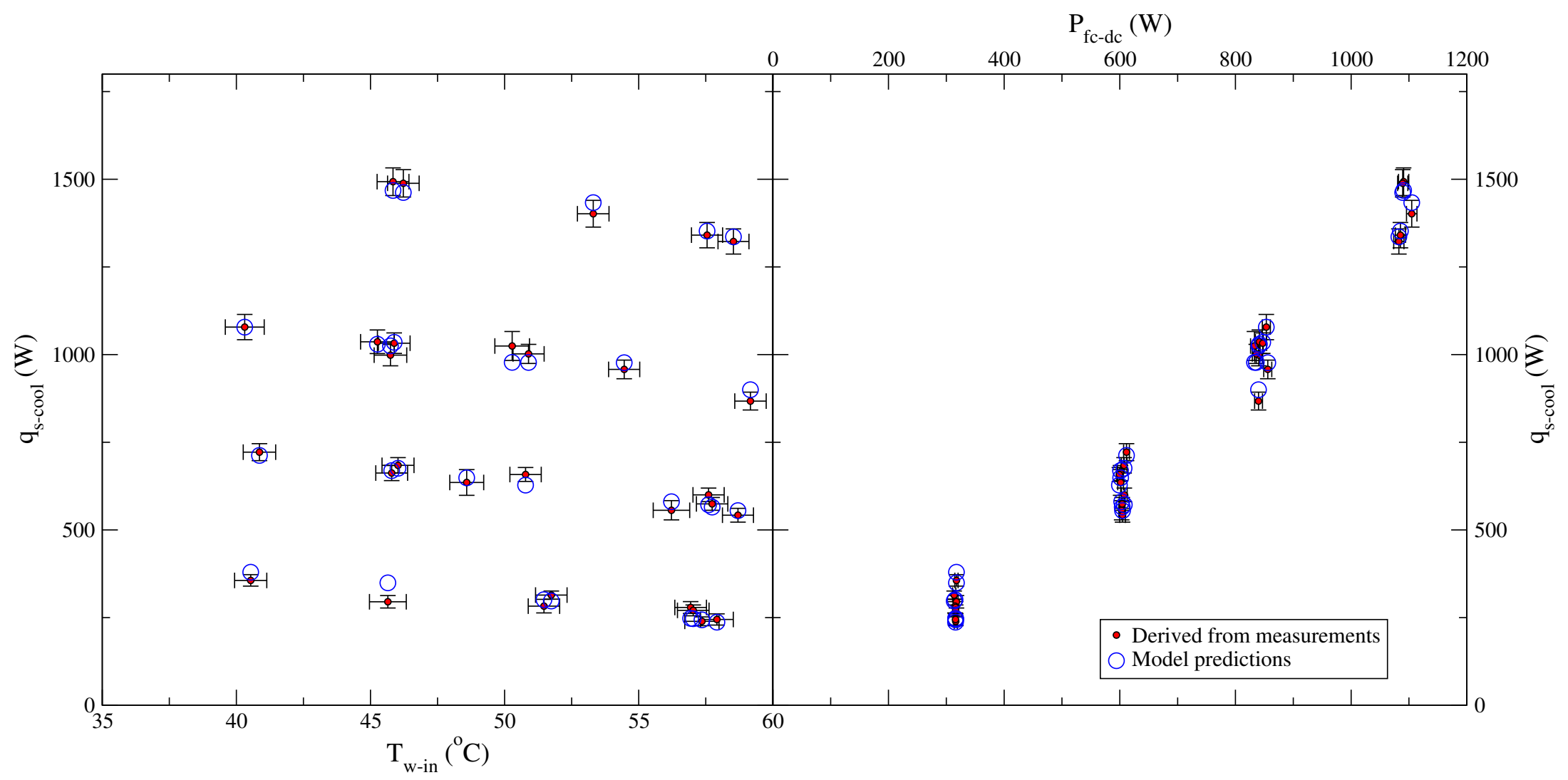

Figure 18: Test-averaged PEMFC heat recovery for each of the 30 steady-state tests 
Figure 18 compares the $q_{s-\text { cool }}$ determined with equation 64 and the parameters of Table 12 with the $q_{s-\text { cool }}$ values derived from the measurements. The left side of the figure examines the variation with $T_{w-i n}$ whereas the right side considers $P_{f c-d c}$. As can be seen, the functional form of equation 64 well represents the dependency of $q_{s-\text { cool }}$ on the experiment's two independent variables.

\subsubsection{Net AC Output}

Similar methods were used to calibrate equation 65 , but in this case a linear model was used. The $e_{i}$ coefficients derived from the primary measurements using equation 65 are given in Table 12. Also note that for the calibration of this aspect of the model, the data that were used were not restricted to be for tests where $T_{w-i n}$ was warmer than $40{ }^{\circ} \mathrm{C}$, therefore, data from 46 steady-state tests were available. 


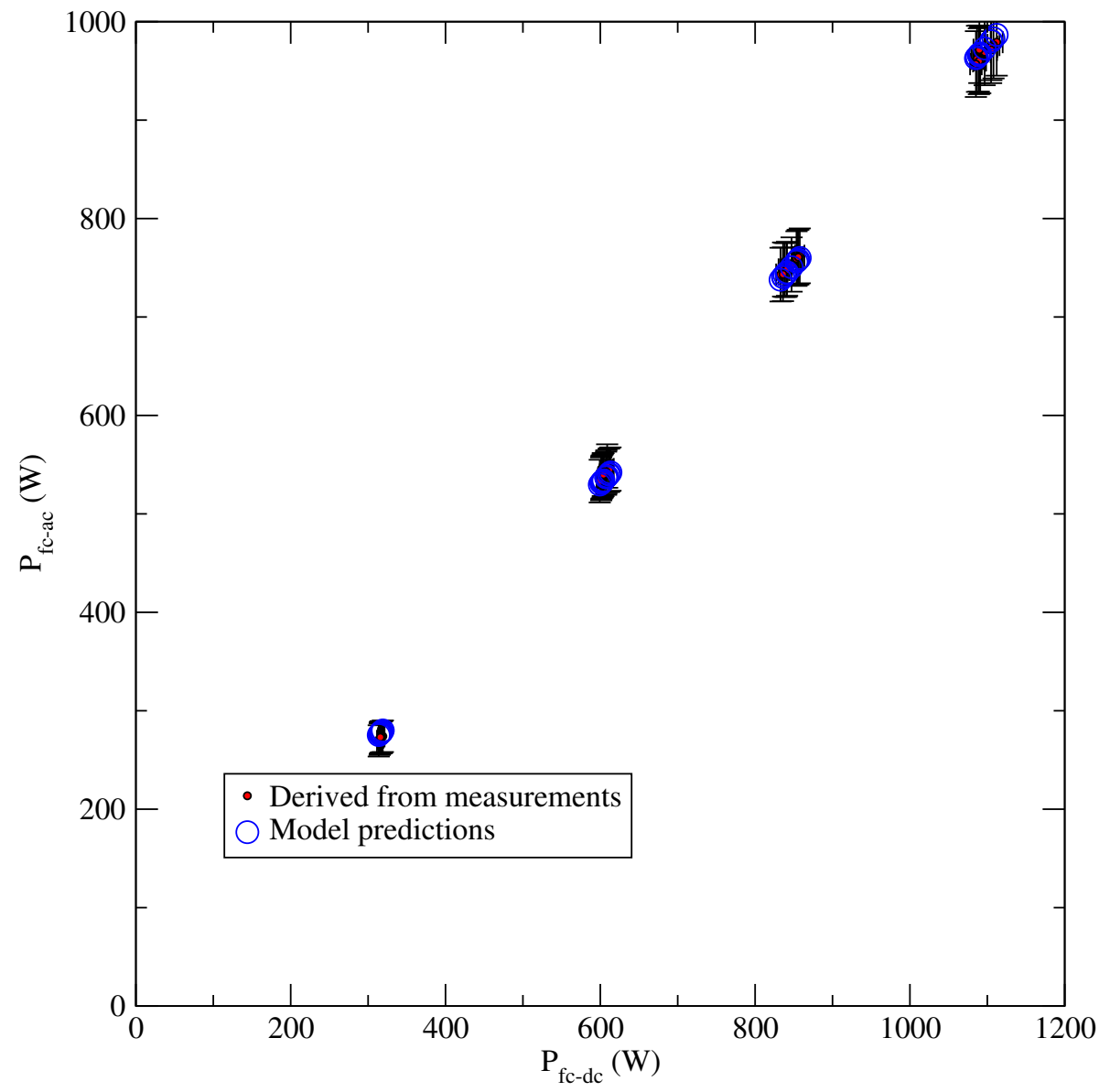

Figure 19: Test-averaged PEMFC net AC output for each of the 46 steady-state tests 
Figure 19 compares $P_{f c-a c}$ determined with equation 65 and the parameters of Table 12 with $P_{f c-a c}$ measurements. The following section summarizes the errors associated with using model equations $64-66$.

\subsubsection{Fuel-Cell Model Uncertainties}

Table 13 describes the uncertainty margins of the primary measurements and derived quantities used in model equations 64-66 in the measurement uncertainty column. For $q_{s-\text { cool }}$ and $T_{w-i n}$ there was a variation in the measurement uncertainty over the range of boundary conditions studied. The maximum value was selected as the measurement uncertainty for these cases. Beside it are the prediction uncertainties associated with using equations 64 to 66 .

\begin{tabular}{lll}
\hline Parameter & Measurement Uncertainty & Prediction Uncertainty \\
$\Phi_{k}$ & \multicolumn{2}{c}{$b_{i, \Phi_{k}}$} \\
\hline$P_{f c-d c}$ & $\pm 0.7 \% P_{f c-d c}$ & \\
$P_{f c-a c}$ & $\pm 3.2 \% P_{f c-a c}, \pm 13.4 \mathrm{~W}$ & $\pm 10.4 \mathrm{~W}$ \\
$\dot{E}_{f c-f u e l}$ & $\pm 1.2 \% \dot{E}_{f c-f u e l}$ & $\pm 43.3 \mathrm{~W}$ \\
$q_{s-c o o l}$ & $\pm 41.2 \mathrm{~W}$ & $\pm 54.1 \mathrm{~W}$ \\
$T_{w-i n}$ & $\pm 0.8{ }^{\circ} \mathrm{C}$ & \\
\hline
\end{tabular}

Table 13: PEMFC model parameter and prediction uncertainties

Here the prediction uncertainties are taken as the maximum residual observed between a measured value and a model prediction. For each parameter, all uncertain-

ties shown in Table 13 were treated as independent sources of bias $\left(b_{i, \Phi_{k}}\right)$ and were combined into a total bias $B_{\Phi_{k}}$ for the $\mathrm{k}^{\text {th }}$ parameter $\Phi_{k}$ according to the following 
equation given by Moffat (1988).

$$
B_{\Phi_{k}}=\sqrt{\sum_{i}\left(b_{i, \Phi_{k}}^{2}\right)}
$$

The values shown in Table 13 were used for the simulations described in Chapter 6. In Chapter 6 , the total bias of each individual parameter is propagated to calculate an overall bias for $B_{P I_{e l}}$ according to the following equation.

$$
B_{P I_{e l}}=\sqrt{\sum\left(\frac{\partial P I_{e l}}{\partial \Phi_{k}} \cdot B_{\Phi_{k}}\right)^{2}}
$$

For the simulations in Chapter 6, $B_{P I_{e l}}$ will be considered as the $95 \%$ confidence intervals of $P I_{e l}\left(U_{95, P I_{e l}}\right)$ for the simulation results of a particular DHW profile.

\subsection{Closing Remarks}

In this chapter an experimental program was conducted to obtain data to calibrate a PEMFC model with. To obtain a model form that would be suitable for the simulations described in Chapter 6, the Annex 42 model was adapted to a form that could be used to directly calculate the quantities necessary to determine the electrical performance index. Since the exact application of this model was known, the adapted model form along with the calibration data were selected so that uncertainties could be minimized. The developed model is intended to be used as a case study to represent the performance of a micro-cogeneration device to demonstrate the methodology being developed in this thesis. The experimental program demonstrated in this chapter could be repeated for other micro-cogeneration devices so that, in the future, they too could be considered using this methodology. The next chapter demonstrates how this methodology is performed using simulations for the previously defined case study. 


\section{Chapter 6}

\section{A Demonstration of the Developed}

\section{Methodology for Assessing the Energy \\ Performance of a Micro-Cogeneration}

\section{System by Considering the Results from a Simulation Based Case Study}

The preceding chapters described the models that were developed as part of the methodology being developed in this thesis. This chapter uses these models in simulations to demonstrate this methodology. An important aspect of this methodology is that the uncertainty of component models is taken into account and then propagated to the results of the simulations. This includes deriving uncertainty margins for the reference combined-cycle electrical efficiency. This aspect is also described in this chapter. This chapter is composed primarily of excerpts from Johnson et al. (2016) (under review). The majority of the writing and almost all of the ideas and analyses presented in this aforementioned paper were my own. The main exception to this was the contribution of my co-author, Adam Wills, who calculated the efficiency of 
the electrical transmission system. My supervisor, Ian Beausoleil-Morrison, provided feedback for the writing and for all of the ideas presented in this paper.

\subsection{Methodology}

The simulations performed will focus on the comparison of the energy performance between the two plant networks shown in Figure 20: a plant network representing the micro-cogeneration case and another representing the reference scenario. It is important to understand that both considered the same DHW profile on an energy basis. For every simulation time-step, the same amount of energy consumption was drawn from the TWH in the reference scenario as was drawn from the tank/auxiliary heater in the micro-cogeneration case.

The DHW profiles that were used in simulations were obtained from Edwards et al. (2015). These profiles are at a 5-minute timescale resolution and a 1 L DHW draw resolution. 12 DHW profiles were obtained, each containing 1 year's worth of data, A summary of the DHW consumption for each of these 12 DHW profiles is shown in Table 14 in both a volumetric $\left(\mathrm{L} \mathrm{day}^{-1}\right)$ and energy $\left(\mathrm{MJ} \mathrm{day}^{-1}\right)$ basis. Note that the house identifiers (H5, H11, H14 etc.) shown in Table 14 are not sequential but do correspond to the naming convention of the 12 profiles Edwards et al. (2015) made available. To convert the profiles from a volumetric to an energy basis a constant outlet temperature of $55{ }^{\circ} \mathrm{C}$ was assumed along with an assumed monthly mains temperature profile shown at the bottom of Table 14. Note that the profiles provided by Edwards et al. (2015) were gathered from storage tank water heaters and not TWHs, therefore, a constant outlet temperature assumption is reasonable for these conversions. Edwards et al. (2015) described these draw profiles in great detail and interested readers are referred to this work for more information. All simulations were conducted for the entire year. 


\begin{tabular}{|c|c|c|c|c|c|c|c|c|c|c|c|c|}
\hline House & H5 & H11 & H14 & H16 & H35 & H38 & $\mathrm{H} 43$ & H49 & $\mathrm{H} 52$ & H59 & H69 & $\mathrm{H} 73$ \\
\hline $\begin{array}{l}\text { DHW } \\
\left(\text { L day }^{-1}\right)\end{array}$ & 166 & 118 & 189 & 124 & 246 & 176 & 116 & 169 & 240 & 219 & 170 & 182 \\
\hline $\begin{array}{l}\text { DHW } \\
(\mathrm{MJ} \\
\left.\text { day }^{-1}\right)\end{array}$ & 30 & 22 & 34 & 23 & 45 & 32 & 21 & 31 & 44 & 40 & 31 & 33 \\
\hline Month & 1 & 2 & 3 & 4 & 5 & 6 & 7 & 8 & 9 & 10 & 11 & 12 \\
\hline mains $\left({ }^{\circ} \mathrm{C}\right)$ & 6.55 & 5.77 & 6.55 & 8.69 & 11.61 & 14.53 & 16.67 & 17.46 & 16.67 & 14.53 & 11.61 & 8.69 \\
\hline outlet $\left({ }^{\circ} \mathrm{C}\right)$ & 55 & 55 & 55 & 55 & 55 & 55 & 55 & 55 & 55 & 55 & 55 & 55 \\
\hline
\end{tabular}

Table 14: Summary of simulated individual DHW draw profiles

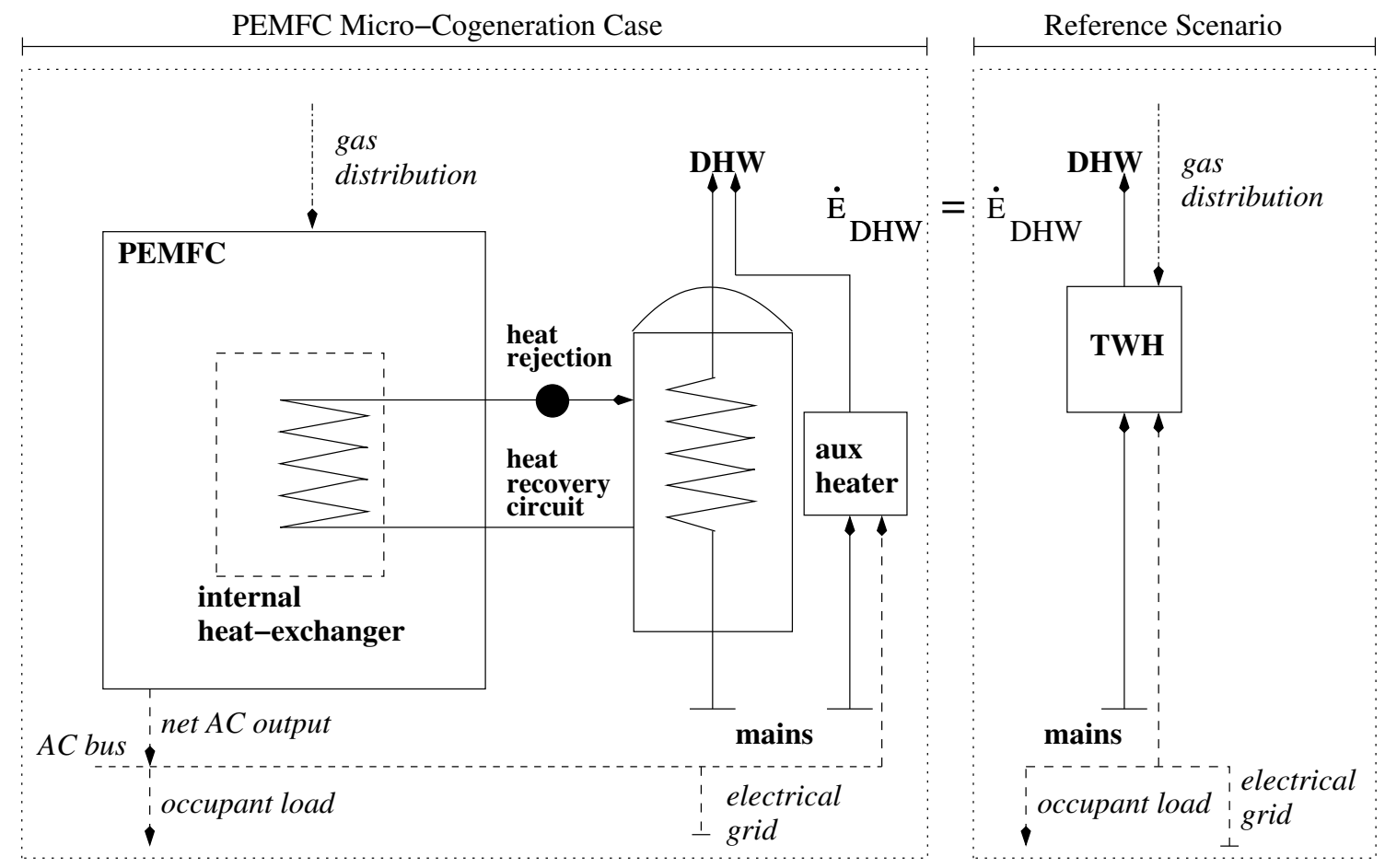

Figure 20: Micro-cogeneration plant network to be used in simulations 
The PEMFC obtains its natural gas fuel supply from the local gas distribution network. In the PEMFC micro-cogeneration case, the $\mathrm{AC}$ bus can interface with the electrical grid. Net AC output from the PEMFC can be consumed locally by the occupants or exported to the grid if there is excess production. The occupants can also consume grid electricity when the PEMFC's output is less than the occupants' demands.

For the simulations described in this section, it was not necessary to explicitly model the electricity demands of occupants for several reasons. First, the control mode described in Section 6.1.5 did not require any knowledge of the occupant's electrical demand at any moment. Second, it was assumed that any electrical production exported to the grid could be done so without any penalty. Therefore, it was not necessary to calculate how much of the PEMFC's electrical production was used on site and how much excess had to be exported to the grid. The sensitivity of the results to this assumption were addressed by the sensitivity case in Section 6.2.1 that considers more losses associated with making use of the distribution system. Finally, only the difference in the occupant demands for electricity between the reference scenario and the micro-cogeneration case needs to be considered to calculate the $P I_{e l}$ in equation 71. This difference is only caused by the difference between the electrical consumption of the TWH in the reference scenario and the auxiliary heater in the micro-cogeneration case. Note that the net electrical output of the PEMFC is also assumed to not impact occupant electrical demands.

If, for example, space heating was also served by the thermal output of the microcogeneration system then occupant electrical consumption would need to be considered in more detail. This is because the space-heating portion of the plant networks (not shown in Figure 20) may be controlled differently or have different component devices. This would result in additional differences in electrical consumption that should be accounted for, but their accounting is considered beyond the scope of this 
research. For the DHW only application in this research, the major differences in the plant network have been considered and should not result in any other significant differences in electrical consumption. For this application, the micro-cogeneration system components were sized based only on the DHW demands.

In the heat-recovery circuit, the thermal output obtained from the PEMFC's internal heat exchanger is circulated to a storage tank. When the incoming water's temperature to the internal-heat exchanger exceeds its limit of $59.1^{\circ} \mathrm{C}$, the PEMFC's thermal output is rejected.

DHW is drawn from the storage tank. For cases where the storage tank's temperature is less than $45^{\circ} \mathrm{C}$ and is insufficient to meet occupants' thermal comfort demands, the DHW is drawn from an auxiliary heater. It was later found in the simulations in Section 6.2 that when DHW consumption was less than $50 \mathrm{MJ}^{\mathrm{day}}{ }^{-1}$ this auxiliary heater provided less than $1 \%$ of the DHW demand and electrical production. Since it was rarely used in the most important region of DHW usage, it was conservatively assumed to be an electrical resistive heater that was powered from the electrical grid and was not modelled in detail. Here conservative assumptions are considered to be assumptions that are to the advantage of the reference scenario. The sensitivity of the results to this conservative assumption will be discussed in Section 6.2.1.

For a DHW only application, a reasonable reference scenario that the PEMFC micro-cogeneration case should be compared to is where the occupants' demands are entirely met by the electrical grid and a condensing TWH.

\subsubsection{Equivalent Electrical Performance Index Definition}

As was described in Chapter 3, an electrical performance index $\left(P I_{e l}\right)$ can be used as a metric to compare the energy performance of the micro-cogeneration case with the 
reference scenario. It is given by equation 71 .

$$
P I_{e l}=\frac{E_{f c-a c}-E_{e l-a u x}+E_{e l-t w h}}{E_{f c-f u e l}-E_{i n-t w h}}
$$

where $E_{f c-a c}$ is the AC electrical production of the PEMFC in kJ. $E_{e l-t w h}$ is the electrical consumption of the TWH in kJ. $E_{f c-f u e l}$ is the energy content associated with the fuel consumption of the PEMFC in kJ. $E_{i n-t w h}$ is the energy content associated with the fuel consumption of the TWH in kJ. $E_{\text {el-aux }}$ is the electrical consumption of the auxiliary heater in $\mathrm{kJ}$. This term is necessary because equation 19 from Chapter 3 requires the net electrical production from the micro-cogeneration case. Equation 71 is essentially equation 19 from Chapter 3 but adapted to this particular application.

\subsection{2 p-Value Definition}

All of the terms on the right side of equation 71 have uncertainty margins associated with them, therefore, the $P I_{e l}$ does as well. These margins can be used to determine the probability that the reference scenario efficiency exceeds the PEMFC micro-cogeneration case $\left(p\left(\zeta_{e l-r e f}>P I_{e l}\right)\right)$. This is termed the p-value. If this pvalue is small then it is likely that the micro-cogeneration case is more efficient than the reference scenario. For this research, if the p-value is less than 0.05 it will be assumed that the micro-cogeneration case is more efficient.

Equation 72 essentially states that to determine the p-value it is equivalent to determine the probability that the difference between $\zeta_{e l-r e f}$ relative to $P I_{e l}$ is greater than zero.

$$
p\left(\zeta_{e l-r e f}>P I_{e l}\right)=p\left(\zeta_{e l-r e f}-P I_{e l}>0\right)
$$


This probability can be assessed using the Standard Normal Distribution with corresponding $Z$ statistics according to equation 73 .

$$
p\left(\zeta_{e l-r e f}-P I_{e l}>0\right)=p\left(Z_{\zeta_{e l-r e f}-P I_{e l}}>0\right)
$$

where $Z_{\zeta_{e l-r e f}-P I_{e l}}$ can be found from equation 74 .

$$
Z_{\zeta_{e l-r e f}-P I_{e l}}=\frac{\zeta_{e l-r e f}-P I_{e l}}{\sigma_{\zeta_{e l-r e f}-P I_{e l}}}
$$

where the standard deviation of the difference between the reference scenario efficiency and the micro-cogeneration electrical performance index $\left(\sigma_{\zeta_{e l-r e f}-P I_{e l}}\right)$ can be found from the following equation.

$$
\sigma_{\zeta_{e l-r e f}-P I_{e l}}=\sqrt{\sigma_{P I_{e l}}^{2}+\sigma_{\zeta_{e l-r e f}}^{2}}
$$

where if the uncertainty margins on each of $\zeta_{e l-r e f}$ and $P I_{e l}$ are known at a $95 \%$ confidence level $\left(U_{95, P I_{e l}}\right.$ and $\left.U_{95, \zeta_{e l-r e f}}\right)$, the standard deviations may be found from the following two equations.

$$
\begin{gathered}
\sigma_{P I_{e l}}=\frac{U_{95, P I_{e l}}}{1.96} \\
\sigma_{\zeta_{e l-r e f}}=\frac{U_{95, \zeta_{e l-r e f}}}{1.96}
\end{gathered}
$$

To perform such an analysis, all of the uncertainties propagated from the models used to represent the various components in Figure 20 must be accounted for along with those of the reference scenario. Such a detailed accounting will be provided in the following sections. Throughout this analysis, in some cases, assumptions were used when it was not possible to evaluate either a parameter value or its uncertainty. The sensitivity of the results to these assumptions is described in Section 6.2.1. The next 
section describes how these components were modelled along with how the associated model uncertainties were handled.

\subsubsection{Plant Component Models}

\section{PEMFC Model}

The PEMFC model that was used is described in Chapter 5.

\section{Storage Tank}

The storage tank shown in Figure 20 was modelled using a lumped-heat-capacity approximation. This approximation neglects any effects of thermal stratification within the tank. This is a conservative assumption since if stratification were considered, cooler water at the bottom of the tank could be used to supply the inlet of the PEMFC's internal heat exchanger to increase the amount of heat recovered. The sensitivity of the results to this conservative assumption will be discussed in Section 6.2.1.

With this approximation, the governing differential equation of the tank can be solved using the following first-order finite difference approximation.

$$
T_{\text {tank }}^{i+1}=\frac{\Delta t}{\rho_{w} \cdot V_{\text {tank }} \cdot C_{w}}\left(q_{s-\text { cool }}^{i}-q_{D H W}^{i}-q_{\text {loss }}^{i}\right)+T_{\text {tank }}^{i}
$$

where $T_{\text {tank }}^{i}$ is the tank's temperature at the current time step and $T_{\text {tank }}^{i+1}$ is its value in the future time step. $\Delta t$ is the duration of the time step $(60 \mathrm{~s}) . V_{\text {tank }}$ is the volume of water stored in the tank in $\mathrm{kg} . C_{w}$ is the heat capacity of water within the tank. $\rho_{W}$ is the density of water stored in the tank.

In equation 78 all of the terms on the right side of the equation are evaluated at the current time step. These terms represent the heat transferred to the tank from the PEMFC $\left(q_{s-c o o l}\right)$, the heat transferred away from the tank from the DHW draws 
$\left(q_{D H W}\right)$ and the heat transferred away from the tank from the losses to the environment $\left(q_{\text {loss }}\right)$. This type of approach is often referred to as an explicit scheme. The standing loss of the tank $\left(q_{\text {loss }}\right)$ was calculated based on a cylindrical geometry, with a height-to-diameter ratio of 1.25 and a heat-loss coefficient of $0.38 \mathrm{Wm}^{-2}{ }^{\circ} \mathrm{C}^{-1}$ (corresponding to $10 \mathrm{~cm}$ of fiberglass insulation (Kopf, 2012)) in an ambient environment of $18^{\circ} \mathrm{C}$.

Since equation 78 is only an approximate solution there are numerical errors associated with its use for its calculations of $T_{\text {tank }}$. These have not been considered in detail for the following reasons. First, any error associated with $T_{\text {tank }}$ would propagate to erroneous values determined for $q_{s-\text { cool }}$ from equation 64 . However, when equation 64 was evaluated for the sensitivity case described in Section 6.2.1 where the PEMFC inlet temperature was fixed at $40{ }^{\circ} \mathrm{C}$, only a small change in the conclusions resulted. Second, any error associated with $T_{\text {tank }}$ would propagate to erroneous values calculated for $q_{\text {loss }}$. However, when $q_{\text {loss }}$ was evaluated for the sensitivity case in Section 6.2.2 where its heat-loss coefficient was reduced by half, only a small change in the conclusions resulted. Since these two sensitivity cases represent extreme scenarios it is unlikely that numerical errors associated with using the explicit scheme shown in equation 78 for the time step chosen would impact any conclusions drawn from the results of these simulations. Therefore these numerical errors were neglected.

\section{Tankless Water Heater Model}

For the reference scenario, the condensing TWH model developed by Johnson and Beausoleil-Morrison (2016) in Chapter 4 was used to predict the energy content associated with its fuel consumption. The individual uncertainties in the calibration parameters propagated to an overall model uncertainty of $\pm 5.5 \%$ for predictions of $E_{i n-t w h}$. It is also apparent that this model consistently under-predicts the energy consumption compared to the data from heaters measured in practice that it was 
validated against. At a maximum, the under-prediction was $8.7 \%$ in the region of interest here as was noted at the end of Section 4.3.8. Conservatively, this amount will be ignored. The sensitivity of the results to this conservative assumption will be discussed in Section 6.2.1.

Also, the TWH modelled in Chapter 4 predicted $E_{\text {in-twh }}$ based on DHW draw data gathered at a 1-second timescale resolution that were obtained from Bohac et al. (2010). This is in contrast to the profiles provided by Edwards et al. (2015) that were based on DHW draw data gathered at a 5-minute timescale resolution and were used in the simulations described in this chapter. The coarser timescale resolution data provided by Edwards et al. (2015) has the effect of artificially aggregating many separate smaller individual DHW draws into larger draws. This effect could potentially artificially enhance the TWH efficiency predicted by the model because in reality, a TWH heater performs less efficiently for draws of shorter duration. For these simulations here, to estimate the effect that using DHW data of coarser resolution has, the profiles from Bohac et al. (2010) were coarsened to a 5-minute timescale resolution and a $1 \mathrm{~L}$ draw resolution. When model predictions for $E_{i n-t w h}$ were compared at the two different resolutions, it was found that $E_{i n-t w h}$ at the coarser resolution should be multiplied by a factor of $1.016 \pm 0.015$ for daily DHW energy consumption levels greater than $30 \mathrm{MJ}$ day $^{-1}$.

The electrical consumption of the TWH $\left(E_{e l-t w h}\right)$ was also considered. This was modelled according to a relationship that was derived from data presented by Hoeschele and Weitzel (2013) for a condensing TWH and is presented below in the following equation.

$$
E_{e l-t w h}\left(\mathrm{MJ} \mathrm{day}^{-1}\right)=0.446+0.0147 \cdot E_{D H W}\left(\mathrm{MJ} \mathrm{day}^{-1}\right)
$$


Equation 79 expresses the electrical consumption as the sum of a fixed consumption and an amount of consumption that is related to the amount of daily DHW energy consumption $\left(E_{D H W}\right)$. The fixed consumption accounts for the parasitic electrical consumption that occurs when the TWH is inactive as was noted in Section 4.3.7. To evaluate the difference between the amount of electrical consumption of the TWH in the reference scenario and the auxiliary heater in the micro-cogeneration case $\left(E_{e l-t w h}-E_{e l-a u x}\right)$ in equation 71 it is assumed that the fixed consumption is the same in both scenarios; therefore, only the term related to use $\left(0.0147 \cdot E_{D H W}\right)$ was explicitly calculated. The overall contribution of this term is small to the numerator in equation 71 ; therefore, its associated uncertainty was neglected.

It should also be noted that $E_{i n-t w h}$ predicted by this model is based on the higher heating value $(H H V)$ of natural gas at $15^{\circ} \mathrm{C}$ and $101.325 \mathrm{kPa}$. Recall from Section 3.2 , to convert from this heating value reference to be consistent with the one used by the PEMFC model ( $L H V$ at $25^{\circ} \mathrm{C}$ and $101.325 \mathrm{kPa}$ ) a factor of 1.11 is appropriate.

\subsubsection{Reference Electrical Efficiency}

The methodology developed in Chapter 3 was used to calculate the reference electrical efficiency $\left(\zeta_{\text {el-plant }}\right)$ of a central combined-cycle plant. Recall that a gas-fired combined-cycle plant was selected as a suitable reference because it consumes the same type of fuel as a typical micro-cogeneration system. Table 15 describes the calculation of the highest electrical efficiency observed from a combined-cycle plant in Ontario, from 2011 to 2013. The bias of $\pm 5 \%$ for the $H H V$ (MOE, 2014) combined with the bias of $\pm 3 \%$ for $V_{\text {fuel-ref }}$ (DOJ, 2016) account for the uncertainty of the energy content associated with fuel consumption as described in Chapter 3.

The IESO (2013b) reported the uncertainty of their generator output data as \pm $10 \mathrm{MW}$. It is assumed that the IESO (2013b) knows when a plant is operating with negligible uncertainty. The yearly variation is a measure of the maximum amount 
that the efficiency in any single year may deviate from the value at the bottom of Table 15 (the 3-year efficiency) for a single plant. As there were only 3 years of available data for each plant, the sample was extended to the 6 largest combinedcycle plants without cogeneration in Ontario to determine the value shown for the yearly variation. The uncertainties of the energy content of fuel consumption, the yearly variation and the electrical production are combined to yield the uncertainty of the electrical efficiency shown at the bottom of Table 15.

\begin{tabular}{lll}
\hline Parameter Description & Value & Uncertainty \\
\hline Average Output & $315 \mathrm{MW}$ & $\pm 10 \mathrm{MW}$ \\
Hours of Operation & $10000 \mathrm{hrs}$ & none \\
Energy Content of Fuel Consumption $(L H V)$ & $21.3 \mathrm{PJ}$ & $\pm 5 \%, 3 \%$ \\
Yearly Variation & & $\pm 4 \%$ \\
Electrical Efficiency & 0.532 & \pm 0.041 \\
\hline
\end{tabular}

Table 15: Calculated reference electrical efficiency for a high-efficiency combinedcycle plant in Ontario, Canada from 2011 to 2013 and uncertainty margins

In comparison to a central combined-cycle plant, one advantage of a microcogeneration system that should be considered is that its electrical production is close in proximity to where it will be consumed. Therefore, a micro-cogeneration system will make no use of the electrical transmission system and limited use of the distribution system. The following equation defines the reference electrical efficiency that was considered against which the micro-cogeneration system was compared.

$$
\zeta_{e l-r e f}=\zeta_{e l-p l a n t} \cdot \zeta_{e l-t} \cdot \zeta_{e l-d}=0.501 \pm 0.039
$$

In equation 80, the reference electrical efficiency $\left(\zeta_{\text {el-ref }}\right)$ was defined as the product of the central combined-cycle plant efficiency $\left(\zeta_{\text {el-plant }}\right)$, the electrical transmission 
system efficiency $\left(\zeta_{e l-t}\right)$ and the distribution system efficiency $\left(\zeta_{e l-d}\right)$. The value at the far right of equation 80 was the $95 \%$ confidence interval $\left(U_{95, \zeta_{e l-r e f}}\right)$ used to determine the standard deviation in equation 77 .

It is important to consider that a micro-cogeneration system may make some use of the distribution system if not all of its electrical production can be consumed in close proximity to where it is located. It is also important to consider that a substantial portion of the losses within the distribution system in urban Ontario are no-load losses that are not directly related to its load and only to the system's existence. To investigate the effect of this, the sensitivity of the results when fewer losses in the distribution system are considered ( $\zeta_{e l-d}$ is increased) is discussed in Section 6.2.1.

\subsubsection{Control Mode}

The particular control mode that was selected represents an attempt to maximize the potential benefit of a micro-cogeneration system by minimizing the difference between the energy content associated with the fuel consumption for the case where microcogeneration is used relative to the reference scenario $\left(\Delta \dot{E}_{g a s}\right)$ as shown in equation 81.

$$
\Delta \dot{E}_{g a s}=\dot{E}_{f c-f u e l}-\frac{P_{f c-a c}}{\zeta_{e l-r e f}}-\frac{q_{s-c o o l}}{\zeta_{T W H}} \cdot \Psi
$$

Because not all of the thermal output of a PEMFC can be used for DHW (a portion is rejected), $q_{s-\text { cool }}$ is multiplied by a factor $(\Psi)$ in equation 81 that represents the percentage of $q_{s-\text { cool }}$ that may eventually be used for DHW. At each simulation time-step, the value of $P_{f c-d c}$ that was selected was that which minimized equation 81. 
Equation 81 is essentially equation 10 from Chapter 2 but with the following adaptations made for this control mode only. For this control mode only, the TWH efficiency $\left(\zeta_{T W H}\right)$ was taken as a constant $100 \%$. The selection of a particular $\zeta_{T W H}$ was not important as $\Psi$ was determined from an optimization procedure to be described in the following paragraphs. Although the particular value of $\zeta_{T W H}$ selected would affect the selection of $\Psi$, the optimization procedure would ensure that their quotient $\left(\frac{\Psi}{\zeta_{T W H}}\right)$ would be the same by adjusting $\Psi$ for any particular value of $\zeta_{T W H}$. Also for this control mode, it was assumed that the entire DHW thermal demand could be met without using an auxiliary source for the micro-cogeneration case. This was for simplicity, but was permissible because the auxiliary source was rarely needed. Finally, the displaced electrical consumption of the TWH was neglected as well. Again, this was for simplicity but was permissible because this value was small $(1.47 \%$ of the daily DHW thermal energy consumption).

In these simulations, the expression for $\Psi$ to be used in equation 81 was only approximated. The expression for $\Psi$ that was chosen is given by equation 82 .

$$
\Psi\left(T_{\text {tank }}\right)=\left\{\begin{array}{rr}
0, & T_{\text {tank }} \geq 59.1^{\circ} \mathrm{C} \\
\Psi_{0} \cdot\left(59.1^{\circ} \mathrm{C}-T_{\text {Tank }}\right), & 59.1{ }^{\circ} \mathrm{C}>T_{\text {tank }}>T^{*} \\
1, & T^{*}>T_{\text {Tank }}
\end{array}\right.
$$

The preceding equation assumes that if the tank temperature increased above the maximum permissible value of the PEMFC heat recovery circuit $\left(59.1^{\circ} \mathrm{C}\right)$ then none of the heat recovered is useful. Below a certain temperature $\left(T^{*}\right)$, all of the heat recovered is useful. Between these two temperatures there is a linear transition region where $\Psi_{0}$ is a parameter determined from optimization. For the preceding equation $T^{*}=59.1^{\circ} \mathrm{C}-\Psi_{0}^{-1}$. 
For the optimization procedure, a Hooke-Jeeves algorithm (Wetter, 2009) was used. This algorithm requires fewer iterations to converge on an optimal solution than others (e.g. a particle swarm algorithm); however, the disadvantage is that it might converge on a local rather than a global optimum. However, it was found that for the optimizations performed here the final converged solutions did not depend on initial conditions. Therefore, the optimal solutions found were global.

As the most profligate of the 12 profiles only demanded approximately $45 \mathrm{MJ}$ day $^{-1}$ of DHW in the simulated year, to estimate how demands of greater consumption levels might have performed, every combination of 2 of the 12 profiles was also considered in these simulations. Note that Edwards et al. (2015) defined profligate consumption to be near the $80^{\text {th }}$ percentile of consumption levels observed in their sample. In total, 78 DHW profiles were simulated. The profiles that are combinations are representative of the DHW demand that would be appropriate for an application where the DHW demands of two sets of occupants are supplied by a single system.

The objective of the optimization was to maximize the average $P I_{e l}$ of three of the 78 DHW profiles. The three selected profiles had DHW consumptions of approximately $50 \mathrm{MJ} \mathrm{day}^{-1}$. This optimization process was also repeated for a group of consumers with $40 \mathrm{MJ}$ day $^{-1}$ of DHW consumption. Although the optimized parameters determined from this were slightly different, the results described in Section 6.2 were insensitive to these alternative values so they were not used. The optimization was performed for profiles for these DHW consumption levels because it was found through repeated simulations that between these values of DHW consumption levels the lowest consumption levels where $p\left(\zeta_{\text {el-ref }}>P I_{e l}\right)<0.05$ would occur.

The optimum storage tank volume found from the $50 \mathrm{MJ}^{\text {day }}{ }^{-1}$ consumption profiles was $1500 \mathrm{~L}$ and $\Psi_{0}$ was determined to be $0.06{ }^{\circ} \mathrm{C}^{-1}$. These optimized parameters were effective at reducing the amount of heat rejected to zero for all simulated DHW 
profiles with greater than $30 \mathrm{MJ}$ day $^{-1}$ of consumption; however, the standing loss of the tank was approximately $8 \mathrm{MJ}$ day $^{-1}$ for all cases.

\subsection{Results}

The results from 1 sample day for 1 of the 78 domestic hot water profiles that was simulated are shown in Figure 21. For this sample profile, the daily average DHW consumption was approximately $40 \mathrm{MJ}$ day $^{-1}$. At the top of this figure, the temperature of the storage tank and TWH are plotted. At the bottom of this figure, the rates of various energy inputs and outputs relevant to the plant network shown in Figure 20 are plotted. The top and bottom of this figure share a common abscissa that represents the number of minutes from the start of this sample day.

For the graph at the bottom of Figure 21, note that the ordinate on the left side of this graph applies to the rates of energy input and output for the TWH. Also note that the rate of energy output for the TWH is equivalent to that of the DHW drawn in a particular time step. Here a single DHW draw is defined as a continuous period of time over which DHW is drawn. Only the average rate of energy input and output over a DHW draw are plotted.

The ordinate on the right side the graph at the bottom of Figure 21 applies to all the other series plotted on this graph (PEMFC fuel consumption, PEMFC AC output, PEMFC thermal output and heat loss of the tank). This second ordinate was only necessary so that these other series could be represented on the same graph as the TWH input and output that are an order of magnitude greater.

For periods of time between DHW draws, it can be seen that the tank's temperature rises slowly while the TWH's temperature decays exponentially. The result from this slow increase in tank temperature is that the control mode directs the PEMFC to modulate its output so that its fuel consumption, thermal and $\mathrm{AC}$ output decrease 


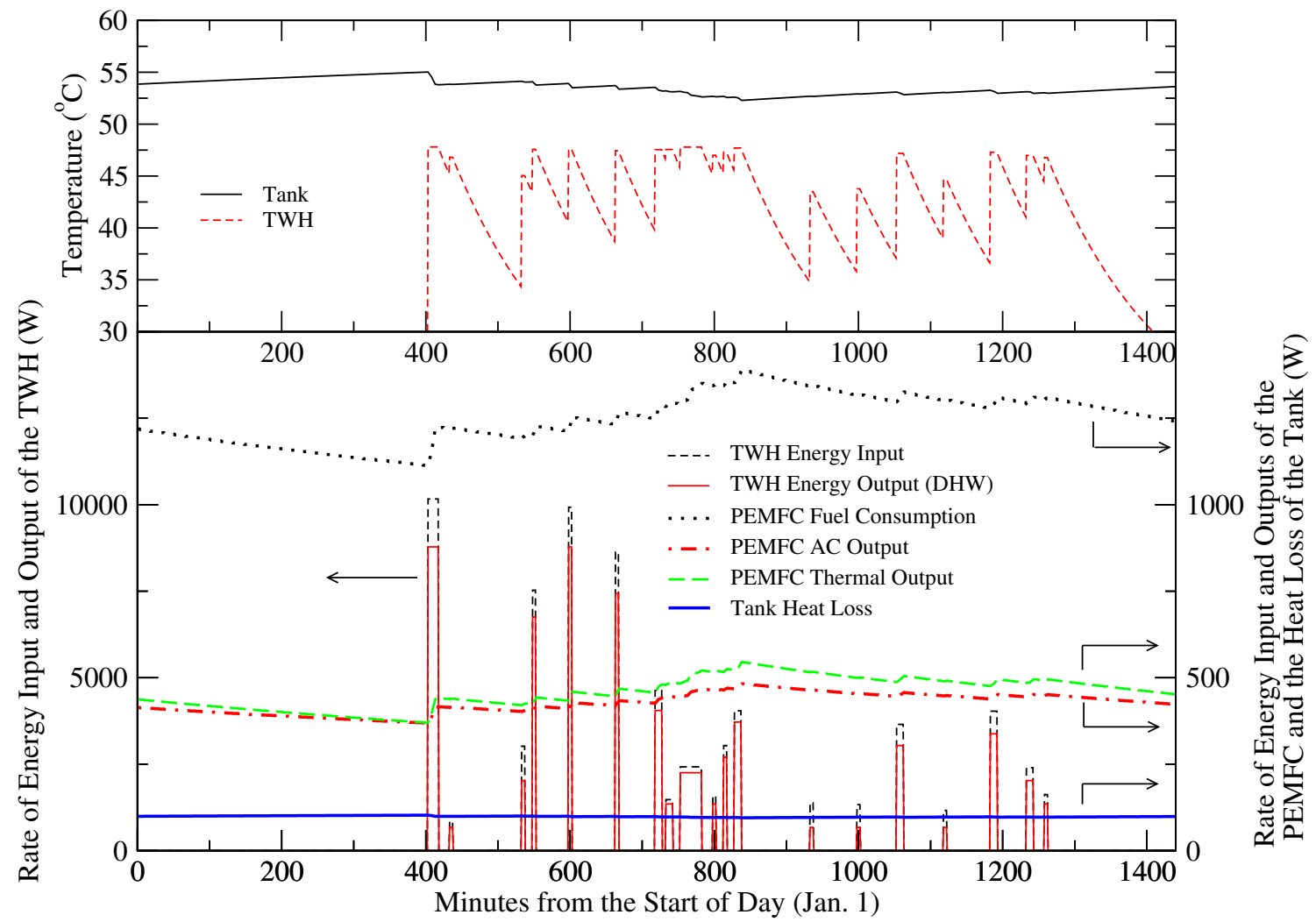

Figure 21: Temporal results for 1 sample day for 1 of the 78 domestic hot water profiles that was simulated 
at a similar rate. While difficult to resolve from the scale of the graph, the tank's temperature increase during these periods also causes the heat loss to increase as well.

During DHW draw periods, the temperature of the tank decreases suddenly. The result from this is that the control mode directs the PEMFC to modulate its output so that its fuel consumption, thermal and AC output increase suddenly as well. The TWH temperature suddenly rises during these periods to reach its setpoint. During these firing periods, the TWH temperature at the end of each firing period is shown to represent the temperature of the TWH for the entire firing period.

The annual results of the simulations of the 78 DHW profiles with the optimized model parameters and the most conservative assumptions are summarized in Figure 22. The DHW consumption of each profile is shown along the abscissa while the $P I_{e l}$ of the micro-cogeneration system and its corresponding $p\left(\zeta_{e l-r e f}>P I_{e l}\right)$ are shown along the ordinates. The error bars shown on the $P I_{e l}$ markers represent the $95 \%$ uncertainty margins.

As can be seen from Figure 22, the $P I_{e l}$ of the micro-cogeneration case begins to exceed $\zeta_{r e f-e l}$ for DHW consumption levels greater than approximately 35 MJ day $^{-1}$ (approximately $190 \mathrm{~L} \mathrm{day}^{-1}$ ). However, when uncertainty margins are taken into account, the $P I_{e l}$ reliably $\left(p\left(\zeta_{e l-r e f}>P I_{e l}\right)<0.05\right)$ outperforms the reference scenario when DHW consumption exceeds $50 \mathrm{MJ}$ day $^{-1}$ (approximately $280 \mathrm{~L}_{\text {day }}{ }^{-1}$ ). This level of consumption is in excess of even a profligate single DHW profile. Note that the scatter that can observed for $P I_{e l}$ and for $p\left(\zeta_{e l-r e f}>P I_{e l}\right)$ from Figure 22 between profiles with similar consumption levels is due to differences in the temporal distribution of the DHW draws between the profiles. 


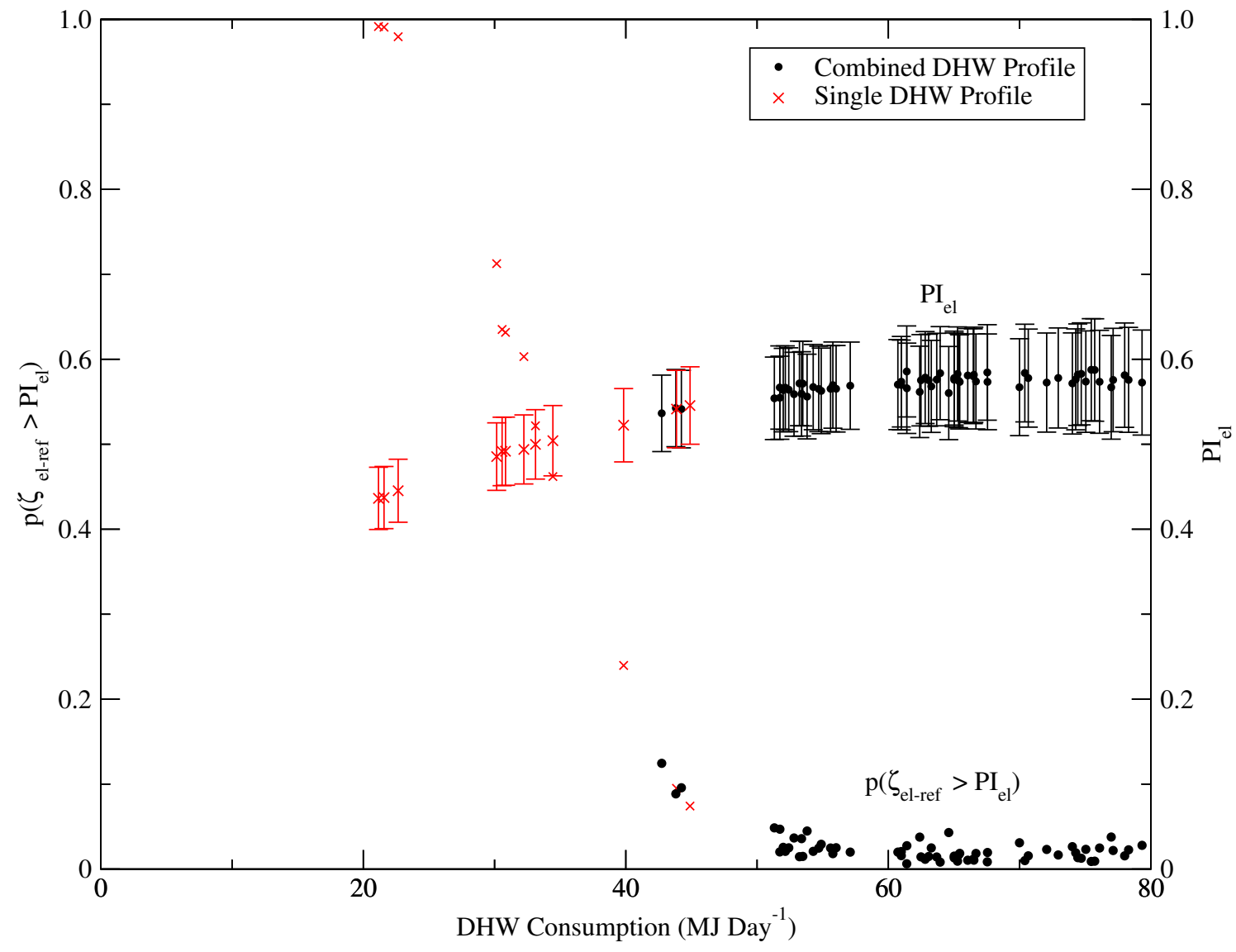

Figure 22: PEMFC electrical performance index and the probability that it does not exceed the reference electrical efficiency versus DHW consumption 


\subsubsection{Sensitivity of Results to Assumptions}

To investigate how other assumptions might influence the aforementioned results, the following sensitivity analyses were performed. For each of the following cases, first a different assumption was made. This was followed by an optimization to determine $\Psi_{0}$ and $V_{\text {tank }}$ under the different assumption. The simulations were then performed with the different assumption to determine the DHW consumption level where $p\left(\zeta_{\text {el-ref }}>P I_{e l}\right)<0.05$.

Some distribution loss may not be avoided by using a micro-cogeneration system. As a more conservative assumption, only half of the benefit the distribution efficiency provides was considered. Under this assumption, it was found that at $55 \mathrm{MJ} \mathrm{day}^{-1}$ of DHW consumption the micro-cogeneration case reliably outperforms the reference scenario $\left(p\left(\zeta_{e l-r e f}>P I_{e l}\right)<0.05\right)$.

Tank stratification might influence this analysis. As a less-conservative assumption, the water inlet temperature of the fuel cell was always set to $40{ }^{\circ} \mathrm{C}$. Below this value the amount of thermal output recovered does not increase substantially. Under this assumption, it was found that at $42 \mathrm{MJ}^{\mathrm{day}}{ }^{-1}$ of DHW consumption the micro-cogeneration case reliably outperforms the reference scenario $\left(p\left(\zeta_{e l-r e f}>P I_{e l}\right)<0.05\right)$. Tank stratification might also allow the tank's size to be reduced since colder water at the bottom of the tank could be used to supply the PEMFC and would, therefore, allow the average tank temperature where heat rejection occurs to be increased above $59.1^{\circ} \mathrm{C}$. This would increase the amount of energy that can be stored within a tank of a given size and therefore reduce the tank's heatloss to the environment. However, as will be shown in Section 6.2.2, reducing these losses does not improve the micro-cogeneration system's performance significantly.

Modelling tank stratification would require a more sophisticated tank model than the lumped-heat-capacity approximation used. However, the objective of this research 
was to develop a methodology to evaluate the energy potential of a fuel-cell system that considers model uncertainties and to demonstrate its utility. Since the preceding results clearly demonstrated that by ignoring uncertainties dubious conclusions can be drawn (i.e. that the considered micro-cogeneration case is more efficient than the reference at average levels of DHW consumption) and that modelling stratification in more detail will not affect the results significantly, performing simulations with a stratified tank model was considered outside of the scope of this present research.

The TWH model may be over-predicting its energy input by as much as $8.7 \%$ in the DHW consumption regions of interest here. As a less conservative assumption, $E_{T W H}$ was multiplied by $1 /(1-0.087)$. Under this assumption, it was found that at $42 \mathrm{MJ}$ day $^{-1}$ of DHW consumption the micro-cogeneration case reliably outperforms the reference scenario $\left(p\left(\zeta_{e l-r e f}>P I_{e l}\right)<0.05\right)$.

The auxiliary heater was assumed to be an electrical resistance heater. As a less-conservative assumption, it was assumed to be a natural gas heater with $100 \%$ efficiency (HHV). Under this assumption, it was found that at $45 \mathrm{MJ}^{-1 a y}{ }^{-1}$ of DHW consumption the micro-cogeneration case reliably outperforms the reference scenario $\left(p\left(\zeta_{e l-r e f}>P I_{e l}\right)<0.05\right)$.

When all 3 previous less conservative assumptions were applied to the same simulation, after optimization, it was found that at $38 \mathrm{MJ}^{\mathrm{day}}{ }^{-1}$ of $\mathrm{DHW}$ consumption the micro-cogeneration case reliably outperforms the reference scenario $\left(p\left(\zeta_{e l-r e f}>P I_{e l}\right)<0.05\right)$. While this is characteristic of an average DHW consumer, it represents an extremely optimistic scenario from the perspective of the micro-cogeneration system. 


\subsubsection{Technological Advancements that Could Improve the Performance of the Considered Micro-Cogeneration System}

The methodology developed in this thesis can also be used to explore what types of technological advancements could help reduce the DHW consumption level where the micro-cogeneration case reliably outperforms the reference scenario. For each of the following cases, first a technological advancement was implemented in the plant network. This was followed by an optimization to determine $\Psi_{0}$ and $V_{\text {tank }}$ for the advancement. The simulations were then performed with the advancement to determine the DHW consumption level where $p\left(\zeta_{e l-r e f}>P I_{e l}\right)<0.05$.

As a technological advancement, it is interesting to consider what effect reducing tank losses would have. At approximately $8 \mathrm{MJ}$ day $^{-1}$, the tank losses account for a significant portion of the PEMFC's thermal output as can also be seen from Figure 21. When the tank losses were reduced by $50 \%$, it was found that at $45 \mathrm{MJ}$ day $^{-1}$ of DHW consumption the micro-cogeneration case reliably outperforms the reference scenario $\left(p\left(\zeta_{e l-r e f}>P I_{e l}\right)<0.05\right)$.

One potential area where the performance of the PEMFC might be improved is its electrical efficiency. As a technological advancement, the PEMFC's AC electrical efficiency was improved by a relative increase of $5 \%$ (e.g. nominal efficiency of $33.6 \%$ to $35.3 \%$ ). With this advancement, it was found that at $42 \mathrm{MJ}^{-1 a y}{ }^{-1}$ of $\mathrm{DHW}$ consumption the micro-cogeneration case reliably outperforms the reference scenario $\left(p\left(\zeta_{e l-r e f}>P I_{e l}\right)<0.05\right)$.

Of these two technological advancements, the improved AC electrical efficiency is more realistically achievable as it only involves an incremental improvement compared to the more substantial reduction in tank losses. Improving the $\mathrm{AC}$ efficiency is also more effective at reducing the DHW consumption level where the PEMFC 
reliably outperforms the reference scenario. With this incremental improvement, this PEMFC is potentially viable for serving a DHW only application for a profligate $\left(80^{\text {th }}\right.$ percentile) consumer. 


\section{Chapter 7}

\section{Conclusions and Future Work}

The overall objective of this thesis was to develop a more defensible methodology to determine whether the energy performance of a micro-cogeneration system was an improvement over conventional methods for satisfying residential thermal and electrical demands. From the literature reviewed, it was clear that while many researchers were comparing the performance of micro-cogeneration systems to more conventional technologies using building performance simulation, little attention was paid to the uncertainties associated with their results. Therefore, a more defensible methodology would consider these uncertainties and for this thesis such a methodology was developed.

To demonstrate this methodology, a case study that considered a PEMFC serving only DHW needs was considered as the micro-cogeneration system for the jurisdiction of Ontario. For this jurisdiction, first an efficient reference scenario had to be defined so that its performance could be compared to the micro-cogeneration system's. For this comparison, it is reasonable to consider the performance of a central gas-fired combined-cycle plant as the reference scenario as it consumes the same type of fuel as a typical micro-cogeneration system. Government data were used to derive the electrical efficiency of an efficient central combined-cycle plant without cogeneration along with the associated uncertainty margins to be used for this reference. 
It might also be the case that a combined-cycle without cogeneration is not the most efficient reference scenario. Central cogeneration plants may be more efficient; however, data describing the amount of thermal output from these plants are currently unavailable to the public and without these data it is not possible to know with more certainty. It would also be a significant advancement if the Ontario government would release better data to the public describing the performance of electrical distribution systems.

In addition to an electrical efficiency, the reference scenario also required a model of an efficient conventional method for satisfying occupant thermal demands. For this, a model of a condensing TWH was sought so that the amount of its fuel consumption that might be displaced by the thermal output of a micro-cogeneration system could be calculated. This necessitated an experimental program where data were gathered to calibrate the developed model form. This model was also validated against data emanating from a separate field-trial. In addition to accounting for the impact of DHW consumption patterns on the efficiency of the TWH, this model also allowed for the uncertainty margins of its predictions to be estimated.

Further experimental work was necessary to model the electrical and thermal output along with the fuel consumption of a PEMFC based micro-cogeneration system. Data gathered from this program were used to calibrate a derivative of the model developed by Annex 42. The model that was used also allowed for the uncertainty margins of its predictions to be estimated.

An electrical performance index was identified as a suitable metric that could be used to account for the benefit of producing both electrical and thermal output from a micro-cogeneration system. If this metric exceeded the reference scenario's electrical efficiency, fuel would be consumed more efficiently in the micro-cogeneration system. 
For all of the previously described experimental work and for the determination of the reference electrical efficiency, it was necessary to account for all of the uncertainties. By considering these uncertainties, the probability that the reference electrical efficiency exceeded the electrical performance index of the micro-cogeneration system was calculated. This concept was central to the new methodology that was developed in this thesis. This methodology was demonstrated using simulations for the case study that considered the previously described PEMFC model and reference scenario relevant to the jurisdiction of Ontario. The results of these simulations based on this methodology have established a range of DHW consumption values where the micro-cogeneration system is viable.

Had uncertainties been neglected, it would have been possible to conclude that the considered micro-cogeneration system was viable for serving only the DHW of an average level of consumption. However, when uncertainties were considered the analysis demonstrated that it is unlikely that the micro-cogeneration device considered here is viable in Ontario, Canada if its thermal output serves only DHW demands; additional uses are required for the thermal output to make it viable (e.g. space heating or load sharing between houses). Therefore, uncertainties are an important aspect to consider in these types of analyses as they can significantly alter the conclusions that are drawn from them.

Some exploratory simulations were conducted to determine what types of technological advancements might be required for the PEMFC considered in the case study to more likely be viable. From these simulations, it was found that an incremental improvement to the electrical efficiency (a relative efficiency increase of 5\%) allowed the considered PEMFC to be viable for profligate consumers of DHW. This is an indication that an application where a micro-cogeneration system serves only DHW may become viable in the future in Ontario. 
The models that have been developed for this thesis have been presented with enough detail to be useful to other researchers. The TWH model can be used by other researchers to calculate the energy savings associated with using any other innovative energy conversion system to provide DHW demands (e.g. solar DHW). The PEMFC model can be used by other researchers studying fuel cell micro-cogeneration systems. The method that was used to derive the electrical efficiencies of gas-fired power plants in Ontario may be useful to other researchers studying power generation systems in this jurisdiction if the lack of a more obvious source of data for this persists.

Future research should concentrate on experimentally characterizing the performance of more recent micro-cogeneration systems. Data gathered from these experimental programs could then be used to calibrate models so that the methodology developed in this thesis could be repeated. Although the case study considered in this thesis has focused on PEMFC micro-cogeneration devices, the methodology developed here could be applied to any type of prime-mover. It would also be interesting to repeat the methodology developed here for other jurisdictions. If in the future gas is discontinued as a fuel source for power generation in Ontario, the methodology developed in this thesis would still be relevant to other jurisdictions that continue to use it. 


\section{References}

Adam, A., Fraga, E., and Brett, D., 2013. Modelling and optimisation in terms of $\mathrm{CO}_{2}$ emissions of a solid oxide fuel cell based micro-CHP system in a four bedroom house in London. Energy Procedia, 42:201-209.

Aguiar, P., Adjiman, C., and Brandon, N., 2004. Anode-supported intermediate temperature direct internal reforming solid oxide fuel cell. I: model-based steadystate performance. Journal of Power Sources, 138:120-136.

Ahmed, S., Papadias, D., and Ahluwalia, R., 2013. Configuring a fuel cell based residential combined heat and power system. Journal of Power Sources, 242:884894.

Anindito, S., Entchev, E., Kang, E., and Lee, E., 2013. Implementation of spreadsheet modeling to compare the annual energy performance and cost of microgeneration systems. In Proc. Third International Conference on Microgeneration and Related Technologies, Naples, Italy.

Arpino, F., Massarotti, N., Mauro, A., and Vanoli, L., 2011. Metrological analysis of the measurement system for a micro-cogenerative SOFC module. International Journal of Hydrogen Energy, 36:10228-10234. 
Arpino, F., Dell'Isola, M., Maugeri, D., Massarotti, N., and Mauro, A., 2013a. A new model for the analysis of operating conditions of micro-cogenerative SOFC units. International Journal of Hydrogen Energy, 38:336-344.

Arpino, F., Frattolillo, M., Dell'Isola, M., Massarotti, N., Mauro, A., and Vanoli, L., 2013b. Experimental and numerical analysis of solid oxide fuel cell based microcogenerative units. In Proc. Third International Conference on Microgeneration and Related Technologies, Naples, Italy.

Arsalis, A., Nielsen, M., and Kær, S., 2011a. Modeling and parametric study of a 1kWe HT-PEMFC-based residential micro-CHP system. International Journal of Hydrogen Energy, 36:5010-5020.

Arsalis, A., Nielsen, M., and Kær, S., 2011b. Modeling and off-design performance of a 1kWe HT-PEMFC (high temperature-proton exchange membrane fuel cell)-based residential micro-CHP (combined-heat-and-power) system for Danish single-family households. Energy, 36:993-1002.

Arsalis, A., Nielsen, M., and Kær, S., 2012. Modeling and optimization of a 1kWe HTPEMFC-based micro-CHP residential system. International Journal of Hydrogen Energy, 37:2470-2481.

Arsalis, A., Nielsen, M., and Kær, S., 2013. Application of an improved operational strategy on a PBI fuel cell-based residential system for Danish single-family households. Applied Thermal Engineering, 50:704-713.

Arsalis, A., Kær, S., and Nielsen, M., 2015. Modeling and optimization of a heat-pump-assisted high temperature proton exchange membrane fuel cell microcombined-heat-and-power system for residential applications. Applied Energy, 147: $569-581$. 
Barelli, L., Bidini, G., Gallorini, F., and Ottaviano, A., 2011. Analysis of the operating conditions influence on PEM fuel cell performances by means of a novel semi-empirical model. International Journal of Hydrogen Energy, 36:10434-10442.

Barelli, L., Bidini, G., Gallorini, F., and Ottaviano, A., 2012. Dynamic analysis of PEMFC-based CHP systems for domestic application. Applied Energy, 91:13-28.

Beausoleil-Morrison, I., editor. Experimental Investigation of Residential Cogeneration Devices and Calibration of Annex 42 Models. IEA/ECBCS Annex 42 Report, 2007. ISBN No. 978-0-662-47523-1.

Beausoleil-Morrison, I., editor. An Experimental and Simulation-Based Investigation of the Performance of Small-Scale Fuel Cell and Combustion-Based Cogeneration Devices Serving Residential Buildings. IEA/ECBCS Annex 42 Report, 2008. ISBN No. 978-0-662-47924-6.

Beausoleil-Morrison, I., 2010. The empirical validation of a model for simulating the thermal and electrical performance of fuel cell micro-cogeneration devices. Journal of Power Sources, 195:1416-1426.

Beausoleil-Morrison, I. and Lombardi, K., 2009. The calibration of a model for simulating the thermal and electrical performance of a $2.8 \mathrm{~kW}_{A C}$ solid-oxide fuel-cell micro-cogeneration device. Journal of Power Sources, 186:67-79.

Beausoleil-Morrison, I., Schatz, A., and Maréchal, F., 2006. A model for simulating the thermal and electrical production of small-scale solid-oxide fuel cell cogeneration systems within building simulation programs. HVACERR Research Special Issue, 12 (3a):641-667.

Belvedere, B., Bianchi, M., Borghetti, A., De Pascale, A., Paolone, M., and Vecci, R., 2013. Experimental analysis of a PEM fuel cell performance at variable load 
with anodic exhaust management optimization. International Journal of Hydrogen Energy, 38:385-393.

Bianchi, M., De Pascale, A., and Ruggero Spina, P., 2012. Guidelines for residential micro-CHP systems design. Applied Energy, 97:673-685.

Bianchi, M., De Pascale, A., and Melino, F., 2013. Performance analysis of an integrated CHP system with thermal and electric energy storage for residential application. Applied Energy, 112:928-938.

Bianchi, M., De Pascale, A., Melino, F., and Peretto, A., 2014. Performance prediction of micro-CHP systems using simple virtual operating cycles. Applied Thermal Engineering, 71:771-770.

Bohac, D., Schoenbauer, B., Hewett, M., Lobenstein, M., and Butcher, T., 2010. Actual savings and performance of natural gas tankless water heaters. Technical report, Center for Energy and Environment.

Boigues-Muñoz, C., McPhail, S., Cinti, G., Penchini, D., and Polonara, F., 2013. Comparitive experimental and technical-economic evaluation of a $1 \mathrm{~kW}_{e l}$ vs. 2.5 $\mathrm{kW}_{\text {el }}$ tubular SOFC system for residential applications. ECS Transactions, 57: $99-104$

Boigues-Muñoz, C., Santori, G., McPhail, S., and Polonara, F., 2014. Thermochemical model and experimental validation of a tubular SOFC cell comprised in a 1 $\mathrm{kW}_{\text {el }}$ stack designed for $\mu \mathrm{CHP}$ applications. International Journal of Hydrogen Energy, 39:21714-21723.

Boigues-Muñoz, C., Pumiglia, D., McPhail, S., Montinaro, D., Comodi, G., Santori, G., Carlini, M., and Polonara, F., 2015a. More accurate macro-models of solid 
oxide fuel cells through electrochemical and microstructural paramater estimation - Part 1: Experimentation. Journal of Power Sources, 294:658-668.

Boigues-Muñoz, C., Pumiglia, D., McPhail, S., Santori, G., Montinaro, D., Comodi, G., Carlini, M., and Polonara, F., 2015b. More accurate macro-models of solid oxide fuel cells through electrochemical and microstructural paramater estimation - Part 2: Parameter estimation. Journal of Power Sources, 286:321-329.

Boscaino, V., Miceli, R., and Capponi, G., 2013. MATLAB-based simulator of a $5 \mathrm{~kW}$ fuel cell for power electronics design. International Journal of Hydrogen Energy, $38: 7924-7934$.

Boucher, E. The design and commissioning of a micro-cogeneration testing facility. Master's thesis, Carleton University, Ottawa Canada, 2013.

Bourke, G. and Bansal, P., 2012. New test method for gas boosters with domestic solar water heaters. Solar Energy, 86:78-86.

Bourke, G., Bansal, P., and Raine, R., 2014. Performance of gas tankless (instantaneous) water heaters under various international standards. Applied Energy, 131: $468-478$.

Brett, D., Aguiar, P., and Brandon, N., 2006. System modelling and integration of an intermediate temperature solid oxide fuel cell and ZEBRA battery for automotive applications. Journal of Power Sources, 163:514-522.

Burch, J., Thornton, J., Hoeschele, M., Springer, D., and Rudd, A., 2008. Preliminary modeling, testing and analysis of a gas tankless water heater. In Proc. SOLAR, San Diego, United States.

Butcher, T. and Schoenbauer, B., 2011. Application of a linear input/output model to tankless water heaters. ASHRAE Transactions, 117:683-689. 
Canelli, M., Entchev, E., Sasso, M., Yang, L., and Ghorab, M., 2015. Dynamic simulations of hybrid energy systems in load sharing application. Applied Thermal Engineering, 78:315-325.

Cao, S., Mohamed, A., Hasan, A., and Sirén, K., 2014. Energy matching analysis of on-site micro-cogeneration for a single-family house with thermal and electrical tracking strategies. Energy and Buildings, 68:351-363.

Chase, D. and Kehoe, P., 2015. GE combined-cycle product line and performance. Technical report, General Electric. http://www.ge-energy.com/ - Accessed Aug. 2016.

Chen, X., Gong, G., Wan, Z., Luo, L., and Wan, J., 2015. Performance analysis of $5 \mathrm{~kW}$ PEMFC-based residential micro-CHP with absorption chiller. International Journal of Hydrogen Energy, 40:10647-10657.

CIEEDAC, 2014. Canadian industrial energy end-use data and analysis centre. Technical report, Simon Fraser University. http://www3.cieedac.sfu.ca/CIEEDACweb/ - Accessed Aug. 2016.

Colpier, U. C. and Cornland, D., 2002. The economics of the combined cycle gas turbine-an experience curve analysis. Energy Policy, 30(4):309-316.

Comodi, G., Cioccolanti, L., and Renzi, M., 2014. Modelling the Italian household sector at the municipal scale: Micro-CHP, renewables and energy efficiency. Energy, 68:92-103.

Contreras, A., Posso, F., and Guervos, E., 2010. Modelling and simulation of the utilization of a PEM fuel cell in the rural sector of Venezuela. Applied Energy, 87: $1376-1385$. 
Cooper, S., Hammond, G., McManus, M., Ramallo-Gonzles, A., and Rogers, J., 2014. Effect of operating conditions on performance of domestic heating systems with heat pumps and fuel cell micro-cogeneration. Energy and Buildings, 70:52-60.

DeMoss, T., 1996. They're he-e-re (almost): the 60\% efficient combined cycle. Power Engineering, 100(7):17-21.

Di Marcoberardino, G., Roses, L., and Manzolini, G., 2016. Technical assessment of a micro-cogeneration system based on polymer electrolyte membrane fuel cell and fluidized bed autothermal reformer. Applied Energy, 162:231-244.

DOJ, 2016. Electricity and gas inspection regulations - part ix - limits of error. Technical report, Department of Justice. http://laws-lois.justice.gc.ca - Accessed Aug. 2016.

Dorer, V. and Weber, A. Methodologies for the Performance Assessment of Residential Cogeneration Systems. IEA/ECBCS Annex 42 Report, 2007. ISBN No. 978-0-662-46951-3.

Edwards, S., Beausoleil-Morrison, I., and Laperrière, A., 2015. Representative hot water draw profiles at high temporal resolution for simulating the performance of solar thermal systems. Solar Energy, 111:43-52.

Elmer, T., Worall, M., Wu, S., and Riffat, S., 2015. Emission and economic performance assessment of a solid oxide fuel cell micro-combined heat and power system in a domestic building. Applied Thermal Engineering, 90:1082-1089.

Elmer, T., Worall, M., Wu, S., and Riffat, S., 2016. An experimental study of a novel integrated desiccant air conditioning system for building applications. Energy and Buildings, 111:434-445. 
Entchev, E., 2003. Residential fuel cell energy systems performance optimization using "soft computing" techniques. Journal of Power Sources, 118:212-217.

Entchev, E., Yang, L., Ghorab, M., and Lee, E., 2013. Simulation of hybrid renewable microgeneration systems in load sharing applications. Energy, 50:252-261.

Environment Canada, 2014. Greenhouse gas emission reporting program online data search - facility reported data. Technical report, Environment Canada. http:// www.ec.gc.ca/ges-ghg/donnees-data/ - Accessed Apr. 2016.

EUROPA, 2011. Commission implementing decision of December 192011 - establishing harmonised efficiency reference values for separate production of electricity and heat in application Directive 2004/8/EC of the European Parliament and of the Council and repealing Commission Decision 2007/74/EC. Official Journal of the European Union, 343:91-96.

Flinn, D., Hall, S., Morris, J., Cummings, A., and Northcote-Greene, J., 1983. Improved methods for distribution loss evaluative techniques volume 1: Analytic and evaluative techniques. Technical report, Westinghouse Electric Corporation.

Frazzica, A., Briguglio, N., Sapienza, A., Freni, A., Brunaccini, G., Antonucci, V., and Ferraro, M., 2015. Analysis of different heat pumping technologies integrating small scale solid oxide fuel cell system for more efficient building heating systems. International Journal of Hydrogen Energy, 40:14746-14756.

Fubara, T., Cecelja, F., and Yang, A., 2014. Modelling and selection of micro-CHP systems for domestic energy supply: The dimension of network-wide primary energy consumption. Applied Energy, 114:327-334.

Gandiglio, M., Lanzini, A., Santarelli, M., Leone, P., and Borchiellini, R., 2013. Study of a low-temperature micro-cogeneration system with a proton exchange 
membrane fuel-cell for residential use. In Proc. Third International Conference on Microgeneration and Related Technologies, Naples, Italy.

Gandiglio, M., Lanzini, A., Santarelli, M., and Leone, P., 2014. Design and optimization of a proton exchange membrane fuel cell CHP system for residential use. Energy and Buildings, 69:381-393.

Glanville, P., Kosar, D., and Stair, J., 2013. Short-term performance of gas-fired tankless water heater: laboratory characterization. ASHRAE Transactions, 119: $248-269$.

Guo, Y., Chen, H., and Wang, F., 2015. The development of a hybrid PEMFC power system. International Journal of Hydrogen Energy, 40:4630-4640.

Ham, S., Jo, S., Dong, H., and Jeong, J., 2015. A simplified PEM fuel cell model for building cogeneration. Energy and Buildings, 107:213-225.

Han, Y., Beausoleil-Morrison, I., and Wang, X., 2015. Increasing the installation capacity of PV with PEMFC backup with a residential community. Energy Procedia, 78:675-680.

Hawkes, A. and Leach, M., 2007. Cost-effective operating strategy for residential micro-combined heat and power. Energy, 32:711-723.

Hawkes, A., Aguiar, P., Croxford, B., Leach, M., Adjiman, C., and Brandon, N., 2007. Solid oxide fuel cell micro combined heat and power system operating strategy: Options for provision of residential space and water heating. Journal of Power Sources, 164:260-270.

Hawkes, A., Brett, D., and Brandon, N., 2009a. Fuel cell micro-CHP technoeconomics: Part 1 - model concept and formulation. International Journal of Hydrogen Energy, 34:9545-9557. 
Hawkes, A., Brett, D., and Brandon, N., 2009b. Fuel cell micro-CHP technoeconomics: Part 2 - model application to consider the economic and environmental impact of stack degradation. International Journal of Hydrogen Energy, 34:95589569.

Healy, W., Ullah, T., and Roller, J., 2011. Input-output approach to predicting the energy efficiency of residential water heaters - Testing of gas tankless and electric storage water heaters. ASHRAE Transactions, 117:521-532.

Herdem, M., Farhad, S., and Hamdullahpur, F., 2015. Modeling and parametric study of a methanol reformate gas-fueled HT-PEMFC system for portable power generation applications. Energy Conversion and Management, 101:19-29.

Hody, S., Contreau, R., Dupe, C., and Dupuis, D., 2015. Feed back from Engie Lab (Crigen) and GRDF on some fuel cell micro-cogeneration systems installed on the field in France within the European program ENE.FIELD. In Proc. Fourth International Conference on Microgeneration and Related Technologies, Tokyo, Japan.

Hoeschele, M. and Weitzel, E., 2013. Monitored performance of advanced gas water heaters in California homes. ASHRAE Transactions, 119:214-225.

Hydro One, 2007. Distribution line losses study. Technical report, Hydro One. http: //www.hydroone.com - Accessed Aug. 2016.

IESO, 2003. Attachment a - functional deferral 6 adjusting dispatch instructions to the defined metering point. Technical report, Independent Electricity System Operator. http://www.ieso.ca/Documents/mr/mr_00237-R00-attA.pdf - Accessed Aug. 2016.

IESO, 2006. System impact assessment report - greenfield and st. clair energy centres connection assessment and approval process. Technical report, Independent 
Electricity System Operator. http://www.ieso.ca/Documents/caa/caa_SIAReport_ 2004-187.pdf - Accessed Aug. 2016.

IESO, 2013a. Realtime constrained totals report. Technical report, Independent Electricity System Operator. http://reports.ieso.ca/public/RealtimeConstTotals/ - Accessed Aug. 2016.

IESO, 2013b. Generators output and capability report. Technical report, Independent Electricity System Operator. http://reports.ieso.ca/public/GenOutputCapability/ - Accessed Aug. 2016.

IESO, 2013c. Monthly average prices. Technical report, Independent Electricity System Operator. http://www.ieso.ca/Pages/Power-Data/Data-Directory.aspx Accessed Aug. 2016.

IESO, 2015. Generator output by fuel type monthly report. Technical report, Independent Electricity System Operator. http://reports.ieso.ca/public/ GenOutputbyFuelMonthly/ - Accessed Aug. 2016.

IESO, 2016. Managing a diverse supply of energy. Technical report, Independent Electricity System Operator. http://www.ieso.ca/Pages/Ontario's-Power-System/ Supply-Mix/Managing-a-Diverse-Supply-of-Energy.aspx - Accessed Aug. 2016.

Iwami, J., Higaki, K., Yasuhara, K., Suzuki, M., and Uenoyama, S., 2015. Development of a residential SOFC CHP system. In Proc. Fourth International Conference on Microgeneration and Related Technologies, Tokyo, Japan.

Johnson, G. and Beausoleil-Morrison, I., 2016. The calibration and validation of a model for predicting the performance of gas-fired tankless water heaters in domestic hot water applications. Applied Energy, 177:740-750. 
Johnson, G., Beausoleil-Morrison, I., Strathearn, B., Thorsteinson, E., and Mackintosh, T., 2013. The calibration and validation of a model for simulating the thermal and electrical performance of a $1 \mathrm{~kW}_{A C}$ proton-exchange membrane fuel-cell microcogeneration device. Journal of Power Sources, 221:435-446.

Johnson, G., Wills, A., and Beausoleil-Morrison, I., 2015. The proposal of a reasonable reference scenario for comparison with micro-cogeneration systems. In Proc. Fourth International Conference on Microgeneration and Related Technologies, Tokyo, Japan.

Johnson, G., Beausoleil-Morrison, I., and Wills, A., 2016. Micro-cogeneration versus conventional technologies: considering model uncertainties in assessing the energy benefits. Applied Thermal Engineering (under review).

Kamen, E. and Heck, B. Fundamentals of Signals and Systems Using the Web and Matlab. Prentice Hall, 2000. ISBN No. 0-13-017293-6.

Kazempoor, P., Dorer, V., and Weber, A., 2011. Modelling and evaluation of building integrated SOFC systems. International Journal of Hydrogen Energy, 36:1324113249.

Kelly, N. and Beausoleil-Morrison, I., editors. Specifications for Modelling Fuel Cell and Combustion-Based Residential Cogeneration Devices within Whole-Building Simulation Programs. IEA/ECBCS Annex 42 Report, 2007. ISBN No. 978-0$662-47116-5$.

Knight, I. and Ribberink, H., editors. European and Canadian non-HVAC Electric and DHW Load Profiles for Use in Simulating the Performance of Residential Cogeneration Systems. IEA/ECBCS Annex 42 Report, 2007. ISBN No. 978-0-66246221-7. 
Koda, J., Tairako, T., Sano, A., Yamada, K., Watanabe, T., and Kobayashi, K., 2015. Development of new model residential fuel cell systems. In Proc. Fourth International Conference on Microgeneration and Related Technologies, Tokyo, Japan.

Kopf, J. The performance of residential micro-cogeneration coupled with thermal and electrical storage. Master's thesis, Carleton University, Ottawa Canada, 2012.

Korsgaard, A., Nielsen, M., and Kær, S., 2008. Part one: A novel model of HTPEMbased micro-combined heat and power fuel cell system. International Journal of Hydrogen Energy, 33:1909-1920.

Kupecki, J., Milewski, J., Szczesniak, A., Bernat, R., and Motylinski, K., 2015. Dynamic numerical analysis of cross-, co-, and counter-current flow configuration of a $1 \mathrm{~kW}$-class solid oxide fuel cell stack. International Journal of Hydrogen Energy, 40:15834-15844.

LaNasa, P., 2003. Overall measurement accuracy - determination and influence. Technical report, American School of Gas Measurement Technology. http://asgmt.com - Accessed May 2016.

Lisbona, P., Corradetti, A., Bove, R., and Lunghi, P., 2007. Analysis of a solid oxide fuel cell system for combined heat and power applications under non-nominal conditions. Electrochimica Acta, 53:1920-1930.

Liso, V., Zhao, Y., Brandon, N., Nielsen, M., and Kær, S., 2011. Analysis of the impact of heat-to-power ratio for a SOFC-based mCHP system for residential application under different climate regions in Europe. International Journal of Hydrogen Energy, 36:13715-13726. 
Mamaghani, A., Najafi, B., Casalegno, A., and Rinaldi, F., 2016. Long-term economic analysis and optimization of an HT-PEM fuel cell based micro combined heat and power plant. Applied Thermal Engineering, 99:1201-1211.

Martins, L., Gardolinski, J., Vargas, J., Ordonez, J., Amico, S., and Forte, M., 2009. The experimental validation of a simplified PEMFC simulation model for design and optimization purposes. Applied Thermal Engineering, 29:3036-3048.

McMurtry, S. On configuration and control of the thermal plant for fuel-cell microcogeneration. Master's thesis, Carleton University, Ottawa Canada, 2013.

MOE, 2014. Guideline for greenhouse gas emissions reporting. Technical report, Ontario Ministry of the Environment.

MOE, 2014. Access environment. Technical report, Ontario Ministry of the Environment and Climate Change. http://www.ontario.ca/ ministry-environment-and-climate-change - Accessed Jan. 2016.

Moffat, R., 1988. Describing the uncertainties in experimental results. Experimental Thermal and Fluid Science, 1:3-17.

Mora, T. and Ulieru, M., 2005. Minimization of energy use in pipeline operations-an application to natural gas transmission system. In Proc. 31st Annual Conference IEEE.

Moran, M. and Shapiro, H. Fundamentals of Engineering Thermodyanamics. John Wiley \& Sons, 5th edition, 2004. ISBN No. 0-471-27471-2.

Murugan, S. and Horák, B., 2016. A review of micro combined heat and power systems for residential applications. Renewable and Sustainable Energy Reviews, 64:144-162. 
Musio, F., Tacchi, F., Omati, L., Stampino, P., Dotelli, G., Limonta, S., Brivio, D., and Grassini, P., 2011. PEMFC system simulation in MATLAB-Simulink environment. International Journal of Hydrogen Energy, 36:8045-8052.

Nakai, T., Okawa, I., Kosumi, T., Dobashi, R., Kurokawa, T., and Uetsuji, A., 2015. T-Grid System: electric power interchange system utilizing ene-farm in apartment. In Proc. Fourth International Conference on Microgeneration and Related Technologies, Tokyo, Japan.

Napoli, R., Gandiglio, M., Lanzini, A., and Santarelli, M., 2015. Techno-economic analysis of PEMFC and SOFC micro-CHP fuel systems for the residential sector. Energy and Buildings, 103:131-146.

Navigant, 2014. Distribution line losses study - prepared for Hydro One Networks Inc. Technical report, Hydro One. http://www.hydroone.com - Accessed Aug. 2016.

Nižetić, S., Tolj, I., and Papadopoulos, A., 2015. Hybrid energy fuel cell based system for household applications in a Mediterranean climate. Energy Conversion and Management, 105:1037-1045.

NRCan, 2016. Comprehensive energy use database, 1990 to 2013. Technical report, Natural Resources Canada, Ottawa, Canada. http://oee.rncan.gc.ca/corporate/ statistics/neud/dpa/comprehensive_tables - Accessed Oct. 2016.

OEB, 2013. Natural gas rates - historical. Technical report, Ontario Energy Board. http://www.ontarioenergyboard.ca/OEB/Consumers/ - Accessed Aug. 2016.

Onovwiona, H. and Ugursal, V., 2006. Residential cogeneration systems: Review of the current technology. Renewable and Sustainable Energy Reviews, 10(5):389-431. 
Ontario Ministry of Energy, 2013. Ontario's long-term energy plan. Technical report, Ontario Ministry of Energy. http://www.energy.gov.on.ca/en/files/2014/10/ LTEP_2013_English_WEB.pdf - Accessed Aug. 2013.

OPA, 2016. Natural gas - simple/combined cycle contracts. Technical report, Ontario Power Authority. http://www.powerauthority.on.ca/current-electricity-contracts/ sc-cc - Accessed Aug. 2016.

Özgirgin, E., Devrim, Y., and Albostan, A., 2015. Modeling and simulation of a hybrid photovoltaic (PV) module-electrolyzer-PEM fuel cell system for micro-cogeneration applications. International Journal of Hydrogen Energy, 40:15336-15342.

Payne, R., Love, J., and Kah, M., 2011. CFCL's BlueGen product. Electrochemical Society Transactions, 35:81-85.

Pellegrino, S., Lanzini, A., and Leone, P., 2015. Techno-economic and policy requirements for the market-entry of the fuel cell micro-CHP system in the residential sector. Applied Energy, 143:370-382.

Phillips, D., 2004. Nodal pricing basics. Technical report, Independent Electricity System Operator. http://www.ieso.ca/imoweb/pubs/consult/mep/LMP_NodalBasics_ 2004jan14.pdf - Accessed May 2016.

Piercy, R. and Cress, S., 2007. 2007 recalculation of distribution system energy losses at hydro one. Technical report, Kinetrics Inc. http://www.hydroone.com - Accessed Aug. 2016.

Polverino, P., Esposito, A., Pianese, C., Ludwig, B., Iwanschitz, B., and Mai, A., 2016. On-line experimental validation of a model-based diagnostic algorithm dedicated to a solid oxide fuel cell system. Journal of Power Sources, 306:646-657. 
Postlethwaite, O., Rogers, S., and Selby, M., 2015. Design for life - fuel cell power systems. In Proc. Fourth International Conference on Microgeneration and Related Technologies, Tokyo, Japan.

Ribberink, H., Mottillo, M., and Bourgeois, D. Performance Assessment of Prototype Residential Cogeneration Systems in Single Detached Houses in Canada. IEA/ECBCS Annex 42 Report, 2008. ISBN No. 978-0-662-47168-4.

Rouholamini, M. and Mohammadian, M., 2015. Energy management of a grid-tied residential-scale hybrid renewable generation system incorporating fuel cell and electrolyzer. Energy and Buildings, 102:406-416.

Safari, S., Ardehali, M., and Sirizi, M., 2013. Particle swarm optimization based fuzzy logic controller for autonomous green power energy system with hydrogen storage. Energy Conversion and Management, 65:41-49.

Saldanha, N. and Beausoleil-Morrison, I., 2012. Measured end-use electric load profiles for 12 Canadian houses at high temporal resolution. Energy and Buildings, 49:519530.

Sasakura, H., 2015. Next-generation household energy system demonstration at Next21 experimental multi-unit housing complex. In Proc. Fourth International Conference on Microgeneration and Related Technologies, Tokyo, Japan.

Sasso, M., Entchev, E., and Tzscheutschler, P., editors. A Review of Existing Microgeneration Studies and Experimental Activities. IEA/ECBCS Annex 54 Report Natural Resources Canada, 2016. ISBN No. 978-0-660-04364-7.

Schoenbauer, B., Bohac, D., and Hewett, M., 2012. Measured residential hot water end use. ASHRAE Transactions, 118:872-889. 
Shaneb, O., Taylor, P., and Coates, G., 2012. Real time operation of $\mu$ CHP systems using fuzzy logic. Energy and Buildings, 55:141-150.

Sommer, K. and Mesenhöller, E., 2013. Practical experience with a fuel cell unit for combined heat and power (CHP) generation on the building level. The REHVA European HVAC Journal, pages 12-16.

Staffell, I. Fuel cells for domestic heat and power: are they worth it? $\mathrm{PhD}$ thesis, University of Birmingham, 2009.

Staffell, I., 2015. Zero carbon infinite COP heat from fuel cell CHP. Applied Energy, $147: 373-385$.

Staffell, I. and Green, R., 2013. The cost of domestic fuel cell micro-CHP systems. International Journal of Hydrogen Energy, 38:1088-1102.

Statistics Canada, 2001. Natural gas transportation and distribution. Technical report, Statistics Canada. http://www.statcan.gc.ca - Accessed Aug. 2016.

Statistics Canada, 2015. CANSIM - Canadian Socio-Economic Information Management System, Tables 127-0004 and 127-0006. Technical report, Statistics Canada. http://www5.statcan.gc.ca/cansim/ - Accessed Aug. 2016.

Sumiyoshi, D., Yamamoto, T., Hirata, T., and Shigematsu, Y., 2015. Installation effect estimation of fuel cells in an apartment by simulation analysis. In Proc. Fourth International Conference on Microgeneration and Related Technologies, Tokyo, Japan.

Tanaka, Y., 2015. Development and demonstration of PV/FC/battery hybrid power system in Toyota City Low Carbon Society Project. In Proc. Fourth International Conference on Microgeneration and Related Technologies, Tokyo, Japan. 
Thorsteinson, E., Strathearn, B., Mackenzie, G., and Amow, G., 2011. Permformance testing of a $1 \mathrm{kWe}$ fuel cell cogeneration system. In Proc. Second International Conference on Microgeneration and Related Technologies, Glasgow, Scotland.

Union Gas, 2016. Chemical composition of natural gas. Technical report, Union Gas. https://www.uniongas.com/about-us/about-natural-gas/ Chemical-Composition-of-Natural-Gas - Accessed Oct. 2016.

Verbruggen, A., Dewallef, P., Quoilin, S., and Wiggin, M., 2013. Unveiling the mystery of combined heat and power (cogeneration). Energy, 61:575-582.

Vialetto, G., Noro, M., and Rokni, M., 2015. Innovative household systems based on solid oxide fuel cells for the Mediterranean climate. International Journal of Hydrogen Energy, 40:14378-14391.

Wakui, T., Wada, N., and Yokoyama, R., 2014. Energy-saving effect of a residential polymer electrolyte fuel cell cogeneration system combined with a plug-in hybrid electric vehicle. Energy Conversion and Management, 77:40-51.

Wang, Y., Ronilaya, F., Chen, X., and Roskilly, A., 2013. Reprint of: Modelling and simulation of a distributed power generation system with energy storage to meet dynamic household electricity demand. Applied Thermal Engineering, 53:312-324.

Watanabe, S., Tanaka, M., Koyama, Y., and Hirai, K., 2015. Development of residential 700W PEFC micro-CHP system. In Proc. Fourth International Conference on Microgeneration and Related Technologies, Tokyo, Japan.

Wetter, M., 2009. GenOpt generic optimization program - User manual version 3.0.0. Technical report, Lawrence Berkeley National Laboratory. http: //SimulationResearch.lbl.gov. 
Windeknecht, M. and Tzscheutschler, P., 2015. Increasing electricity self-consumption of micro CHP-systems with electrically driven heater. In Proc. Fourth International Conference on Microgeneration and Related Technologies, Tokyo, Japan.

Wu, B. and Wang, L., 2014. Comparable analysis methodology of CCHP based on distributed energy system. Energy Conversion and Management, 88:863-871.

Wu, S. Steady-State Simulation and Fuel Cost Minimization of Gas Pipeline Networks. PhD thesis, University of Houston, 1998.

Xu, H., Dang, Z., and Bai, B., 2013. Analysis of a $1 \mathrm{~kW}$ residential combined heating and power system based on solid oxide fuel cell. Applied Thermal Engineering, 50: $1101-1110$.

Yaji, S. and Diarra, D., 2013. Operating strategy of a solid oxide fuel cell system for a household energy demand profile. In Proc. Third International Conference on Microgeneration and Related Technologies, Naples, Italy.

Yang, W., Zhao, Y., Liso, V., and Brandon, N., 2014. Optimal design and operation of a syngas-fuelled SOFC micro-CHP system for residential applications in different climate zones in China. Energy and Buildings, 80:613-622.

Zafar, S. and Dincer, I., 2014. Energy, exergy and exergoeconomic analyses of a combined renewable energy system for residential applications. Energy and Buildings, $71: 68-79$.

Zuliani, N. and Taccani, R., 2012. Microcogeneration system based on HTPEM fuel cell fueled with natural gas: Performance analysis. Applied Energy, 97:802-808.

Zuliani, N. and Taccani, R., 2013. Micro combined heat and power systems based on HTPEM fuel cell and Li-Ion batteries: analysis of performance under different 
operating strategies. In Proc. Third International Conference on Microgeneration and Related Technologies, Naples, Italy. 